\title{
Richard Linklater's “Before” Series: Time, Duration, and Memory
}

by

Matthew Sanders

A thesis submitted to the Faculty of Graduate and Postdoctoral Affairs in partial fulfillment of the requirements for the degree of

Master of Arts

in

Film Studies

Carleton University

Ottawa, Ontario

(C) 2016, Matthew Sanders 


\begin{abstract}
This thesis investigates the relationship between the films in Richard Linklater's "Before" series, Before Sunrise (1995), Before Sunset (2004), and Before Midnight (2013). Linklater's career is full of experiments with narrative structure and time. But, the "Before" series is unique among these experiments, and among other series, because of the strategy Linklater used to produce it: what this thesis refers to as Linklater's strategy of duration. This thesis argues that Linklater uses his strategy of duration to explore what it means to be in time. In turn, this creates a temporal experience for the spectator that highlights being in time and their own temporality. Situating this series amongst various approaches to temporality showcases how its simple story belies a complex and multifaceted expression of being in time.
\end{abstract}




\section{Acknowledgements}

First, I want to thank my parents, Heather and Michael. Through accidents, mistakes, and successes, my parents have never stopped supporting and loving me. A son could not wish for better parents.

This thesis would not be what it is today without the advisement from Marc Furstenau. His constructive criticism and our conversations were vital to its creation.

I also want to thank my friends, Josh, Evan, Gavin, Maddi, Ana, David, and Alex, for their support and laughter. Words hardly describe how much your friendship has meant to me over the years.

I have nothing but gratitude for all of the faculty and staff in the Film Studies department at Carleton. You are directly responsible for fostering in me a tireless desire to question and seek answers.

In particular, I want to thank Diane Berezowski, Nancy Duff, Laurie Jaeger, Barbara Shannon, and Jack Coghill, for always being welcoming and for helping me whenever I needed it (especially with those last minute, frantic emails).

Adrian Sheppard was the nicest man I have ever met. I will cherish the memories of us living together and our long debates into the night. It hurts that he did not get to read this. I will miss you Adrian.

The same is true for Alan Nymark. He always spoke to us kids like equals (in fact, at heart, Alan had more energy than any of us), and for that I will always remember you Alan. 


\section{Table of Contents}

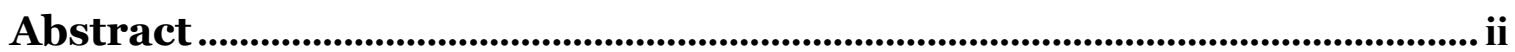

Acknowledgements ...................................................................................................ii

Table of Contents.................................................................................................. iv

Introduction: Linklater's Strategy of Duration ................................................... 1

Chapter 1. Linklater's Narrative, Change, and Consequences ................ 13

Narrative and Being in Time ........................................................................................... 13

Desire

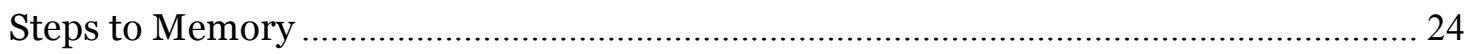

Memory and Consequences.................................................................................... 32

Consequences and Romantic Conventions ................................................................. 38

Chapter 2. Interseriality: Recollection and The Past .....................................43

Interseriality and Intertextuality ................................................................................... 43

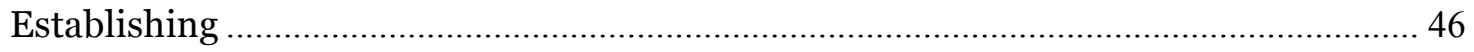

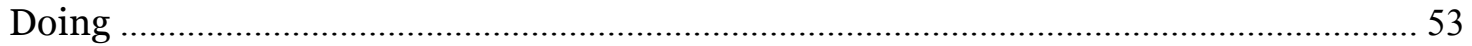

Chapter 3. Interseriality: Order and The Aging Body ................................... 72

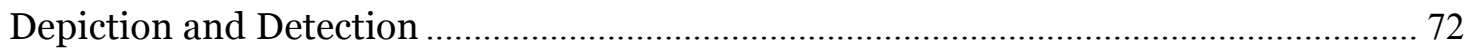

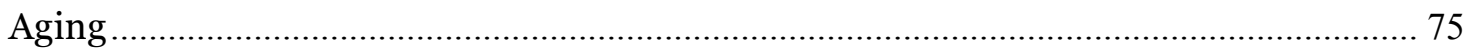

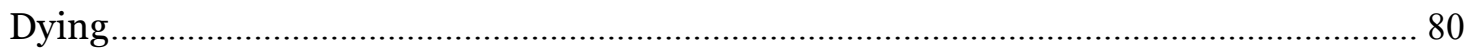

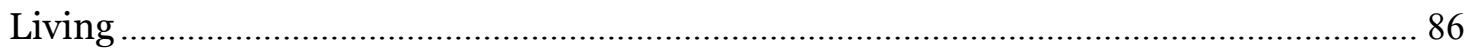

Conclusion: ..................................................................................................................... 92

Figures:..................................................................................................................................... 95

Bibliography:.......................................................................................................... 114 


\section{Introduction: Linklater's Strategy of Duration}

This thesis investigates the relationship between the films in Richard Linklater's "Before" series. The "Before" series is produced with a strategy of duration that ties the films together narratively and temporally. This unique temporal relationship between the films creates a unique temporal experience for the spectator. This thesis argues that Linklater uses his strategy of duration to explore what it means to be in time. In turn, this creates a temporal experience for the spectator that highlights being in time ${ }^{1}$ and their own temporality. This thesis will substantiate these claims with close readings of the films of the "Before" series, Before Sunrise (1995), Before Sunset (2004), and Before Midnight (2013), and by situating this series within various approaches to temporality.

Linklater is well known for his film Boyhood (2014). That film followed Mason (Ellar Coltrane) from the age of six to eighteen. It is one movie, but it took twelve years to make. Linklater returned to the same characters and story in yearly increments. Through an editing strategy that condensed those twelve years into three hours, Linklater transformed the process of a young boy and his family growing up into the narrative of his film.

But, before Boyhood, Linklater had a history of experimenting with narrative structure and time. The "most sustained" of these experiments is the

\footnotetext{
${ }^{1}$ The phrase "being in time" is famously related to the philosophy and work of Martin Heidegger. However, for this thesis, it will be used in relation to the philosophies of Henri Bergson, Paul Ricoeur, and R.G. Collingwood, and to a state of duration and passing time.
} 
"Before" series. ${ }^{2}$ In fact, only after completing Before Sunset was Linklater confident enough to begin Boyhood. While Boyhood is a single film, the "Before" series is three films with a single story stretched over eighteen years.

The story in the "Before" series is simple. In Before Sunrise, Jesse (Ethan Hawke) and Celine (Julie Delpy) are young travellers who meet by chance in Vienna, where they spend a romantic twelve hours together. Before they separate in the morning, when Celine has to catch her train and Jesse has to catch his early flight, they promise to reunite six months later, in Paris. In Before Sunset, Jesse and Celine meet again, again apparently by chance, in Paris, having not met as they had originally planned nine years earlier. While they are different people now since the last time they saw each other, their romance seems to be rekindled at the conclusion of the film. A further nine years later, in Before Midnight, Jesse and Celine, having settled into a relationship, and are on vacation in Greece with their twin daughters, but, where their romance was once youthful and spontaneous, they now face the monotony and responsibility of parenting. They argue, seemingly break up, yet seem to save their relationship in the end.

What seperates the "Before" series from other fiction film series is the unique relationship between the films in the series to one another, as well as the way this unique relationship manifests in the treatment of time in the individual films. This unique relationship is the result of what I will call Linklater's strategy of duration. Duration is defined as "Lasting, continuance in time; the continuance or length of time; the time during which a thing, action, or state, 
continues." 3 Duration is synonymous with passing time. To pass time, be it in the development of the series over time, or for the characters in the narrative of the series, is to be in duration, in time. While most films shorten and compress the actual time of a story's duration, Linklater strives to recreate the sense of time actually passing through his strategy. Two key components to this strategy give it this effect: correspondence and regularity. Together these components operate on the level of narrative and in the structure of the series to embed the series in time for the spectator, to grant the series a particular underlying theme and trope of duration and passing time. The relationship between the films expresses this state and theme of passing time, and time passing.

We can read Linklater's strategy of duration as an extension of his own experiments in the interaction between time and narrative in his previous films. 4 These experiments defied conventional Hollywood treatments of narrative and temporality. As Thomas A. Christie describes, Slacker (1991), Linklater's debut feature film, is a collection of vignettes with an "unorthodox structure" that "has to be seen to be experienced." Without a main character, developing over twentyfour hours in Austin, Texas, and with time and happenstance meetings dictate the narrative parameters, Christie suggests Slacker's narrative is about the passage of time involved in watching it. It is about passing time, and Linklater did that on

3 "duration n.," OED Oxford English Dictionary Online, http://www.oed.com.proxy.library.carleton.ca/view/Entry/58626? redirectedFrom=duration\# \#id 4 In interview Linklater mentions that "time and narrative have always been overlapping constants that are worthy of exploration." Interviewed in, David T. Johnson, Richard Linklater, (Urbana: University of Illinois Press, 2012), 138. 
purpose. 5 For David Bordwell, Slacker's narrative is in stark opposition to Hollywood narrative; at "the extremes of indie risk taking" it "would likely seem unintelligible or pointless" to audiences raised on Hollywood narrative. ${ }^{6}$ But this break from Hollywood narrative, what critics and scholars called its "plotless" quality, is precisely what speaks to a new experience of time for a new generation: "Generation X."7

Before the "Before" series, Linklater subtly changed Slacker's vignette form in his next film Dazed and Confused (1993). Linklater focused his episodic narrative on a set of characters, rather than a single main character, during their last day of high school in Austin, Texas in 1976. Like Slacker, temporal constraints once again define the narrative. The film's narrative follows the events of a single hot day on the brink of summer. But, Linklater's tightening focus on characters in Dazed and Confused marks a crucial step towards his further experiments with narrative and time in the "Before" series.

The transition from Slacker to Dazed and Confused in regards to narrative experimentation lead to the "Before" series" interesting relationship with Hollywood conventions. Importantly, the "Before" series, while unique because of Linklater's strategy of duration, is not incomprehensible. The "Before" series is

5 See: Thomas A. Christie, The Cinema of Richard Linklater (Kent: Crescent Moon Publishing, 2008), 27: “...the only real meaningful answer in narrative terms [to the question, what is Slacker about] is that it is about an hour and a half long."

6 David Bordwell, The Way Hollywood Tells It: Story and Style in Modern Movies, (Berkeley:

University of California Press, 2006), 73.

${ }^{7}$ See: Scott Tobias, "The New Cult Canon-Slacker" AVClub. September. $3^{\text {rd }}, 2009$. http://www.avclub.com/article/islackeri-32471; and, Roger Ebert, "Slacker" RogerEbert.com. August $3^{\text {rd }}$, 1991. http://www.rogerebert.com/reviews/slacker-1991; and, Jon Radwan, "Generation X and Postmodern Cinema: Slacker," Post Script, Vol. 19 No. 2 (1999): 35, for these associations. 
not a surrealist trip into the world of dream time, nor is it an avant-garde film. ${ }^{8}$ Indeed, David Sims, in an article written for The Atlantic, commented that Linklater's work in Before Sunrise, in contrast to Slacker and Dazed and Confused, marks "a major progression for him into conventional storytelling."9 But, while Sims was right to classify Before Sunrise as a major move for Linklater towards Hollywood conventions, the strategy of duration for the "Before" series is, to my knowledge, unique for a fiction film series. The first key component in Linklater's strategy of duration is correspondence. The "Before" series consists of three films with large, multi-year gaps between their release. Large gaps between the release of films in a series are not uncommon, but what is uncommon is that in the "Before" series the time passed in these gaps between films corresponds to time passed for the characters in the film. The time passing between Before Sunrise to Before Sunset to Before Midnight is time passing for the characters. This component in Linklater's strategy of duration connects the release of the films, the characters, and the narrative, creating a particular relation to time, a recurring theme, and trope, for the spectator: time is always passing in the series.

Regularity is the second component of Linklater's strategy of duration and it specifies this correspondence between his films and passing time. Linklater

\footnotetext{
8 Both of these ideas have been applied to Linklater's film Waking Life (2001), which uses dream logic and a wildly eclectic animation style. See: Ellen Grabiner, "The Holy Moment: Waking Life and Linklater's Sublime Dream Time," Film Quarterly Vol. 68 No. 3, (2015): 41-47.

9 David Sims, "The Frozen in Time Optimism of Before Sunrise," The Atlantic, January $27^{\text {th }} 2015$, http://www.theatlantic.com/entertainment/archive/2015/o1/the-frozen-in-time-optimism-ofbefore-sunrise/384881/; see also, Christie, The Cinema of Richard Linklater, 41: "[Before Sunrise] was to mark something of a change in of pace to Linklater's filmography. . .the film's intimate atmosphere was a world away from the vast ensemble casts of Slacker and Dazed and Confused."; and, Filippo, "Growing Old Together," 53 for a description of Linklater's career as "Indiewood," straddling the lines between independent and Hollywood filmmaking."
} 
released his films in the "Before" series in a regular pattern. Nine years separates each release in the "Before" series. This regularity enhances the component of correspondence by situating events and the films into a particular and specific temporal relationship to each other. Nine years separate the films from one another, and nine years have passed for the characters, nine years separate the events from each other. Regularity grants specificity to the time that is always passing in the series for the characters, and for the spectator, as a result of correspondence.

The strategy of duration is "real time" filmmaking, but it does not produce "real time" films. We can understand "real time" in two fashions. First, there is the real-time of the earliest "actualities," where "the eye saw events unfold before them at the pace at which they happened" in a single take. ${ }^{10}$ But since cameras hold a limited amount of film, such early real-time films could only be of a short duration. Even in later decades, no more than about ten minutes of film could be housed in a camera's magazine. With the advent of editing techniques, and the popularity of long-form narratives, a different conception of real time emerged. This conception of "real time" connected the run time of the film with the events of the narrative. If a film was ninety minutes long, all the events in the narrative correspond and occur within ninety minutes as well. Rope (Alfred Hitchcock, 1948) cleverly hid the technological limits of its long takes in an attempt to establish this connection between its runtime and the duration of a murder

${ }^{10}$ Helen Powell, Stop the Clocks!, (London: I.B. Taurus, 2012), 12; see also, Andy Warhol's "antifilm" experiments, such as Eat (1963), Sleep (1963), Empire (1964), and Blow Job (1964), which are more avant-garde examples of "real time" filmmaking, in their case, the "anti-film" designation revealing how they were purposely contrasting to the treatment of time in mainstream narrative film. 
investigation in an apartment. Nick of Time (John Badham, 1996), and Phone Booth (Joel Schumacher, 2002), are two more recent examples of this "real time" cinema. ${ }^{11}$ Developments in digital cinema and technology have brought back the first sense of "real time" cinema by extending the possible length of single takes. Russian Ark's (Alexander Sokurov, 2002) single-take narrative of Russia through the halls of the Winter Palace, and Victoria's (Sebastian Schipper, 2015) singletake exploration of the eponymous girl's unlucky attempt at crime in Germany, are examples of this return to "real time" with the possibilities offered by digital cinema. Their narratives "unfold before" the spectator as if in their complete immediate happening.

While Before Sunset's short runtime, and heavy use of long takes, a tool that Linklater uses throughout the series to produce a similar effect, is often claimed as "real time," that film does not go out of its way to emphasize direct correspondence between the events in the narrative and the run time of the film, nor any other film in the series. As many have pointed out, one of Linklater's consistent stylistic traits to his films is the association of his narratives to the events of a single day, rather than a slavish attachment to "real time." ${ }^{12}$ The events that occur in Before Sunrise and Before Midnight all take place over ten hours in the film, but the runtime of these films do not extend beyond the industry standard of about ninety to one-hundred-and-twenty minutes. Unlike

${ }^{11}$ Ibid., 22.

${ }^{12}$ See: Christie, The Cinema of Richard Linklater, 30-31; and, Johnson, Richard Linklater, 37, where Linklater is quoted saying, "I really just want to capture two people existing." 
"real time" films, the films in the "Before" series feature a loose correspondence between the events of the narrative and the runtime of the film.

But, Linklater's strategy of duration does grant the "Before" series a "real time" aspect as a function of it being a series. This is to say, Linklater's strategy of duration creates a particular relationship between the films in the series. Where "real time" filmmaking and films emphasize the passage of time for the spectator as a function of the runtime of the film, Linklater's series emphasizes the passage of time between the films in the series through correspondence and regularity. The "real time" is between the films in the series. Jesse and Celine are aware of and reflect on the nine years that pass between films because their passage of time corresponds to this time. That nine years between the films is "real" for them because nine years did, in fact, pass between the release of the films. The total twenty years which the release of the series has spanned is also twenty years of narrative development, and choices, for them as well. Linklater has not made a single film that presents time passing during its runtime, but rather has embedded a series of three films within this real passing time.

By making his characters aware of the passing of time through his strategy of duration Linklater also grants his characters, and the series, a connected sense of a past. This is in stark contrast to many other series, regardless of medium, where their seriality denies a past and a sense of time passing, denies change, memory, and aging. Umberto Eco and Natalie Chilton argue that, for example, the Superman comic book series rejects the passage of time to conserve the mythic qualities of Superman: 
In Superman it is the concept of time that breaks down. . .In Superman stories the time that breaks down is the time of the story, that is, the notion of time which ties one episode to another. In the sphere of a story, Superman accomplishes a given job (he routs a band of gangsters); at this point the story ends. In the same comic book, or in the edition of the following week, a new story begins. If it took Superman up again at the point where he left off, he would have taken a step toward death...13

"A step toward death" would shatter the god-like myth Superman relies on: that he does not age. The series denies the passage of time between stories: "what has happened before and what has happened after appears extremely hazy."14 A similar phenomenon occurs in film series, most notably, perhaps, as Nicola Evans has argued, in action film series, where characters and stories have no sense of duration. ${ }^{15}$ Rudmer Canjels continues Eco and Chilton's argument for the "James Bond" series, arguing that the lack of connections between films constitute a "lack of a past and memory." The result: "it is almost impossible for a character to develop and change."16 The passing of time is not obscure across these series; it does not exist.

By employing a strategy of duration, Linklater's "Before" series creates a strong sense of the passing of time. The characters are deeply aware of their past, because, rather than shield them from it, Linklater's strategy embeds them in

13 Umberto Eco and Natalie Chilton, "Review: The Myth of Superman," Diacritics vol. 2 No. 1, (1972): 17 .

14 ibid.

15 Nicola Evans, "No Genre for Old Men? The Politics of Aging and the Male Action Hero," Canadian Journal of Film Studies Vol. 24 No 1 (2015): 26.

16 Rudmer Canjels, Distributing Silent Film Serials: Local Practices, Changing Forms, Cultural Transformation, (New York: Routledge, 2011), xix. Although the latest films in the "James Bond" series involving Daniel Craig have injected a past for the main character and this has manifested as a marketing trick, to assert Craig's Bond as a "new" Bond, and as a means to mine the past of the series itself, the entirety of the series save for Craig's three films as Bond has rejected a sense of temporality. 
duration. Time passing and passing time are central themes and recurring tropes on the narrative and formal level of the films in the series as it develops. As the following chapters will show, change, memory, and aging, are essential to the "Before" series, and the experience of watching it for the spectator. The relationship between the films becomes an expression of being in time.

Because this relationship explores and expresses facets of being in time, this thesis situates the "Before" series within a broad range of scholarship from film theory, to historiography, and philosophy. While prominent scholars have written on the question of cinematic time-Philip Rosen's Change Mummified: Cinema, Historicity, Theory, Mary Ann Doane's Emergence of Cinematic Time: Time, Modernity, and the Archive, and Laura Mulvey's Death $24 x$ a Second: Stillness and the Moving Image, are some examples-they have all focused their studies on the experience of a single film, or on the "essence" of film time. None of these recent works have looked at a type of series like the "Before" series, nor, as a result, have they focused on the relationship between films in a series and the ways that relationship can present and expresses being in time. To fill this gap this thesis turns to the philosophical work of Henri Bergson and his concept of durée, the philosophy of history developed by R.G. Collingwood and his emphasis on thinking historically, and the work of Paul Ricoeur and his studies on the intersections between narrative and temporality.

The majority of scholarship on Linklater's "Before" series has not approached all three "Before" series films as an interconnected whole or looked 
closely at how it functions as a series. ${ }^{17}$ This thesis uses this scholarship but takes a different approach. Each chapter approaches the series as an interconnected whole rather than one film at a time. The first chapter looks at how the particular relationship between the films created by Linklater's strategy of duration affects the narrative and the experience of the series for the spectator. Formal features in the films reflect Linklater's strategy of duration while also breaking the series away from Hollywood conventions. These features lead to an interaction between desire and memory in the narrative of the series, and a changing structure to the series as each film builds on the previous film. Both of these interactions, breaking from Hollywood conventions, and between desire and memory, the films building on the films in the past, highlights the concept of consequences and leads to an experience like durée for the spectator.

The second chapter investigates how Linklater's strategy of duration grants the characters a past and memory. This is approached by developing the concept of interseriality, a variant on intertextuality that takes into account the ways in which the "Before" series is able to refer to specific events in the past, that is, the corresponding past of the series. First, I argue that Linklater uses the sole flashback in the "Before" series, in Before Sunset, to establish interseriality and one way it manifests: in recollection. Second, I argue that Linklater uses a particular formal strategy to make the spectator recollect the past of the series,

\footnotetext{
17 The few exceptions are: Rob Stone, "About Time: Before Boyhood," Film Quarterly Vol. 68 No. 3 (2015): 67-72; Filippo, "Growing Old Together: Linklater's Before Trilogy in the Twilight Years of Art House Distribution,"53-59; and, Peter Lurie, "Digital Déjà Vu: Cinephilia, Loss, and Medial Integrity in Linklater's Before Trilogy," Film Quarterly Vol. 68 No. 3 (2015): 60-66. But, these articles do not explore the nature of the series as a series, and the experience it produces, to the degree that this thesis does.
} 
think over the duration of the series, and in the process understand the ways in which we fashion historical narratives and understand ourselves as historical and temporal.

The third chapter considers another way interseriality is manifested in the "Before" series: in the representation of the aging body. This chapter argues that this representation grants the series one underlying order. Linklater emphasizes this feature by casting the same actors over the twenty years of the production of the three films, and by emphasizing the changes to their bodies that are registered in the films. Jesse and Celine regularly discuss aging, comparing themselves to their past, and, encouraging the spectator to engage in similar comparisons. I then explore how this manifestation of interseriality seems to transform the series into a memento mori, highlighting the inevitability of death for the characters and spectator. But, I also offer a counter reading of the series and this interseriality as a calendar. As a calendar, the series becomes a record of invested time, time lived and living, for the spectator.

This thesis will show that the "Before" series is far from a simple romance story. By using his strategy of duration, Linklater embeds his series in time, while also embedding the spectator's experience of time into the relationship between the films in his series. Many people watch movies to "pass the time." When you watch the "Before" series, you are not only passing time; you are reminded that you are in time as well. 


\section{Chapter 1. Linklater's Narrative, Change, and Consequences}

\section{Narrative and Being in Time}

We often think film narratives have a beginning, middle, and end. These narratives occur within a finite amount of time. The story ends when the film ends. This is particularly acute in conventional Hollywood romantic films. The stories are full of lovers, blinded by love, chasing their soul mates. Actions have cause and effect, but there is little exploration of the consequences of actions. Time in the narrative ends when the film ends. This is not the case in the "Before" series.

In the "Before" series, time passes for the two main characters, Jesse and Celine, and for the series itself. "Passing time" becomes a trope in the narrative and Linklater's formal expression of this narrative across the series. This trope manifests in the series as an interaction between desire and memory for Jesse and Celine, ultimately, a recognition of consequences that is also reflected in the relationship between the films as the series develops and time passes. Linklater's strategy of duration leads to an experience similar to Bergsonian durée for Jesse and Celine, and this is mutually experienced by the spectator. In the "Before" series, Linklater's narrative reminds us of what it means to be in time, and to change as a result.

Linklater's narrative, like all narratives, describes and expresses a particular view of what it means to be in time. Narratives present and explainnarratives allow us to speak about being in the world. Hayden White argues, in "The Value of Narrativity in Representation of Reality," that narrative is "a solution" to "the problem of how to translate knowing into telling, the problem of 
fashioning human experience into a form assimilable to structures of meaning that are generally human rather than culture specific." ${ }^{1}$ Narratives give experience "a metacode, a human universal" to communicate "the nature of a shared reality."2 For Paul Ricoeur, narratives excel at communicating and expressing the experience of being in time. Ricoeur states: "I take temporality to be the structure of existence that reaches language in narrativity and narrativity to be the language structure that has temporality as its ultimate referent. Their relationship is therefore reciprocal."3 Malin Wahlberg describes Ricoeur's framework as one where "narrative is the mediating dimension between time and the ways in which time is understood in practical life." 4 Wahlberg's description of Ricoeur's theory emphasizes the very practical nature of narrative. Narrative is a basic means to understand our experience of time. 5 By presenting a narrative in the "Before" series, Linklater is describing and expressing a particular way of being in time.

Linklater's narrative and its particular expression of being in time are affected by his strategy of duration. This strategy enables Linklater to break Hollywood conventions of narrative, and in the process highlight certain

\footnotetext{
${ }^{1}$ Hayden White, "The Value of Narrativity in Representations of Reality," Critical Inquiry Vol. 7, No. 1 (1980): 5 .

2 ibid. 6.

3 Paul Ricoeur, "Narrative Time," Critical Inquiry Vol. 7, No. 1 (1980): 169

4 Malin Wahlberg, Documentary Time: Film and Phenomenology, (Minneapolis: University of Minnesota Press, 2008), 39.

5 ibid. "[T]ime becomes human to the extent that it is organized after the mover of a narrative; narrative, in turn, is meaningful to the extent that it portrays the features of temporal experience."
} 
temporal experiences through the relationship between the films in the series. ${ }^{6}$ Ricoeur, looking at literature, argues that we understand a narrative's treatment of time in relation to narrative norms. ${ }^{7}$ Tradition, the works of the past, is the foundation that new narratives build upon. The same occurs in film. According to David Bordwell, often the continuing dominance of the classical Hollywood narrative model is only realized upon its violation. ${ }^{8}$ It is this violation, or change, from classical Hollywood conventions that the strategy of duration achieves and that allows the "Before" series to present and highlight unnoticed temporal experiences.

The particular experience Linklater's strategy of duration highlights by breaking narrative conventions is very similar to Bergsonian durée. Bergson sought to erode sharp distinctions between past, present, and future. For him, "the essence of time is that it goes by. . .the real, concrete, live present. . .that present necessarily occupies a duration. . .what I call 'my present' has one foot in my past and another in my future."9 In Bergson's view, the present only has meaning insofar as it emerges out of the past and in relation to a future. Bergson called this heterogeneous experience of time durée. Durée is an awareness and reflection on actions in the past and possible actions in the future. It is an understanding of consequences. Bertrand Russell summarizes durée as the

\footnotetext{
${ }^{6}$ According to David T. Johnson, "Not in One Dream, But in Many: Discipline, Dialogue, And the Cinema of Richard Linklater," Film Quarterly Vol. 68 No. 3 (2015): 38, a feature of Linklater's work is his investment in experience.

7 Helen Powell, Stop the Clocks!, 123.

8 David Bordwell, Narration in the Fiction Film, (Madison: University of Wisconsin Press, 1985), 60 .

9 Henri Bergson, "Matter and Memory," Henri Bergson: Key Writings ed. Keith Ansell Pearson and John Mullarkey. (New York: Continuum, 2002), 127.
} 
interaction between desire and memory: "Apart from mind, the world would be perpetually dying and being born again; the past would have no reality, and therefore there would be no past. It is memory, with its correlative desire, that makes the past and the future real and therefore creates true duration."10

As this chapter will show, the past, present, and future, are never sharply divided in the "Before" series due to Linklater's strategy of duration. ${ }^{11}$ Time passes in the series for Jesse and Celine and as it passes their narrative involves more and more reflection on their actions in the past, the past of the series. Like Bergsonian durée, desire and memory interact across the series for Jesse and Celine and for the spectator in the relationship between the films of the series. Out of this interaction emerges an awareness that our choices in the present have a past and effect a future, an awareness of consequences and change.

\section{Desire}

The "Before" series is a romance. Throughout the series, to varying degrees, Jesse and Celine desire each other. Because it is a romance I will start with how Linklater breaks Hollywood conventions to express Jesse and Celine's desire to the spectator. Desire manifests in the narrative through its treatment of Jesse and Celine's goal. Traditional Hollywood narratives are often structured around characters achieving a goal. But the "Before" series disrupts this convention by presenting Jesse and Celine's principal goal as the desire to pass

${ }^{10}$ Bertrand Russell "The Philosophy of Bergson” The Monist Vol. 22, No. 3 (1912): 331.

${ }^{11}$ Though not associated with Linklater strategy of duration, Rob Stone also emphasizes that Linklater's films tend to look both backward and forward. Stone also uses Bergson for a short period in his analysis, however, his analysis is focused on dialogue and "street level interaction" rather than the interaction between films, what is presented in this thesis. See: Stone, "About Time: Before Boyhood," 67. 
time with one another..$^{12}$ Through tight framing, the spectator sees Jesse and Celine mutually desire their goal throughout the narrative. This tight framing also enables the spectator to achieve this goal, their desire, alongside them. The visible image of the couple together becomes associated with their desire.

Tight framing emphasizes the intimacy of Jesse and Celine's time together, despite their almost always being in public spaces together. In Before Sunrise, Jesse and Celine, after hours together, step into a bar. The sequence begins with a long shot, panning right, that presents the crowded bar. When Linklater's camera finds Jesse and Celine in the crowd playing pinball the panning stops. From this long shot Linklater cuts to a series of long takes with two repeating compositions as Jesse and Celine discuss love and their romantic pasts.

In the first composition (Figure 1) Linklater tightly frames their discussion through a medium shot at a low angle. This leaves the right part of the image filled with the pinball machine's display, a beam in the center, and the left part filled by Jesse and Celine alternating as the player. In the second composition (Figure 2) Linklater uses a medium shot at a high angle over the player's shoulder. The framing is tight, leaving the left of the image filled with the player's body, the center with the onlooker's face focusing on the player, and the right filled with the pinball machine. In both repeating compositions, the tight framing makes it difficult, if not impossible, to focus on anything else in the image but the couple.

12 The disruption here is similar to David Bordwell, Kristin Thompson, and Janet Staiger's comments on Rope. See: David Bordwell, Kristin Thompson, and Janet Staiger, The Classical Hollywood Cinema: Film Style and Mode of Production, (New York: Columbia University Press, 1988), 47 "Time in the classical film is a vehicle for causality, not a process to be investigated on its own" like in Rope. 
This example is only one example of the tight framing that occurs throughout the series that partitions the couple from public space. Whether the couple is static or mobile, in a restaurant or a streetcar, this trait emphasizes their intense focus on one another while in public places by filling the spectator's image with only the couple. In the sequence previously described, in contrast to the preceding long shot presenting the crowded bar, the tight framing excludes the crowd from the image, creating an intimate and private space for the couple within the crowded space of the public bar. The visible image itself for the spectator becomes the private place where Jesse and Celine pass time together.

This tight framing gives formal expression to Jesse and Celine's goal throughout the series: each other. It is an expression of desire. Throughout the series, their focus only occasionally turns to anything but the person beside them. In Classical Hollywood Storytelling, Bordwell, Thompson, and Staiger argue that a central part of Hollywood narratives are characters striving toward and completing goals: "Hollywood characters. . .are goal oriented." 13 Thompson adds in Storytelling in the New Hollywood that, "desire provides the forward impetus for the story"14 (my emphasis). A character desires something and this drives the narrative forward. Like Russell's description of our relation to the future in durée, desire orients the film narrative and projects us into the coming story.

But, Jesse and Celine's goal, communicated to the spectator through Linklater's tight framing, breaks this convention by presenting the principal goal

13 Ibid., 16.

14 Kristin Thompson, Storytelling in the New Hollywood: Understanding Classical Narrative Technique (Cambridge: Harvard University Press, 1999), 14. 
as merely the desire to pass time together. But such a goal can never be simply accomplished; it is constantly delayed or thwarted. With the passage of time, this desire is continually renewing itself. For Bordwell, romance is often one of the goals, if not the goal, in a Hollywood narrative. Kiss, have sex; with the goals accomplished the film ends. However, Jesse and Celine's romantic narrative is guided less by the completion of romantic goals, a kiss or sex, than by simply spending time together regardless of what they are doing. With nothing else to desire, no destination to reach, no finite clear goal to strive for, their time together becomes the goal they fulfill by proximity, and also the very thing they are focused on, what they desire more of. In turn, the couple fills the image for the spectator. Watching the "Before" series is watching the couple pass time together. Linklater expresses this intense focus on each other, this desire, for the spectator through his tight framing that visually excludes Jesse and Celine from their surrounding environment for their time together.

Linklater's tight framing further enables the spectator to fulfill Jesse and Celine's goal, their desire for time together, with them. In Before Sunset, nine years after Before Sunrise, Jesse and Celine argue, in the back of a moving car, about the significance of their past. During this long sequence (Figure 3) Linklater points the camera towards the couple sitting in the back seats and uses the edges of the car's interior to frame the image. With static shots, the tight confines of the car, and the faces of the couple filling the image, Linklater's composition emphasizes the sense that Jesse and Celine cannot escape or forget one another. 
This tightly framed composition creates a feeling of collusion for the spectator with the couple's tightly-focused desire for one another. D.J. Thomas argues that tight framing sequesters the characters away from the outside world and brings the spectator intimately close to the "circle of action."15 Linklater's compositions brings the spectator into Jesse and Celine's "circle of action," we might call it a "circle of duration": their desire and focus for one another's time. Jesse and Celine ignore the Parisian streets for each other, and the spectator is in the same position by nature of Linklater's tight framing that fills the image with Jesse and Celine. If their desire to pass time together is expressed through tight framing, then this tight framing also makes the spectator a third partner in their passage of time together. We desire to know what happens next, where will they go? But, by virtue of Linklater's tight framing, what is next is continuously passing more time with Jesse and Celine in their circle of action.

When Jesse and Celine are alone, Linklater uses long and wide shots to suggest a correspondence between the wider image and the expansion of their circle of action. In Before Sunrise, after Jesse and Celine spend the night in a park, Linklater uses a wide shot as they walk down an empty Viennese street in the morning. Linklater's expanded frame leaves the city seeming empty except for the couple walking together as if the city has become a private place for their time together. In turn, this compounds the close association between what the spectator sees, be it tightly framed or widely shot, with the desire of the couple for time together and the goal in the narrative across the series.

\footnotetext{
15 D.J. Thomas, "Framing the 'Melancomic' Character, Aesthetics, and Affect in Wes Anderson's
} Rushmore," New Review of Film and Television Studies Vol. 10 No. 1 (2011): 112. 
Leaving the image and frame, in turn ending their time together, signals a crisis in the narrative. In Before Midnight, the hotel room, like the Viennese street, is at first private and intimate as Linklater expands the frame through wide shots. But when Celine leaves the hotel room at the climax of their argument, her departure from this expanded private space, and the wide shot, expresses a crisis: their twenty-year relationship is potentially over. Leaving this space and the expanded frame signals the end of their shared desire for time with one another. In turn, leaving the frame also ends the spectator's ability to spend time with Jesse and Celine as they are no longer together in the diegetic space or in the image. Much as the tight framing expressed their intense desire for each other, leaving the frame and the image signals the potential end of this desire, that is, the continuation of the narrative and the series.

By refusing to cut away from the tightly framed couple Linklater further expresses Jesse and Celine's desire and goal for passing time together, a goal that breaks from Hollywood convention. In Before Midnight Jesse and Celine walk through a Grecian village. Linklater points the camera in a reverse tracking shot towards the couple but in the opposite direction of their, and the camera's, movement. At one point Celine, in the middle of a long take, points to something outside the frame while saying, "look at this. . .wow!" (Figure 4). Traditionally there would be a cut to an accompanying shot of what Celine is seeing, the image a stand-in for her subjective focus. ${ }^{16}$ Instead, Linklater maintains the long take and tight framing of the couple as they continue to walk. Linklater forces the

16 ibid., 110. 
spectator to focus on the couple in the image as they walk past whatever momentarily stole their attention from each other. Whatever Celine pointed to, it was unimportant. What matters is the couple and their goal to pass time together, a passage the spectator joins with Linklater's refusal to cut away.

Linklater's refusal to cut away from the couple even denies the spectator a spectacular view of Vienna in Before Sunrise. At one point, while riding a Ferris wheel in the middle of the city, the view of the city distracts them. Jesse even comments on the view. Linklater, in turn, provides a quick pan of the city. But Jesse is more interested in Celine, and Celine him. And Linklater's camera quickly returns its focus to the couple's blossoming romance, their first kiss, and the city is now blurry in the background, a graphic expression of where their, and the narrative's, focus and desire lies: each other (Figure 5).

This focus by Linklater on the couple's time together stands out because it denies the spectator a prolonged "touristic" vision of the cities across the series. Save for Celine in Before Sunset, the couple are tourists through the series. A defining trait of modern tourism is "sight-seeing": going somewhere simply to look at it. ${ }^{17}$ The city is also regarded as the sight of the flâneur, a mobile and perceptually engaged walker attuned to the change in European cities such as Paris and Vienna. ${ }^{18}$ And the cinema itself, capable of recording and distributing images, has been associated with the flâneur figure, the window of a traveling

\footnotetext{
17 Judith Adler, "Origins of Sightseeing” Annals of Tourism Research Vol. 16 No. 1 (1989): 8. ${ }^{18}$ Walter Benjamin proclaimed Paris was the city of the flâneur; see also, Susan Sontag, "The photographer is an armed version of the solitary walker reconnoitering, stalking, cruising the urban inferno, the voyeuristic stroller who discovers the city as a landscape of voluptuous extremes. Adept of the joys of watching, connoisseur of empathy, the flâneur finds the world "picturesque." From Susan Sontag, On Photography (New York: Picador, 2001), 55.
} 
train, and a style of armchair-tourism we might call 'movietheater-tourism.'19 Carolyn A Durham has expressly argued that Hollywood conventionally constructs a touristic vision of Paris and the wider world. ${ }^{20}$ One would think that with tourists as its characters, dynamic modern cities and ancient landscapes filled with landmarks, and a mobile visual medium like film, that Linklater would produce a film of tourism, a "sight-seeing" film.

But the "Before" series is far from a "sight-seeing" film. While Linklater's narrative has ample opportunity for sight-seeing and has been associated by some with the flâneur, it focuses more on Jesse and Celine's time together, much like the couple themselves. ${ }^{21}$ When Jesse and Celine disembark from a street car in Before Sunrise there is a quick montage sequence of Viennese architecture, statues, and a palace. Yet, quickly thereafter Linklater returns to shots of the couple "forging their own path away from the well-worn sightseeing destinations." ${ }^{22}$ Jesse leads Celine to an ancient Coptic church in Before Midnight. Inside, however, in a reference to a similar event that occurred in a Viennese church in Before Sunrise, their conversation quickly revolves back to

\footnotetext{
19 Dominique Brégent-Heald, "Vacationland: Film, Tourism and selling Canada 1934-1948," Canadian Journal of Film Studies Vol. 21 No. 2 (2012): 28 "The photographic realism of motion pictures had the unique ability to transform spectators into armchair tourists. While the cinematic experience could function as a surrogate for actual travel, it could also potentially fuel a desire for the experiences witnessed on screen."

${ }^{20}$ Carolyn A. Durham, "Sighting/Siting/Citing The City The Construction Of Paris In TwentyFirst Century Cinema," Post Script Vol.27 No.1 (2007): 72-89.

${ }^{21}$ While Durham explicitly aligns Before Sunset with a touristic vision of Paris, I'd disagree. Aside from one moment when their discussion turns to the Notre Dame cathedral, the entirety of the film is incredibly focused on the couple and their dialogue rather than the cities landmarks. Jesse is a tourist, but tourism and sight-seeing is clearly not the film's, nor Jesse and Celine's, focus. For further arguments see also, Christie, The Cinema of Richard Linklater, 93: "Parisian landmarks [are] subjects to be actively engaged with through the characters' conversational interplay, rather than as merely a superficial backdrop to the action."

${ }^{22}$ Christie, The Cinema of Richard Linklater, 42.
} 
each other, and, Celine jokes, blasphemously, to sex and their children out of wedlock. The couple is not indifferent to their surroundings. Jesse and Celine look where they are walking. They care, but Linklater's characters care for each other and their time together, their "inner lives" more than they do for the sights and cities.23 In the same fashion, Linklater refuses to cut away from the couple for the city sights to emphasize their desire to pass time together in spite of the many tourist opportunities, the many great "sights". The couple filling, and at the center of, the image for the vast majority of series reflects the narrative focus for the series. For the spectator, to watch the series becomes watching and joining the couple, and, for much of the series, only the couple, passing time together.

\section{Steps to Memory}

Linklater further expresses desire by breaking two overriding and complementary conventions of Hollywood narrative: the importance of deadlines, and complete closure. This leads to a listless and directionless quality in the narrative across the series. The only direction to the narrative across the series is the passage of time. Linklater's strategy of duration develops this quality across the series for the spectators into a structure of questions and answers between the narratives of the films in the series.

In the "Before" series deadlines are simply not important. For Bordwell, Thompson, and Staiger, deadlines are essential for establishing larger structural relationships in a Hollywood narrative. They mark the conclusion of a character's journey. One achieves their goal, or the goal is dashed, at a deadline and finally

\footnotetext{
23 Lesley Speed, "The Possibilities of Roads Not Taken: Intellect and Utopia in the Films of Richard Linklater," Journal of Popular Film and Television Vol. 35 No. 3, (2007): 105.
} 
the film's conclusion. ${ }^{24}$ But with Jesse and Celine's goal being to spend time together the deadlines imposed on them are, much like the cities they walk and talk through, less important. The future, a deadline, does not matter as long as they are spending time together: the future for them, and the spectator, is passing time.

Linklater expresses this with intermittent cuts into his long takes that show the couple heading 'nowhere.' Christie identified the "theme of the journey" as a major thematic feature of Linklater's output. In the "Before" series the couple journey through time rather than towards a destination. ${ }^{25}$ In Before Sunrise it occurs as the couple walks and talks through a carnival. In Before Sunset it occurs as the couple walks and talks through the Promenade Plantée, an elevated park built on an old railway viaduct. In Before Midnight it occurs as the couple walks through the twisting streets of a Grecian village (Figure 6). From the usual mobile and tightly framed long take facing the couple as they walk, Linklater suddenly cuts to a shot from behind the couple of their backs. We expect to see where the couple is walking to after Linklater's cut to the camera following the couple. Instead, Linklater's cut leaves the destination of the couple indefinite, as if destinations are only momentary stops during their long walks together. Linklater's tight framing and shallow depth of field in these shots compound this effect. The back of the couple is clear, but their destination in the background is blocked by their bodies and unfocused. The cumulative effect leaves the spectator

24 Bordwell, Thompson, Staiger, The Classical Hollywood Cinema, 44.

${ }_{25}$ See a discussion of Jesse and Celine's movement and its relation to "free time" and the spectator experience in: Johnson, Richard Linklater, 85. 
sharing in a sense of Jesse and Celine's directionlessness save for the passage of time.

But this is not to say that Linklater's series is without deadlines. One assumes the strategy of duration would heighten the importance of deadlines. But, in fact, the opposite occurs. Jesse's need to catch a plane home in twentyfour hours in Before Sunrise, Jesse's need to catch a plane home in "a couple" hours in Before Sunset, and the end of the couple's vacation in Greece, are still deadlines and temporal constraints that set the terms for the films. The films have a finite run-time. But, unlike Hollywood narrative conventions, upon meeting the 'final' deadline of the film's run-time, there is no conclusion to desire and time for Jesse and Celine. At the conclusion of his films, Linklater rejects complete closure. A question always lingers for the spectator, what are the consequences for what has happened? And the answer, through Linklater's strategy of duration, can only come with time.

Linklater creates the structure of question and answers through open endings, the rejection of complete closure. Closure is often seen as the point of a film; “[e]verything you've enjoyed about the film, the ending somehow comments on." ${ }^{6}$ According to Thompson, "virtually all Hollywood films achieve closure in all plotlines and subplots.”27 Happy endings, a mainstay in Hollywood narrative, occur when characters have met, or beat, their deadlines, leaving nothing more to the narrative. ${ }^{28}$ But so long as the ending leaves no lingering questions there is no

\footnotetext{
${ }^{26}$ Jeff Nichols Quoted in Robert Abele, "Year of Fade to What?," Variety January 9 9 $^{\text {th }} 2012$.

27 Thompson, Storytelling, 10.

28 Bordwell, "Happy Endings," The Way Hollywood Tells It, 50.
} 
requirement for a happy ending. As Noël Carroll argues, every narrative presents "a question (or set of questions) to which the audience expects answers. . .Closure transpires when all the questions that have been saliently posed by the narrative get answered."29 "[C]losure," Carroll continues, "yields a feeling of completeness."30 Good or bad, we expect answers to our questions, we expect an ending.

The Clock (Vincent Minnelli, 1945) is an excellent example of closure in a conventional Hollywood narrative and romance because it shows how ideas of temporal continuity are rejected. In many respects, it is similar to Before Sunrise. A soldier, on a two-day leave of duty in New York City before heading off to fight, meets a young woman by chance in Grand Central Terminal. After twenty-four hours they are in love and, with the soldier going off to war, they decide to marry. The couple, fighting a bureaucratic nightmare, completes their marriage in a municipal chapel and again in a church. Though throughout the film their love is tested, they are certain they are meant to be together because, according to the characters, God willed them together. At the film's conclusion, the husband departs for war aboard a train and the wife walks away from the train station certain of her husband's safety and their marriage as the camera soars upwards and looms over her and the city street in a crane shot.

Closure in The Clock is the product of theological certainty. Despite the uncertainty of the future-and the fact that no one returns from war unscathedtheir marriage and her husband will survive because God, looming over the wife

\footnotetext{
29 Noël Carroll, "Narrative Closure," Philosophical Studies Vol. 135 No. 1 (2007): 4.

30 ibid., 5 .
} 
and city in the final crane shot, says so. Will they last? The answer to this question comes less by way of the film's narrative than by the function of faith in God. This is an example of complete closure-can there be a more complete ending than one promised by God?31-and a narrative that has evaded any sense of consequences. The question, "what happens next?" is unnecessary. Time, insofar as the narrative expresses it, ends at the conclusion of the film.

Unlike The Clock, in the "Before" series there is a tension between Jesse and Celine's desire and the arrival of the final deadline-the passage of time and the end of each film. Broadly, Christie has argued that Linklater's characters and complex and "seem to extend beyond the confines of the film." 32 With the strategy of duration time is always passing in the series, even past the end of the films. Rather than seeming "to extend beyond the confines of the film," with the "Before" series the characters do extend beyond the confines of each film into the passage of time between them. As a result, the end of each film leaves a question and an answer that can only come with the following film, with time passing. This is a conflict between the story across the series, and the plot presented in each film. Out of this tension between Jesse and Celine's desire and the end of the film emerges the open endings.

All of the films in the series feature an open ending as deadlines come and pass and closure slips away to time, that is, to the next film in the series. After

\footnotetext{
${ }^{31}$ According to Philip Rosen, pre-enlightenment Christian histories were defined by their eschatology, the end of time was certain, a theological fact. See: Phillip Rosen, Change Mummified: Cinema, Historicity, Theory (Chicago: Minnesota University Press, 2011), 104-105. ${ }^{2}$ Christie, The Cinema of Richard Linklater, 35: “. . .Linklater's characters are never ciphers, and are always presented as living, breathing people with complicated and sometimes weighty concerns which seem to extend beyond the confines of the film."
} 
only a few hours together in Before Sunrise, Jesse and Celine seem to accept their limited time. They say goodbye to each other before they separate in order to make their remaining time together free from emotional commitment. But this premature goodbye foreshadows the open ending at the film's conclusion. At the train station, where the couple must separate, they turn to each other and reaffirm their desire for one another. The film concludes with Celine and Jesse promising to return in six months and leaving in different directions. Rather than ending their time together, rather than complete closure, Linklater ends Before Sunrise with lingering desire. For both the couple and the spectator, this desire persists as a question into the future beyond the confines of the film's plot: will they meet again?

Nine years later in Before Sunset, and in the narrative, an answer comes to this question. Linklater brings them together again, but once again limits their time together. However, Jesse's deferral of his plane home is a recurring motif throughout the narrative as the final deadline is less important than the couple's renewed time together. After an hour wandering through Paris, it looks like Jesse and Celine will separate again. Surely, the deadline will drive Jesse and Celine apart again. The end of the plot will end the story. However, Jesse ignores the deadline and heads up to Celine's apartment. "Have your tea and then. ..," Celine says to Jesse as the deadline's approach fades into an ellipsis. "You're going to miss that plane," Celine mockingly says to Jesse as she dances and imitates Nina Simone. Jesse, shot in a long take watching Celine off screen, without a care in the world, replies: "I know." Linklater concludes the film with a fade-out on a shot of Celine dancing, the reverse shot of Jesse's desiring gaze and a formal 
expression of their desire to spend time together beyond the confines of the film's runtime. Their time together, their story literally fades beyond the plot and the film's conclusion. For the spectator, a question remains: Are they together again?

Before Midnight, eighteen years after Before Sunrise, answers this lingering question for the spectator while, inescapably with Linklater's strategy and rejection of complete closure, providing another. Now firmly embedded in family life together, Jesse and Celine expound on the confines of parenting through the first half of the film. In the second half, they finally have time alone. They wander through the town towards a hotel, booked as a gift by friends, where they are to spend the final night of their vacation. There they fight. Celine departs after saying, "I don't think I love you anymore." What was the destination of their journey, the romantic climax of their vacation, becomes a site of conflict. This seems like the end of their story and the "Before" series. However, after Jesse, now alone, scans the room, he leaves to find Celine, who is sitting at a café patio by the sea. After a desperate conversation, their relationship seems to have survived. Jesse and Celine's time together continues. Though once again it suggests a continuation of their time and uncertainty in equal measures. A final tracking shot moving backward from the seated and talking couple uncertainly ends the film. Through Linklater's strategy of duration, we understand that after the frame goes black Jesse and Celine are still in conversation on the patio, still passing time together. But, will they stay together? Is this but a lull in their conflict? These are questions that linger due to Linklater's open endings, and that, with Linklater's addition of time and a strategy of waiting, only a future film can answer for the spectator. 
The open endings in Linklater's series break Hollywood narrative convention, create a structure of questions and answers between the films, and express the passage of time that results from Linklater's strategy of duration for the spectator. When the spectator faces unanswered questions posed by the narrative they are left demanding answers. Carroll nicely describes this with a very relevant hypothetical for the "Before" series: One may, as Carroll says,

. . . arouse in the audience for a romantic comedy the desire to know 'Whether the young woman will marry the boy next door, or whether she will run off with the city slicker?' and then withhold the answer until the last reel. One may confirm the effectiveness of this technique. . .by shutting down the projector before the final reel unfolds. The viewers will jump up-as if from a trance-and demand to know who the young woman finally married. 33

However, Linklater's strategy of duration leads to exactly what Carroll hypothesizes: ending the film before the final reel, or, we should say, the final film. This lack of closure, however, does not produce the same violation for the spectator of the "Before" series as withholding the answer at the end of a film as Carroll suggests would happen with a more conventional narrative. Instead, because of Linklater's strategy of duration, the narrative of each film in the "Before" series extends beyond the open ending as a lingering question for time to answer. More so, Linklater suggests that even if the hypothetical final reel were seen, with his strategy of duration, it would offer no final closure for the spectator. There will always be a "desire to know," a withheld final reel and indeterminate future for the "Before" series, that is, until the series can no longer

\footnotetext{
33 Carroll, "Narrative Closure," 5.
} 
be made. 34 Linklater's rejection of the importance of deadlines and complete closure connects the films in the series with a structure of questions and answers that projects desire from within each film into the future.

\section{Memory and Consequences}

This structure of questions and answers between the films in the "Before" series does not work solely in one direction. The past, present, and future, are interconnected for Jesse and Celine, as well as the series. Each open ending connects each film to the next, as well as providing the grounds for the next narrative to occur. Coinciding with each additional film in the series, building on the past of the series (what we can call the tradition of the series), are Jesse and Celine who focus on their past, the events in the past films, more and more with each additional film. Their decade-spanning desire, a constant feature in each film, interacts with memory, the past of the series. Jesse and Celine begin to reflect on their actions in the past, on consequences, and this is highlighted for the spectator in the "Before" series by changes to the narrative structure of each film as it develops. Changes in the narrative structure reflect the interaction of desire and memory that happens for Jesse and Celine over time and lead to an experience that is similar to Bergsonian durée for the spectator when watching the series.

Because Jesse and Celine first meet in Before Sunrise, and because it is the first film in the series, it is the foundation, the zero point, which Jesse and Celine

\footnotetext{
34 Glen Norton, “Seductive Slack of Before Sunrise," Post Script Vol. 19 No. 2 (1999): 72, argues Before Sunrise and Linklater's filmmaking "affects one's consciousness. . .long after the images have faded from the screen. They persist. The question of aging, order, and death, are taken up in detail in Chapter 3 of this thesis.
} 
reflect upon in each of the following films. Linklater initially made Before Sunrise with no intention of it belonging to a series, though. 35 Despite this, the film establishes the conditions for Linklater to begin his strategy of duration. In it, Linklater's characters ruminate constantly on the passage of time, and the inability to escape it. ${ }^{6}$ When Jesse and Celine stand on a stone balcony talking, Jesse says, "And what's so cool is that this whole evening, all our time together, shouldn't officially be happening." Celine replies, "Yeah, it's so weird. It's like our time together is just ours. It's our own creation. . .But then the morning comes and we turn into pumpkins, right?” Jesses wants to view their time outside of "official" time. Celine agrees, but then dashes his view with her Cinderellainspired joke on the coming morning, when the couple is indeed forced to depart with only a single night and a promise to reunite at Linklater's open ending.

Due to Linklater's strategy of duration, these events become the past which Jesse and Celine remember and, alongside the structure of the films, bear the consequences of. The spectator sees characters grappling with their past, the past of the series. In both Before Sunset and Before Midnight, Jesse and Celine deal with the consequences of their actions and the change that comes from time passing. In both films, they still desire one another. In Before Sunset it is a desire

\footnotetext{
35 Richard Linklater: "The 'band' got back together, not by popular demand, but just because the band wanted to jam," Linklater, 52, says from his Austin home. "No one was suggesting it. People were completely miffed that we did a second one. However much they liked Before Sunrise - it did well and got good reviews - the question the second time around was, 'Why? What brought that up? All these years later, why?' Well, Jesse and Céline kind of reared their heads and had something to say. It happened again this time." Quoted in "Richard Linklater on his accidental movie franchise, the 'Before' trilogy” Peter Howell, The Toronto Star, June 062013 https://www.thestar.com/entertainment/movies/2013/o6/o6/richard_linklater_on_his_accide ntal_movie_franchise_the_before_trilogy.html.

${ }^{36}$ See: Christie, The Cinema of Richard Linklater, 44: "'they are just as aware that this waking daydream is ultimately a finite one, and destined to end. .."
} 
that instantly rekindles after nine years kept apart, while in Before Midnight it is a desire that has deepened over nine years together and the birth of their children. However, this desire cannot escape their past and memory. Their single night together in Vienna in Before Sunrise haunts the couple in Before Sunset. For Jesse, this culminates in a desperate rhetorical question for Celine: "Why weren't you in Vienna. . .Our lives would be so much different!" Literally, it seems, Jesse understands his now failing marriage as the consequence of their missed reunion. For Celine, this inability to forget culminates during the car ride to her apartment. Exasperated over the passage of time and memory she says, "It pisses me off I can't forget, that moment in time that's forever gone." In Before Midnight it is the consequences of their affair begun in Before Sunset, and the continuation of their relationship from Before Sunrise, that haunts them. Jesse, by staying in Paris, chose time with Celine over time with his son. His desire overrode any obligation to return to America, even for his son. As Jesse states: "I fucked up my entire life to be with you in Paris." However, this disturbs Celine precisely because at this point in her life she is devoted to her twins above everything, even Jesse. Jesse's comment on the consequences of their affair reveals that at the conclusion of Before Sunset he chose his desire for Celine over his own child. Through the strategy of duration which embeds his series in time, Jesse and Celine's passing into middle-aged life and parenting, Linklater transforms the act of desire at the conclusion of the previous film into a deep violation of responsibilities for Celine. What emerges for the spectator is a series with characters grappling with their memory, the past of the series, interacting 
with their desire for one another, the narrative goal of the film, and the ways in which they have changed with the passage of time.

The changes that come about from the passage of time and the couple's desire interacting with their memory, the highlighting of consequences across the narratives in the series, is also reflected between the films in the series through changes in narrative structure from one film to the next for the spectator. The changes correspond to the passage of time that Linklater's strategy makes Jesse and Celine subject to. In Before Sunrise, Jesse and Celine's romantic ten hours together occurs over the ninety minutes to the consequences of their actions and Linklater expands the couple's time together relative to the runtime of the film. In contrast, in Before Sunset and Before Midnight, time is constrained by responsibilities. In the former, the couple is in constant conversation as if in the limited time they have together, and for the spectator the limited run time of the film, they must account for the entire nine years between meetings and between films within the shortest film in the series. In the latter film, the couple faces the monotony of parenting and the faux free time of a vacation. As Celine puts it, "there's no room for spontaneity, it is all gone from our lives." In turn, the first half of the film sees the couple caring for their children, spending the afternoon with friends at a villa, and eating dinner there in the afternoon. Responsibilities and other people pull the couple away from private time together. In the latter half of the film, this changes with the gift of a night in a hotel, a gift of precisely what used to be in their lives: spontaneity and freedom. As a result, the latter half of the film develops and is presented to the spectator like the past films. Jesse and Celine wander at the whims of desire. The characteristic long takes and 
directionless wanderings from the earlier films reappear as it seems as if the couple has gone back in time, back to Before Sunrise and Before Sunset. Changes in narrative structure between the films in the series correspond to Jesse and Celine's reflection on their past, to their recognition of consequences.

Before Midnight is particularly interesting because it suggests that this similarity to the previous films, the impossibility of what it stands for now that Jesse and Celine are parents, is what leads to the conflict in the narrative. The climax of the film is a lengthy argument about their past, the events from the previous films. The consequences of their actions weigh on them more than ever. The free-flowing spontaneity of desire from the previous films, and the spontaneous gift of the hotel, now becomes the source of the conflict in this film. They can no longer be together because of the time that has passed because they are now adults with responsibilities. The free-flowing structure of the films from the past only partly corresponds to who Jesse and Celine are now. They cannot go back to who they were. 37 Jesse and Celine's narrative conflict is further expressed to the spectator as a conflict in narrative structure in the film, a conflict predicated on memory, the past of the series, and the passage of time, the development of the series.

The resolution to this conflict in Before Midnight arises less within the film than as a result of Linklater's strategy of duration. The couple recognizes the changes that time passing have brought to them. Jesse recommits his love for

37 This is similar to Christie's description of the "collective burden of responsibilities" between Jesse and Celine and expressed between Before Sunrise and Before Sunset. See: Christie, The Cinema of Richard Linklater, 127. 
Celine and their children, and Celine, it seems, recommits her love for Jesse. Rather, than becoming an impasse, the end of their relationship and the series, their past becomes the foundation for their relationship to renew itself. As Maria San Filippo describes, Before Midnight "softens into a resolution about a present made possible by, however tentatively, making peace with both the past and the future." 38 Precisely because they have spent so much time together is their relationship important to them. In turn, Before Midnight has an open ending, like the open endings and structure of questions and answers in the previous films that built towards this film, and leaves a question for time to answer. Nine years will have passed if Linklater maintains his strategy of duration to the next film. Jesse and Celine will have changed and will be aware of the consequences of their decisions in the past. So too will the narrative structure in this future film change in relation to the past films in the series. Linklater's strategy of duration leaves the relationship between the films articulating for the spectator the reason that Jesse and Celine have stayed and continue to stay together: a past invested in each other.

For Jesse and Celine, and the spectator, the interaction of desire and memory leads to an experience like durée. Jesse and Celine cannot escape the events in the past that linger in their memory. They are continually pushed by desire in the present and into the future and pulled by their memories into the past. As a result of this interaction between desire and memory they reflect on the consequences of their actions, and recognize that they have changed with the

\footnotetext{
${ }^{8} 8$ Filippo, "Growing Old Together: Linklater's Before Trilogy in the Twilight Years of Art House Distribution," 53 .
} 
passage of time. This recognition of consequences and change that comes through the interaction of desire and memory is an experience like durée. For the spectator, Linklater's series has its past, present, and future, interconnected as well as it brings desire, the narrative goal of the films and its lingering question, into contact with memory, the narratives in the past films. This sees the series reflecting on consequences by changing to reflect this interaction between the narrative of a film in relation to the narrative in the past of the series. The relationship between the films expresses the passage of time and the experience of being in time. As a result, through the relationship between the films, Linklater creates an experience like durée for the spectator that interacts desire with memory, the past with the present, the narrative of one film with the narrative in the past of the series.

\section{Consequences and Romantic Conventions}

Usually, recurring features, traits, or institutional and cultural iconography, across sets of films define genres. Genres can go through cycles, and these cycles emerge from different uses of the respective generic building blocks. Yet, genre theory faces certain 'problems.' How do you define a genre without the films that make it up? And, conversely, how do you initially define a film's genre without an already defined notion of a genre? In other words, the problem of genre is when to say one ends and another begins: it is a problem of closure.

Ironically, it is precisely the "Before" series' use of the formal and narrative trope of "time passing" that denies closure and that defines its own unique status, a series-cum-subgenre. That the "Before" series is embedded in time, and consequences are highlighted in the films, and by the relationship between the 
films in the series, the "Before" series marks out its own peculiar space in the romance genre. Instead of sheltering its romance and story from time, it explores the ramifications of a romance exposed to time. While the "Before" series bears affinities to single films focusing on love affairs and relationships over time, such as An Affair to Remember (Leo McCarey, 1957), where the tribulations of an affair and the aftermath of a failed reunion are explored, or Annie Hall (Woody Allen, 1935), which portrays "the lovers trying to negotiate their life together" while facing "unending change,"39 or The Graduate (Mike Nichols, 1967), where a young college graduate gets caught up in an affair with an older woman while falling for that same woman's daughter, it develops these ideas over the course of three films and in the relationship between the films through Linklater's strategy of duration. In marking out its own space in the romance genre through its exploration of consequences, the "Before" series presents to the spectator a subtle critique of romance films that only offer a "snapshot" of a relationship.

This exposure to time brings into question one of the central myths in Hollywood romance: the 'soul mate', the 'perfect partner'. For Mary-Lou Galician, this is one of the more popular myths perpetuated in mass media regarding romance and she summarizes it as: "Your perfect partner is cosmically predestined, so nothing/nobody can ultimately separate you."40 She reminds the

\footnotetext{
39 Leger Grindon, “Annie Hall (1977) The Trials of Partnership," The Hollywood Romantic Comedy: Conventions, History, Controversies (Malden: Wiley-Blackwell, 2011), 150.

40 Quoted in Kevin A. Johnson, "Unrealistic Portrayals of Sex, Love, and Romance in Popular Wedding Films," Critical Thinking About Sex, Love, and Romance in the Mass Media. Ed. MaryLou Galican and Debra L. Merskin (Mahwah: Lawrence Elbraum Associates, 2007), 356.
} 
reader that “. . .you're living in the 21st century. And you're a human capable of changing and improving your 'destiny' rather than letting it enslave you." 41

On the one hand, Linklater is playing into this myth. From their meeting on the train and night together in Vienna, to their reunion in Paris, and their fight in Greece, it seems that Jesse and Celine are destined to stay together. Not even time has separated them. However, Linklater, through the relationship between his films, is also emphasizing Galician's reminder as well, that Jesse and Celine are not simply the same people they were when they met. They are a dynamic and evolving couple facing the consequences of their actions over twenty years. Often compromise brought on by a knowledge of their past, a past which is, for the spectator, the past of the series, is necessary instead of any notion of destiny. For the spectator, Jesse and Celine have learned from the passage of time rather than rely on destiny, an effect that is highlighted in the relationship between the films in the series, and that highlights the passage of time.

Where many single romance films end, the "Before" series continues. An Affair to Remember ends with its romantic couple finally reuniting after one year and a crippling accident; Annie Hall ends with its romantic couple breaking up, meeting again, and finally parting ways; The Graduate, famously, ends with the runaway bride and her suitor sitting in the back of a bus as slowly the possible effects of their hasty exit dawns on them. The "Before" series progresses between the initial meeting (Before Sunrise) to the reunion (Before Sunset) by nine years, features an affair (Before Sunset) and then, unlike An Affair To Remember, 
explores how this couple would be nine years later (Before Midnight) and beyond, and how at every stage they make decisions that ricochet consequences through time and into the series. Instead of evading the question of whether the relationship will continue, Linklater patiently waits for it to continue and explores the nature of a relationship over time through his series.

Linklater's subtle critique, then, is like a trailing thought that persists in time after a film: When the romance film you are watching ends, perhaps the complete closure is not as complete as you think. This is a realization that arises from Linklater's strategy of duration and the relationship between the films in his series. It is a realization that closely mirrors Cavell's reading of and reaction to It Happened One Night (Frank Capra, 1934), from his study of his own genre, "comedies of remarriage," formulated from a roughly chronological grouping of films. In that famous romantic comedy, the couple (Clark Gable and Claudette Colbert) desperately try to get away from one another. But then, over the course of the narrative they, and Cavell, realize that they have in fact been craving their time together. As Cavell explains:

What this pair does together is less important than the fact they do whatever it is together, that they know how to spend time together, even that they would rather waste time together than do anything else-except that no time they are together could be wasted. ${ }^{2}$

For Jesse and Celine, it is much the same, only this realization develops over the course of a series, develops with the passage of time and through Linklater's strategy of duration. Desire and memory mix in a recognition of the time they

\footnotetext{
${ }^{42}$ Stanley Cavell, Pursuits of Happiness: Hollywood Comedy of Remarriage (Cambridge:
} Harvard University Press, 1981), 88. 
have spent together and will seemingly continue to spend time together. And, much like Bergsonian durée, this recognition of the time they have passed together and desire together, the interconnectedness of their past, present, and future, is what continues to give their relationship meaning despite all the changes in their life and the consequences of their actions in the past.

By expressing this experience of temporality for Jesse and Celine in the relationship between the films in his series, the "Before" series also creates an experience like durée for the spectator. Linklater blends the desire of Jesse and Celine, the narrative focus of each film, with the consequences and memories of their actions, the narratives of the previous films in the series. Over time this blend grows more complicated and the narrative of the films in the series change to reflect this. Difference and change in the structure of narrative communicate and express Linklater's emphasis on consequences and change, on the passage of time, for Jesse and Celine throughout his series to the spectator. Linklater's narrative, as a result, makes experiential something that we often take for granted: because time passes our decisions have consequences. But, because time passes there is also the potential for change, to learn, to compromise. 


\section{Chapter 2. Interseriality: Recollection and The Past}

\section{Interseriality and Intertextuality}

The previous chapter focused on how Linklater's strategy of duration leant the "Before" series an ability to reflect on its past, to highlight consequences. As time passes, and the series develops, there is an obscuring of the past, that is, its own past. For Mary Harrod, history "in its broad sense is a central preoccupation for Linklater." 1 Throughout the "Before" series, Jesse and Celine attempt to understand their past. They form historical narratives, and this has a formal expression in the series reflecting on its own past. This chapter will be the first part of a study of this reflection in the series, what I call interseriality. Linklater uses interseriality to create experiences of recollection for the spectator that has the effect of historicizing their spectatorship, in the process revealing what it means to understand and narrate the past.

This chapter proceeds in two sections. The first addresses Linklater's sole use of flashbacks in the series in Before Sunset. I argue that, by composing them from scenes from Before Sunrise, Linklater is establishing for the spectator the process of interseriality that will be a feature of the rest of the series. The second section argues that, following the example from his flashback sequence, Linklater uses a particular formal construction to enable the spectator to interact with the

\footnotetext{
${ }^{1}$ Mary Harrod, "The Aesthetics of Pastiche in the work of Richard Linklater," Screen Vol. 51 No. 1 (2010): 21-37. Harrod explores the concept of pastiche through Linklater's treatment of intertextuality in his films individually, predominately Dazed and Confused in relation to American Graffiti (1973, George Lucas), and A Scanner Darkly's (2006, Richard Linklater) play with identity and the performance of its actors. She does not, as this thesis does, explore intertextuality, through the lens of a series like the "Before" series, as interseriality, where it is interacting with its own duration.
} 
interseriality of the series in their memory and to think of themselves as historical as they face the passage of time.

Linklater creates a relationship between the films in the series where each film becomes the past that the following film refers to and uses, a relationship I am calling interseriality. Interseriality is a variation on intertextuality. Judith Still and Michael Worton, in Intertextuality, describe the theory of intertextuality as one that "insists that a text. . cannot exist as a hermetic or self sufficient whole, and so does not function as a closed system." 2 This is because intertextuality is at the fulcrum of two axes: "texts entering via authors (who are, first, readers) and texts entering via readers (co-producers)," meeting to form a particular relation to a text.3 Intertextuality is not limited to literature; it also applies to other media, including film. As Keith A. Reader points out, Robin Wood's comments on $E l$ Dorado (Howard Hawks, 1966) "could pass for a working definition of (one kind of) intertextuality.

The difficulty for the critic arises not only from the fact that the superficial resemblances to Rio Bravo, though so close, are misleading; there is also the fact, although everything in El Dorado is new, it is in many ways dependent on the earlier film for its significance. It is precisely our awareness of its differences from Rio Bravo that matters. 4

We must also be aware that film adds a third axis to intertextuality: what is filmed. One axis of this intertextuality established itself in the star system and the popular appeal of an actor across their films. The appeal is to at once see the actor

${ }^{2}$ Judith Still, and Michael Worton, "Introduction" Intertextuality: Theories and Practices, ed. Judith Still and Michael Worton, (New York: St. Martin's Press, 1990), 1.

3 ibid.,2.

4 Keath A. Reader, "Literature/cinema/television: intertextuality in Jean Renoir's Le Testament du docteur Cordelier," Intertextuality Ed. Judith Still and Michael Worton, (New York: St. Martins Press, 1990), 177. 
and see the character simultaneously, so much so that, for some actors, like John Wayne in the incredibly similar Rio Bravo and El Dorado, their identity surpasses their character, their identity becomes an intertextual character itself.

Woods' "working definition" is an effective one for showing how interseriality is a variant of intertextuality, a specific and historical relationship between the films in a series. Instead of engaging with the totality of cultural texts that impinge on spectatorship, as Wood implies in his comments on the interaction between El Dorado and Rio Bravo, yet also maintaining the "awareness" of differences from one film to a later film, interseriality focuses on specific events in the past of a series. Rather than seriality, where simply a sequence is implied 5 , interseriality refers to a previous instance in the series to emphasize and highlight the real time that has passed between "then" and "now." Interseriality explores the duration of a series. While Chapter 3 will look at bodies and interseriality in the "Before" series through the lens of aging and death, this chapter focuses on the ways in which interseriality engages with how we come to understand our past-how we remember and think historically. Practicing and engaging with interseriality involves working with the material past of the series. Crucially, in interseriality, we also engage with the past of a series in our imagination through our own past as spectators, much like the central role of the reader in intertextuality. A variant on intertextuality, interseriality highlights how a historical narrative forms out of references to and uses of specific events within

5 See: "seriality n." OED Oxford English Dictionary. www.oed.com.proxy.library.carleton.ca/view/Entry/327123?redirectedFrom=seriality\#eid, "Serial arrangement; the fact or state of being arranged or ordered in a series." 
a series, in order, that is, to emphasize the passing of time for the characters, but also for the audience.

\section{Establishing}

The first film in the "Before" series has no past. As discussed in Chapter 1, Linklater made Before Sunrise with no intention of it being the beginning of a series. While in that chapter I approached that feature as the means by which Linklater establishes the possibilities for consequences in the later films of his series, in this chapter I will approach this feature as the zero point of the "Before" series' past. As the first film in the series, there was no past, there was no interserial interaction possible.

In the nine years that followed, after Linklater waited, he released Before Sunset as the sequel to Before Sunrise. Nine years following that, he released Before Midnight. While by Before Midnight Linklater's strategy was established, the correspondence established earlier between Before Sunrise and Before Sunset at the time of its release was unique for a fiction series. Linklater had continued his story across a real nine-year gap, and the characters were aware of and reflected on this gap. In turn, he would have to establish the ways in which his strategy enables interseriality, enables him to refer to and interact with the films in the past, and that emphasizes the passage of time and how we come to know our past.

Linklater uses a quick flashback sequence at the beginning of Before Sunset to establish interserial interaction. Jesse is on the final leg of his book tour, in Paris, nine years after Vienna. A reporter asks him whether his book, an account of the events from Before Sunrise, is autobiographical. Jesse's answer, 
"that we are the sum of all the moments of our lives," implies that it is and that memory played a crucial part in its creation. As his answer continues in voiceover, Linklater intermittently presents a montage of scenes from Before Sunrise in loose narrative order (Figure 7)-Jesse and Celine meeting on the train, the first time they tell each other their names on a bridge, their first kiss on the Ferris wheel-interspersed with shots of Jesse answering the question in the present at the bookshop. Then, another reporter asks Jesse whether they got back together or not. Once again, as Jesse answers, Linklater intermittently cuts to a flashback of the final moments of Before Sunrise, when the couple desperately agreed to meet again. Finally, someone asks what his next book will be about. While explaining the narrative of his book, a story of temporal divisions between the past and present collapsing for a man, Linklater cuts to a scene near the end of Before Sunrise when Celine and Jesse are dancing.

This flashback establishes memory, the act of recollection, and what recollection enables, as a key component of interseriality. Linklater's montagestyle editing cuts back and forth from Jesse in the book shop in Before Sunset to the images from Before Sunset and formally presents the temporal divides that Jesse crosses in his mind to retrieve these images. The cuts emphasize a distinction between "then" and "now" by contrasting the shots of Jesse in the book shop, with the changing settings and visual features in the images from Before Sunrise. Through its consistency of shot type and setting, the shots of Jesse in Before Sunset identify themselves to the spectator as "now," as the moment when the images of the flashback, as images in Jesse's memory, are created in his act of remembering as his mind searches back to "then" in Before 
Sunrise. Furthermore, Jesse's romantic voiceover that loosely coincides with Linklater's editing emphasizes the subjective and personal nature of the flashback, that is, how they function interserialy, as Jesse's memories and his history. Recollection enables Jesse to think of himself as historical, and the series expresses in this initial flashback that establishes the interserial structure for the films.

A similar example, but with a significant difference, is seen in Steven Soderbergh's The Limey (1999). In this film, with numerous flashbacks that represent the memories of the main character Wilson, played by Terrence Stamp, Soderbergh occasionally uses scenes from the film Poor Cow (Ken Loach, 1967) featuring the character Tom, played by the younger Terrence Stamp (Figure 8). The flashbacks are, like Before Sunset's for Jesse, clearly intended to establish a past to Wilson. However, The Limey's flashbacks are an example of intertextuality, while Before Sunset's are an example of interseriality. Poor Cow is a different film from The Limey, but more importantly, Wilson and Tom are different characters in different narratives. The Limey uses Poor Cow to create a past in The Limey. This is in contrast to Before Sunrise and Before Sunset which are different films but tied together by the same story, the same characters, and, as Chapter 3 will explore in detail, the same actors. Thus, while both The Limey and Before Sunset draw from an earlier film, the relations between the films are different. The former, bringing disparate texts with different characters together to assert an indistinct past for one character through their actor, is intertextual; the latter, bringing texts joined by the same story, character, and actor, together to assert and explore a specific and continuous past between films, is interserial. 
Another comparable us of the flashback can be found in Love on the Run (Francois Truffaut, 1979), the fourth installment in Truffaut's "The Adventures of Antoine Doinel" series. Truffaut's series is perhaps the closest fiction series to the "Before" series. Throughout the film, the eponymous character of the series, played by the same actor throughout the series (Jean-Pierre Léaud), divorces his wife and runs into a woman from his past, the past of the series. These events see him reflecting back on his life. Truffaut uses numerous flashbacks over the film made from scenes cut out of his previous films in the series to express Antoine's reflection (Figure 9). These flashbacks are made all the more significant as, like Before Sunset's flashback, the same actors are seen at different times. Coincidentally, Antoine in Love on the Run has, like Jessie in Before Sunset, written a book about his past.

But there are key differences between the flashbacks in Love on the Run and Before Sunset. First, there is no correspondence or regularity between the films in Truffaut's series like there are in Linklater's. The passage of time for Antoine is unspecific, in contrast to time's passage for Jesse and Celine which is nine years between each film. Second, Love on the Run is full of flashbacks. They occur throughout the film, are often lengthy, and frequently feature their original audio and no voiceover. Furthermore, the flashbacks reflect over the entirety of Truffaut's series. Love on the Run was explicitly the end of Truffaut's series. ${ }^{6}$ In contrast, the flashback in Before Sunset is the sole flashback in that film, and the entire series. Unlike Love on the Run, the flashback in Before Sunset back to

\footnotetext{
${ }^{6}$ Francois Truffaut, Love on the Run (1979) DVD special features from The Adventures of Antoine Doinel (The Criterion Collection).
} 
Before Sunrise presents the specific interserial action possible in Linklater's series through his strategy of duration, and then no other flashback occurs again. Why?

Linklater uses this sole flashback sequence to establish the interserial relationship between the films in his series, but also to emphasize the experience of recollection associated with this flashback in order for the spectator to interact with the series in a similarly experiential manner, through recollection. Analyzing the nature of Linklater's sole flashback sequence will explain how this shift from the flashback to the spectator occurs.

By drawing on a previous film from the series in the flashback, Linklater suggests that interseriality is archival in nature. As the "Before" series develops, the previous films become a personal archive, a historical repository of records, images, scenes, events, for Linklater to build his following films from. Simultaneously, shown in interseriality's association with memory, as the series develops the past of the series becomes an archive of memories for Jesse and Celine, and, as I will explain later in this chapter, the spectator as well.

But, can we label the entire "Before" series as archival because of this flashback and interseriality? To a certain degree, yes. I suggest that we describe the "Before" series as archival in strategy and experience instead of as fully archival in the appropriative sense. I make this distinction based on Jamie Baron's arguments about the experience of found footage film, or what she calls "archival cinema." For Baron, the spectator experiences in archival film a sense of "temporal disparity," "the effect within a given film generated by the juxtaposition of shots perceived as produced at different moments in time," 
creating a sense of "pastness." 7 Crucially for Baron, and for this thesis, they do not need to be shots produced by two different filmmakers, the images can come from the same filmmaker over time. Baron draws on the famous "Up" series by Michael Apted as an example. In the series, Apted has revisited the English children featured in the first film, Seven Up! (1964) every seven years, documenting their passage from children to adults, up to the latest installment, $56 U p$ (2012) where they are all fifty-six years old. His films frequently feature footage from his earlier films. He has essentially, like Linklater, produced his own archive to draw upon, to "find" material, and work into the subsequent films. ${ }^{8}$ Linklater's flashback sequence creates Baron's "temporal disparity" by contrasting the older Jessie in the book shop with Jessie in the images from Before Sunrise, his long hair now cropped short and his boyish good looks faded and rougher, and the voiceover which "speaks" for the past rather than the original audio from Before Sunrise. For Johnson, this flashback sequence beckons the spectator to think about time passing. ${ }^{9}$ We get a sense of the "pastness" of Before Sunrise in relation to Before Sunset through this juxtaposition that arises from Linklater's archival workings with his own series.

But, while an archival film is produced from "found" documents, even if it is by the same filmmaker drawing from a series created over a span of time, like Apted's "Up" series, the flashback sequence in Before Sunset is not "found" in a similar way. The biggest difference is that operating in a relatively conventional

7 Jamie Baron, The Archive Effect: Found Footage and the Audiovisual Experience of History, (New York: Routledge, 2014), 21-25.

8 ibid., 18.

9 Johnson, Richard Linklater, 84. 
documentary mode, Apted is free to edit his films in an expository manner in his role as director. When he places his "found" material from the past in his films they are not flashbacks. He uses the "powerful effect" of film, the third intertextuality discussed above, to strongly associate its images with "truth" stripped of the subjectivity and fallibility of memory. ${ }^{10}$ Indeed, while flashbacks are often taken for "true," there is a long lineage of films undercutting or explicitly presenting the flashback as a fabrication, Stage Fright (Alfred Hitchcock, 1950) ${ }^{11}$ and Usual Suspects (Bryan Singer,1995) ${ }^{12}$ being two infamous examples. In contrast, to the "Up" series, with the "Before" series, Linklater is making a relatively conventional fiction film so the "finding" and the flashback must be motivated in the narrative. For the flashback, this motivation is Jessie's need to remember. The footage is "found" by Jesse remembering the past of the series. Instead of a result of the director's expository editing, appropriation, and

\footnotetext{
10 Tamás Csönge, "Moving Picture, Lying Image: Unreliable Cinematic Narratives," Acta Universitatis Sapientiae Vol. 10 No. 1 (2016): 89-104; see also, Maureen Turim, Flashbacks in Film: Memory and History, (New York: Routledge, 1989), 166: “...there is the overriding sense, somewhat naïve, that anything presented by concrete imagery in a film actually happened...A character can lie verbally, but images, especially flashback images were usually employed to correspond to a fictionally true version of events and often have the additional function of contradicting verbal lies." This association between the image with truth, and the voice with lying, also occurs in American legal settings where the admission of video evidence often involves the removal of a voiceover or, sometimes, the audio entirely to preserve the "truthful" character of video evidence. See: Regina A. Coleman, "Why Seeing Isn't Always Believing: A Look at Videotape Evidence and Change of Venue in the Wake of Rodney King," Western State University Law Review Vol. 21 No. 1 (1993-1994): 321-340. ${ }^{11}$ Csönge, "Moving Picture, Lying Image: Unreliable Cinematic Narratives," 100: "The movie greatly relies on the mimetically motivated tradition that characters can lie verbally, but the images we see are objective and represent the truth ...In other words, the big twist was based on the subversion of a cinematic code."; see also, Bordwell, Narration in the Fiction Film, 61: "It's not just the character's yarn that is unreliable, narration shows itself to be duplicitous by neglecting to suggest any inadequacies in Johnnie's account and by appearing to be highly communicative - not just reporting what the liar said but showing it as if it were indeed objectively true," and, Kristin Thompson, "The Duplicitous Text: An Analysis of Stage Fright," Film Reader Vol. 2 (1977): 52-64.

12 Stanley Orr, "Postmodernism, Noir, and The Usual Suspects," Literature Film Quarterly Vol.27, No. 1 (1999): 69.
} 
explicitly formal juxtaposition, the flashback sequence and the "foundedness" of the images from Before Sunrise is archival as a result of Linklater's strategy of duration.

Because of this distinction, I would describe this flashback, the series, and its interseriality, as archival in experience and strategy instead of fully archival in form. The central reason for this is that the "Before" series features only one flashback sequence in its entire running time. Why would Linklater do this? In this flashback he establishes the interserial relationship that emerges between his films as a result of his strategy of duration. Moreover, by emphasizing the close association between interseriality and memory, and by basing its archival qualities in the experience and act of remembering as a result of his strategy of duration, Linklater establishes one way the spectator will experience this interseriality in the rest of series beyond this flashback: through the experience of recollection. With no flashbacks in the series to "find" their footage when interseriality occurs, the spectator will instead, like Jesse and Celine remembering their past, "find" the footage from the previous films in their minds. This allows them, like Jesse in the flashback, to think of themselves as historical.

\section{Doing}

In the flashback sequence, Linklater establishes one way the spectator will engage with interseriality in the series: through the experience and act of recollection. Linklater enables the spectator to recollect in moments of interseriality with a particular formal and narrative strategy that has Jesse and Celine's dialogue about the past contrasting with the immediacy of long takes in which they speak. Instead of presenting footage from the previous film(s), 
Linklater enables the spectator to pull up that footage in their minds. This enables the spectator to do historical thought, to think historically about themselves and in relation to Linklater's series, and in the process gain a heightened awareness of their relationship to time and how we come to understand the past.

When we recollect we are retrieving the past for the present. The Oxford English Dictionary defines the verb "recollect" as: "To go over again, review, recapitulate," 13 and "recollection" as: "A thing or fact recalled to the mind; a memory." 14 Recollection is an act and an experience, a conscious retrieving of the "then" from and for "now". Memory emerges out of a sense of the present as an imaginary representation of the past. For R.G. Collingwood this representation of the past is "historical imagination," "a certain kind of memory." It bridges the past and the present in our imagination and is necessary for thinking historically. To understand the past, to reflect on it for the present, we must first recollect it. Furthermore, to think historically about the past, even events that occurred long before you were born, is to reciprocally think historically through and of yourself. 15

To enable the spectator to recollect, Linklater first uses long takes to create an experience that emphasizes the immediate and perceptible present. Theorists often view the long take as "intensifying the experiential." 16 According to David T.

\footnotetext{
13 "recollect v." OED Oxford English Dictionary Online.

14 "recollection n." OED Oxford English Dictionary Online.

15 R.G Collingwood, The Idea of History (Oxford: Clarendon Press, 1946), 288: ““Thought can never be mere object. . .'to know what one's thinking' involves thinking it for oneself." 16 Donato Totaro, "Muriel: Thinking With Cinema About Cinema," Offscreen Vol. 6, No. 7 (2002) (n.p.)., http://www.horschamp.qc.ca/new_offscreen/muriel.html
} 
Johnson, Linklater "is very much interested in the experience of temporality, for both characters and spectator, and in particular what it means to inhabit the present." ${ }^{17}$ The "Before" series is full of long takes that emphasize an experience of immediacy, an intensified perception of "now." The listening booth scene from Before Sunrise is exemplary of this immediacy. After rummaging through crates in a record store, Jesse suggests that Celine joins him in a listening booth. The camera captures the couple from a low angle. Tight framing emphasizes the intimate setting as the love song, Kath Bloom's "Come Here”, plays (Figure 10). The duration of the long-take holds on the couple as they playfully smile, stare at each other's lips and evade each other's eyes. Linklater denies the arrival of a cut, in turn heightening the ambiguity of the moment. Will they kiss?

Here Linklater's long take pulls the spectator into the lengthy and uninterrupted time of the long take, a sense of "now" that comes with expectation. The long take defers the answer of whether they will kiss. Yet, it also heightens the passing moments until the kiss will, hopefully, come; it makes us desire it. The connection between the long take and the run time of the love song further heightens the expectation of a kiss. The experience for the spectator is like Henri Bergson's experience with a melting sugar cube: "It coincides with my impatience, that is to say, with a certain portion of my own duration, which I cannot protract or contract as I like. It is no longer something thought, it is something lived."18 Like Bergson, who feels his place in time while waiting for a

${ }_{17}$ Johnson, Richard Linklater, 8.

18 Bergson, Creative Evolution Trans. Arthur Mitchell (New York: Henry and Holt Company, 1913), 9-10. 
sugar cube to melt, the spectator feels the extended duration of "now" as they, alongside Jesse and Celine, wait and expect a kiss, given that Linklater eschews the cinematic means available to condense the time by cutting. ${ }^{19}$

Most of these long takes are mobile. This mobility further connects the spectator to Jesse and Celine's experience of time passing. An intimate camera follows the wandering couple and captures their time together. Through the streets of Vienna in Before Sunrise, the streets of Paris in Before Sunset, and the Mediterranean Coast in Before Midnight, Linklater has the camera wander along with the couple. Jesse and Celine wander with no goals but to spend time together. The surroundings are not the focus, the ancient and famous streets of the cities pass by one-by-one along Jesse and Celine's aleatory strolls. The focus is on the immediacy of their time together in a long take.

These mobile long takes in the "Before" series achieve a similar Daniel Morgan calls "dual attunement": the ability for a tracking shot to reveal the subjective state of characters and their state in the world as a function of the mobile nature of the shot and the mobile scene it presents. ${ }^{20}$ In Morgan's analysis of Max Ophuls' films, this "dual attunement" presents a morality that leaves individuals across classes trapped in an interconnected social world. ${ }^{21}$ In the "Before" series we see these wandering long-takes with their immediacy attuned to the couple's goal, the passage of time together, as it presents this duration, this sense of time passing, to the spectator.

\footnotetext{
19 See: Johnson, Richard Linklater, 37, for his discussion of Jesse and Celine's trolley ride which "encases us in the present moment."

${ }^{20}$ Daniel Morgan, "Max Ophuls and the Limits of Virtuosity" Critical Inquiry Vol. 38 No.1 (2011): 131.

21 ibid., 162.
} 
This immediacy perceptible in the long take and the attunement of the mobile cameras to this immediacy for Jesse and Celine corresponds to one part of historical thought: the immediacy of perception. But, there is another part to historical thought: historical thought is also attuned to the past. Collingwood writes:

historical thought is in one way like perception. . What I perceive is this room, this table, this paper. What the historian thinks about is Elizabeth or Marlborough, or the Peloponnesian War or the Policy of Ferdinand and Isabella. But what we perceive is always the this, the here, the now. . .Historical thought is of something that can never be a this, because it is never a here and now. Its objects are events which have finished happening, and conditions no longer in existence. Only when they are no longer perceptible do they become objects for historical thought. ${ }^{22}$

Like Collingwood's definition of historical thought, Jesse and Celine are on the one hand fixated on the immediacy of their time together, and on the other hand fixated on their past together that is "no longer perceptible." The couple is constantly discussing their memories of their time together, which, in the case of Before Sunset, are the events of Before Sunrise. For the spectator, the narrative of the couple is, like Bergson's description of the perceivable present, "continually invaded by memory." 23 Like Jesse and Celine, too, the events of Before Sunrise for the spectator are "no longer perceptible" while in the experience of immediacy created by Linklater's long takes. Linklater's "dual attunement," then, has two dueling elements for the spectator, a pull into the present from the long takes and a conscious push into historical thought generated by Jesse and Celine's debates and discussions about their past, the past of the series.

${ }^{22}$ Collingwood, The Idea of History, 233.

${ }_{23}$ Quoted in Mary Ann Doane, The Emergence of Cinematic Time: Modernity, Contingency, the Archive (Cambridge: Harvard University Press, 2002), 77. 
This dialogue contrasts with the long take's immediacy and demands the spectator cast back to "then," enabling the spectator to recollect and, often, leaving them uncertain. A key example of this occurs in Before Sunset. Jesse and Celine debate whether they had sex in Vienna, an event that supposedly occurred in Before Sunrise. Linklater begins the sequence with a long take of the couple as they walk up the stairs in the direction of the camera to a park (Figure 11). During this shot, their debate begins. As the couple turns a corner in the stairwell, the camera, now facing their backs, begins to follow them. When they stop, and the attuned camera stops with them, Jesse says: "I find it very scary you don't remember what happened." The sudden disparity of their memories, and time passed together, seems to disable the dual attunement of the mobile camera to the couple's ability to wander in time in two directions. But, Linklater cuts and begins a new long take facing the couple as Celine explains that she does remember what happened. But it is different than how Jesse remembers it. Where Jesse recorded his memories into his book, Celine recorded her memories into a journal. The long take continues and soon Celine becomes less sure as she tries to remember the exact chain of events from Vienna and Before Sunrise. Celine asks, "Was it in the cemetery?" and Jesse replies, "No! No. We went to the cemetery in the afternoon-was it that forgettable?"

Well, was it? This conscious retrieval of the past films from within the immediacy of the long takes creates the experience of recollection for the spectator. The long takes heighten the moment Jesse and Celine spend together with a sense of "now." But instead of focusing purely on "now," the couple splits their focus on "then." This involves remembering and discussing moments in the 
previous films. They recollect. But they recollect these moments differently. Did they have sex? Was it in the cemetery? Through Linklater's tight framing, close camera, and long take, Jesse and Celine's questions seem posed to the spectator as they are to each other. As a result, the questions during the long take enable the spectator alongside the couple to question and try to recollect the events from their past. This offers the spectator the experience of having a kind of shared memory with the characters, insofar as the spectator can remember the film that they saw in the past. If the spectator cannot remember the film they saw in the past then they are also like the characters, insofar as now they too are unsure about the past. For Jesse and Celine, this disagreement in the present requires them to remember their past. Correspondingly, the spectator has the experience of "now" in one film created by the long-take invaded by a hail to remember "then" from the previous film in the series.

This experience is different than the flashback from Before Sunset or a Hollywood film. For Gilles Deleuze, the normal instance of a flashback in Hollywood film functions like a "conventional extrinsic device," like a sign with the words: “"watch out!' recollection.”24 A flashback presents recollection. In contrast, Linklater's construction is enabling the spectator to experience recollection, to recollect. Lee Carruthers describes Bazin's view of film time as "the lived time of thought and body" of the spectator. ${ }^{25}$ Similarly, the sequences from the "Before" series, by activating an experience of the present and the past

\footnotetext{
${ }^{24}$ Quoted in Russel J. Kilbourn, Cinema, Memory, Modernity: The Representation of Memory from the Art Film to Transnational Cinema (New York: Routledge 2010), 19. 25 Lee Carruthers, "Bazin et le prens-temps: The Timeliness of Cinema," Screen Vol. 52 No.1 (2011): 10.
} 
to enable recollection, is also enabling the spectator to think about the past through their own consciousness, to think about themselves as historical. ${ }^{26}$ Unlike the conventional flashback, Linklater creates an experience that pushes and pulls the spectator into the past and present of the series, into the nine years between the films, and, thus, also the temporality of their own spectatorship by reflecting on their past. Linklater makes the spectator experience thinking historically about themselves through recollection.

This experience of recollection and historical thought emerges out of uncertainty and debate over competing representations of the past for the characters and the spectator. As Jesse and Celine debate over whether they had sex during these long takes they fall back on written records as evidence to prove their point. In effect, they take on the role of two competing historians. Both of them maintained written accounts of Vienna, Jesse in his book, and Celine in her journal. But their narratives do not match. In the ensuing debate Celine becomes unsure of her memory. In the debate, at the point when two divergent historical accounts meet, a gap widens between Jesse and Celine's experience of the past and their records of it. The experience of recollection confronts and faces an uncertain and obscure past.

Understanding that there are different accounts of the past is itself a revelatory experience about the passage of time. According to Philip Rosen: "Disputes around the authenticity of preserved objects and the uses to which they should be put are ... disputes about the best ways to deal with temporality,

${ }^{26}$ See note 53 above. 
always associated with change (the difference between past and present) and therefore evanescence in time." 27 Indeed, Jesse and Celine's debate over their records and memory coincides with a heightened sense that they have changed. They are no longer who they were in Vienna as they walk in Paris with Linklater's strategy of duration, precisely because it is now the past and uncertain. The immediacy of the long takes heightens this effect. As the duration of the long takes extend, the past of the shot, the film, and the series, fades into uncertainty by relative degrees. Thus, the debates and discussions reveal and remind Jesse and Celine of the fading past.

Where Jesse and Celine have their written accounts of their past, the spectator has the films in the series. The spectator is brought into Jesse and Celine's debate and discussion, and their revelation, through the interseriality in Linklater's enabling of recollection. By hailing the spectator to think of their thought and body as historical, it also makes them subject to historical debate. Did you actually see them having sex in Before Sunrise? Do you remember? Where were you when you watched it? When were you when you watched it?

This interserial experience of recollection for the spectator, like Jesse and Celine's, emerges out of uncertainty over their past, in particular, their past as spectators. When Jesse and Celine debate in Before Sunset over an event in Before Sunrise, the past, they are also debating with the series' record of those events and the spectator's memory. Martha Blassnigg argues,

when film time is disrupted, the activity of the spectator is doubled with two repositories to draw upon - the past image perceived in the screen

${ }_{27}$ Phillip Rosen, Change Mummified, 85. 
as well as the recollections from the spectator's personal life, as they both intermingle and intersect as a double stream that impinges on the ongoing perception of the film. ${ }^{28}$

With the "Before" series, the spectator has as part of their own recollections the viewing of the previous films. In the midst of the long take, the spectator faces a specific question: did Jesse and Celine have sex? As Blassnigg has described, the spectator seeks the answer not only in the image but also in their memory. But the "Before" series produces a unique experience. In addition to the present film seen, and their personal memories, there is also the film in the past, the film of Jesse and Celine's past. The effect leaves the spectator questioning the events in the previous film, questioning its record of the past. What was present, that is, the present of viewing Before Sunrise, becomes the mutable and uncertain past in Before Sunset.

This experience of recollection emerging from these long takes, and the ensuing debate, asks the spectator to retrieve in their memory an imaginary representation of the event from the previous film. This is similar to Martin Lefebvre's concept of the "figure." The figure, according to Lefebvre, is "the result of an interaction between the film, on the one hand, and the memory and imagination of the spectator, on the other." The figure is "what one retains from a film." The mind functions as "a sort of imaginary museum of the cinema where we keep the various films and film fragments that have touched us deeply or made a profound impression on us." ${ }^{29}$ Crucially, for Lefebvre, the figure is not

${ }_{28}$ Martha Blassnigg, Time, Memory, and Consciousness and the Cinema of Experience:

Revisiting Ideas on Matter and Spirit (Amsterdam: Rodopi, 2009), 178.

29 Martin Lefebvre, "On Memory and Imagination in the Cinema," New Literary History Vol. 30 No. 2 (1991): 480. 
part of a symbolic system for discovering intent behind a film. ${ }^{30}$ Instead, it emerges out of the experience of viewing; it is an interpretative tool for the spectator, "an imaginary representation of the content of the film." ${ }^{11}$ The "figure," Lefebvre argues, allows the spectator to make sense of a film through their memory of other films.

But, Lefebvre's concept is simultaneously too specific and too general to describe the unique interaction between the spectator and the relationship between the films in the "Before" series. Any interactions between the film and the viewer produces the figure. It is an interpretative tool that allows the viewer to make sense of the film they saw, and also to contrast that film with the many other 'figures' in their mind, their total collective memory of film. The figure's scope then extends from a singular film to the entirety of movies seen, to the horizon of film viewing by a spectator. It suggests interpretation, informed by the figure of a film, and the figures from many others, is itself intertextual. But, this does not accurately describe how the recollection enabled in the "Before" series leads the spectator to reflect on their own specific past of spectatorship, to bring their past spectatorship back to the present.

Through the strategy of duration and interseriality, Lefebvre's "figure" becomes historical. The act of recollecting and reflecting on the imaginary representation of the previous film in the series historicizes spectatorship. It makes that representation and memory, conjured through the spectator's own temporality, historical imagination, historical thought, and subject to debate. 
Through this historical imagination and thought we face the passage of time which obscures the past and leaves us uncertain over the events in Before Sunrise, and we attempt to understand our place in this passage of time by bringing Before Sunrise back to the present in our experience of watching Before Sunset. This experience recurs again and again throughout other interserial moments in the "Before" series.

Of course, unlike Jesse and Celine we can go back and check Before Sunrise and the previous events in the series. But this rewatching is 'tainted' by a necessity of validation, or, in other words, the passage of time. As Collingwood emphasizes: "every new generation must rewrite history in its own way. . .historical thought is a river in which none can step twice-even a single historian. . finds when he tries to reopen an old question that the question has changed."32

If you rewatch Before Sunrise you discover that you do not actually see Jesse and Celine having sex. A cut, from their kiss and embrace to the morning sky and the couple walking, implies the event and overcomes the gap in the narrative (Figure 12). What seemed certain, 'verified' on film, is now part of a debate. As Glen Norton suggests, whether Jesse and Celine had sex during the cut is up to the viewer to decide. 33 For Collingwood, this gap in available "evidence" is overcome through historical imagination. ${ }^{34}$ It bridges this gap. Later on in Before Sunset, Celine reveals that she does remember having sex with Jesse. In fact, they

$3^{2}$ Collingwood, The Idea of History, 248.

33 Norton, "Seductive Slack of Before Sunrise," 70.

34 ibid., 241. 
had sex twice. But, no matter how many times the spectator returns to Before Sunrise that sex is only ever implied, an imaginary bridge across two cuts and a gap in their narrative for the spectator.

The debate and recollection over Jesse and Celine's night in Vienna showcases how available resources construct our understanding of the past. Instead of the totality of events that occur in Jesse and Celine's time together, the spectator only has access to a single piece of evidence: the previous film. In Before Midnight, Jesse and Celine wander down the Peloponnesian coast and Linklater's camera follows the couple in a mobile long take as they discuss their past. Here are all the ingredients to enable the shared experience of recollection for the spectator with Jesse and Celine: long takes, tight framing, dual attunement of the mobile camera, and interserial references in the dialogue. Celine even remarks on how their current walk and conversation seems so much more like their past than their present as parents. In response, Jesse asks, "How long has it been since we just wandered around bullshitting?"

Well, how long? Once again this question between Jesse and Celine is as much posed to the spectator. The answer is obvious-one could facetiously say "wandering around bullshitting" is the perfect description for the "Before" series. Unlike much of the film before this walk, where Jesse and Celine are never alone and Linklater uses mainly static shots, this moment, formally and narratively, is the most like the previous films in the series as the wandering mobile long takes capture the wandering couple and seem to transport them back in time. When was the last time they wandered around? The answer for the spectator accordingly is nine years ago in Before Sunset. But as the conversation continues 
the spectator discovers this is not the answer, or more accurately, this is the spectator's answer.

Linklater suggests to the spectator that, in fact, the history of Jesse and Celine exists beyond the scope of the content of films that have recorded their time together. They persist between the films, in the gaps of nine years. For Philip Rosen, there are two key problems that emerge from representations of the past based on indexical evidence. First: the disjuncture that persists for historians, and always will, between past and present, parts and wholes, "a logical gap between source and conclusion". 35 And second: the historian can not remove themselves from time. $3^{6}$ The spectator, actively engaging with the "Before" series through recollection brought on by interserialization, faces both of these problems.

For the spectator, the answer to Jesse's question is in Before Sunset, but for Jesse and Celine, the answer is in the time between Before Sunset and Before Midnight, when Celine was pregnant with twins and when Jesse delighted in defeating a pregnant woman at table tennis in the Luxembourg Gardens. The spectator has the limitations, the gaps and "disjunctions" in time, of their records of Jesse and Celine's past revealed to them. Their records of Jesse and Celine's twenty years together only run for roughly six hours and show roughly forty-eight hours worth of those years. Ultimately, their sense of Jesse and Celine's past is a small part of a larger whole that continually resists complete certainty and representation. With the strategy of duration, there will always be something

35 Rosen, Change Mummified, 118.

36 ibid., 121. 
missing, events which fall through the cracks between the films in the series. Moments are lost with the passage of time, and the past is only ever 'available' through the traces that remain, through a construction.

The spectator's recollection and interseriality, then, reveals both the uncertainty of the past and the sutures of historical narrative. Like Jesse and Celine's implied sex, we have only the passage of time and a narrative that bridges the gap between the films in the "Before" series. When did Jesse and Celine have sex? Sometime during Before Sunrise in the cut between two shots. When did Jesse and Celine last wander around? Sometime between Before Sunset and Before Midnight. Through interseriality and enabling the experience of recollection, the series enables the spectator to reflect on the structuring components of its historical narrative, essentially the structure of the series itself: gaps and passages of time, time passed and passing. 37

The revelation of these gaps in the historical narrative, and of the spectator's reliance on limited evidence, also produces a sense of alienation. Jesse and Celine's time is their own, and by revealing the sutures of narrative Linklater widens the gap of understanding the past between the couple and the spectator. The spectators, like Rosen's historians, cannot remove themselves from time. While Collingwood goes through pains to emphasize that historical knowledge and thought is brought about by historical imagination, there is a sense that he

37 Hayden White, The Content of the Form: Narrative Discourse and Historical Representation (Baltimore: John Hopkins University Press, 1987), 5: White elaborates on the idea that histories use narratives, just as they reveal the structuring of narratives by emphasizing the ordering of meaning,: "The events must be not only registered within the chronological framework of their original occurrence but narrated as well, that is to say, revealed as possessing a structure, an order of meaning, that they do not possess as mere sequence." 
collapses different histories, cultures, and experiences, into a uniform and imminently retrievable past. Perhaps this is why his book, The Idea of History, is predominately a study of western historiography and historical practices: he comes from a similar context. As Ricoeur argues, Collingwood's view of history reduces the sense of historical otherness that comes from the disjuncture between the past and the present, between our experience of time and time as a natural force independent of our experience. 38

But, just because Linklater used his strategy of duration and gaps resulted, does not mean that Jesse and Celine lived a time completely alien to our experience. Ricoeur's response to Collingwood and the otherness of history is to emphasize the power of narrative to construct and reveal experiences of time. He includes both the sameness and otherness of the past and history by arguing that narrative presents the past as analogous with our experience of time. ${ }^{39}$ Narrative becomes a way to fit our experience of time into history and the past: our sense of time fills in for the time passed, into the gaps. This is not to deny Collingwood's analysis of historical thought or the practice of making history, but to recognize

${ }_{38}^{8}$ Paul Ricoeur, Time and Narrative Vol. 3 Trans. Kathleen Blamey and David Pellauer (Chicago: University of Chicago Press, 1990), 146-147: “...we have to say that historians do not know the past at all but only their own thought about the past. But history is not possible unless they know that they re-enact a past that is not their own. Collingwood may attempt to respond to this by introducing into thought a power whereby it distanciates itself from itself. But this selfdistanciation will never be equivalent to the distanciation between one self and another. His whole enterprise breaks down over this impossibility of passing from thought about the past as my thought to thought about the past as other than my own. The identity of reflection cannot account for the otherness of repetition...The very mediations that make historical time a mixed form of time are lost..."

39 ibid., 150-156. 
that the otherness of history, the uncertainty of the past is unavoidable. Historical narrative must weave this otherness into itself. 40

By making the spectator think historically about themselves and in relation to the series by enabling them to recollect, Linklater weaves his spectator into his series, a series that is actively historicizing its own past. Through interserialization and enabling recollection, Linklater creates the experience of historical thought and imagination for the spectator. This same experience leads to the revelation for the spectator that they themselves are historical, temporal, and facing an uncertain past. Linklater uses this experience to reveal the sutures of narrative, his own constructed narrative, and the otherness of history. But where this otherness emerges from an experience of recollection brought on by the series reflecting on its own uncertain past, so too does the spectator reflect on their own uncertain past in the past of their spectatorship. In turn our sense of ourselves as historical fill in the gaps in the narrative. When did Jesse and Celine walk around bullshitting? Sometime between Before Sunset and Before Midnight. Through interseriality and the experience of recollection, it was also sometime in our past. It is never wholly and completely our past, because it is their own time, but it is analogous to our past insofar as it is through reflecting on our own past, the past of spectatorship, and that we see our past as the past of the series, that we can attempt to understand their past.

Through interseriality and enabling recollection and historical thought, the series explores and reveals to the spectator their own relation to an uncertain

\footnotetext{
${ }^{40}$ See similar arguments raised for historiography in: Vivian Sobchack, "What is Film History? Or the Riddle of the Sphinxes" Spectator Vol. 20 No.1 (2000): 8-22.
} 
past that grows more uncertain as time passes, as well as its means for mediating and making a communicable form of this past and time's passage. An essential component of this is bringing the spectator into this mediation, as well as making the spectator think of themselves as historical.

When Linklater's series continued nine years after Before Sunrise in Before Sunset he established one way that his series would utilize interseriality: the act of recollection. He establishes this in a single sequence of flashbacks, which emphasizes the archival nature of interseriality while also emphasizing its association with memory, with the act of recollection. Linklater never uses flashbacks again. But the series features a particular formal strategy that enables the spectator to experience recollection and historical thought. In the process, the spectator faces the uncertainty of the past and the ways in which narratives reflexively present the very gaps which they are meant to suture. In turn, Linklater's strategy enables the spectator to fill these gaps with their own past, the past of spectatorship of the series.

For Collingwood, history reveals the autonomy and freedom of humanity. History is about trying to understand the choices we make, in turn revealing the power to make choices at all. ${ }^{41}$ The "Before" series reveals the power of historical reflection and narrative to face the passage of time and to reflect on actions in the past. In the previous chapter, it was argued that the series reflects on consequences. This chapter has shown one way the spectator experiences this reflection: through the act of recollection. Instead of choosing flashbacks,

${ }^{41}$ Collingwood, The Idea of History, 318. 
Linklater's strategy of duration, his interseriality, and his emphasis on recollection pushes the spectator to think and imagine like a historian, to also face their passage of time, to face their choices, and make some sense out of the time that has passed. 


\section{Chapter 3. Interseriality: Order and The Aging Body}

\section{Depiction and Detection}

This chapter is about order, making order, using order, and reading order. This thesis has approached the series linearly, from its beginning onwards. Interseriality functions in the previous chapters as the series develops and as the series reflects on its past. Backward and forward. Of course, one can watch the films in the series in a different order. We could watch Before Midnight first, Before Sunrise second, and Before Sunset third, as an order that defies the narrative. However, this chapter argues that Linklater uses the technology of photography and interseriality to establish one order to the series: the order of aging. As Stone emphasizes, "no one pretends to grow older" as the series develops. ${ }^{1}$ In turn, the spectator is able to read their own aging from Linklater's use of aging and the relationship between the films. Depiction and detection align as aging in the series itself to become an attraction, a calendar, for the spectator.

Returning to intertextuality and interseriality is essential before we begin. In Chapter 2, intertextuality was presented as the relation between a text and other texts, the creator, and the reader. I finished my discussion on intertextuality with a discussion on the basic ability for film to record. Interseriality was presented as a variant on intertextuality and seriality that references specific events in a series. The relationship between texts, creator, and reader, develops within a single series and reflects on the duration of the series. While the previous chapter focused on the act of recollection, and historical

\footnotetext{
${ }^{1}$ Stone, “About Time: Before Boyhood,” 71.
} 
narrative, this chapter will address the "Before" series and interseriality in light of film's ability to record and the aging body.

One of the manifestations of intertextuality that is often hidden in plain sight is the star system. As I discussed earlier the appeal of certain fiction films arises from the pleasure to see the actor and see the character simultaneously despite that actor often playing many different characters in different films. Put another way, the appeal of certain actors is the appeal of the technology of photography itself; film as a record and as a vehicle for storytelling, simultaneously. This intertextuality is the interaction of depiction and detection in a fiction film. For Patrick Maynard, "Pure depiction occurs when what is depicted [in a photograph] is not detected, such as when a man in a red suit is photographically depicted as Santa Claus."2 Indeed, fiction film is much like this photograph of Santa Claus. Film records the actor's body, we can detect it, but more often the filmmaker intends for the actor to depict a character, for us to see that character instead of the actor. At times, at the height of an actor's appeal, despite the filmmaker's intentions, the inverse might occur. The spectator detects the actor, the man in the red suit playing Santa Claus, instead of the character. The appeal of certain actors, what makes them into stars and recognizable regardless of their characters they play, is this intertextual quality of film.

In Linklater's series, this intertextual quality of film becomes interserial. Depiction and detection are closely aligned through continuity of casting for his main characters across his series. In all three films, as the credits show, the same

\footnotetext{
2 Patrick Maynard, quoted in Lauren Perini, "Depiction, Detection, and the Epistemic Value of Photography," Journal of Aesthetics and Art Criticism Vol.70 No.1 (2012): 152.
} 
actors play Jesse and Celine: Ethan Hawke and Julie Delpy (Figure 13). Due to this continuity of casting, the bodies of Ethan Hawke and Julie Delpy are always the bodies of Jesse and Celine. The depiction and detection of their characters becomes the detection of their bodies in service of those characters.

Continuity of casting and the detection it entails as a practice is not novel. The "Doinel" series by Francois Truffaut maintained continuity of casting for a number of characters, most prominently Jean-Pierre Léaud as Antoine Doinel, and Claude Jade as Christine Darbon. Continuity is a Hollywood convention for editing, storytelling, and also casting. The "Star Wars," "Harry Potter," numerous generations of "Star Trek," and "Rocky," series' maintained their casting for main characters across their films. In these films one can read the aging the actors as the aging characters, indeed for many of the later films in these series, that was precisely their intention. An interesting example Rocky Balboa (Sylvester Stallone, 2006), the sixth film in the "Rocky" series, which once again features Sylvester Stallone in the titular role. Nicola Evans argues Rocky Balboa selfconsciously comments on, and in the process emphasizes the detection of, Stallone's aged body as the aged Rocky. At the center of the film is a question: is Rocky too old to box? And, in parallel, is Stallone too old to be still playing this character?3 Like in Rocky Balboa, continuity of casting weaves bodies into other series and heightens the detection of their bodies.

But, with Linklater's strategy of duration this detection is more pronounced and more specific. Through correspondence, the time passing

\footnotetext{
3 Nicola Evans, “No Genre for Old Men?,” 30.
} 
between the films in the series, and for the characters, is also time passing for the actors. Through regularity, the specific time of nine years between the films in the series, nine years for the characters, is also nine years for the actors. Depicting Jesse and Celine nine years from Before Sunrise in Before Sunset involves the nine-year older body to detect. Their aging becomes specific and woven into the series itself. The interserial relationship between the films tracks the aging of their bodies in service of their character. Watching the series, for the spectator, is watching bodies age.

\section{Aging}

At times, Linklater emphasizes detection by showing a lot of a character's aging body. Celine's scene from Before Midnight with nudity is a prominent example. After their walk through the Grecian village, and checking-in to their hotel room, Jesse begins to undress Celine. While their romantic night in the hotel transforms into a lengthy argument, Linklater does not turn his camera away from Celine's nude upper body. This is the first instance of nudity in the "Before" series and Linklater's frank filming of Celine's nudity corresponds to the ease of a now married couple with each other's bodies. Indeed, they are able to maintain an argument the entire time. This display is important precisely because we do not normally see aging women on screen nude. Margaret Gullette argues, "film is a youth ghetto in which few actors survive past their own natural youth."4 Pointedly, Hollywood film is a "youth ghetto" that often discriminates

4 Margaret Morganroth Gullette, Aged by Culture (Chicago: University of Chicago Press, 2004), 177. 
and excludes women over the age of 40.5 Presenting Celine's nude body with frankness, and, in turn, emphasizing detection of Julie Delpy's body as the character, becomes the means to communicate the passage of time in the series.

At other times Linklater's series emphasizes detection of the bodies for the spectator by featuring characters that reflect on their aging bodies as the series develops. In Before Sunset, after Jesse and Celine have reunited, the couple sit in a café and, in a shot-reverse-shot sequence, compare their bodies to the last time they saw each other in Vienna in Before Sunrise. Celine asks, "Do I look any different?” At first, Jesse replies with, "I'd have to see you naked." But, he adds that she wore her hair differently and that she lost weight. Later, in the same sequence, Jesse returns Celine's question and asks, “Do I look any different?” At first, Celine says not at all, but then points out the deep wrinkle that now slashes between Jesse's eyebrows. The characters emphasize to each other the passage of time written on their bodies, the signs of aging they detect between films, for the spectator.

Jesse and Celine's detection and discussion of their aging, the passage of time between the events in Before Sunrise and Before Sunset, enables them to understand themselves as aging. Bryan S. Turner describes this as "interpersonal monitoring." For Turner, aging is distinctly social and visual. He writes, "the aging body (the spread of grey hair, the decline of mobility, or the loss of skin tone) becomes the topic of comparison. ... . These social observations and

5 Stacy L. Smith, Marc Choueiti, and Katherine Pieper, Inclusion or Invisibility? Comprehensive Annenberg Report on Diversity in Entertainment (Los Angeles: Institute for Diversity and Empowerment at Annenberg, 2016), 2. 
interpersonal monitoring of the transformation of bodies are our best index of the passing of time." 6 Jesse and Celine's discussion over their physical appearance is a form of this "interpersonal monitoring." It allows them to understand themselves as aging. Wrinkles, weight, hair, become the visible traces of aging that in turn reveal and show the passage of time to the watchers and comparers. Jesse and Celine's recognition of their aging bodies enables them to understand themselves as aging.

But this interpersonal monitoring is also a comparison between films, back through the time of the series. This comparison is interserial and involves the spectator as well. This is in contrast to Nicholas Nixon's "Brown Sisters" series. Beginning in 1975, once a year Nixon has photographed his wife and her three sisters in a group portrait. Like the "Before" series, Nixon's approach ties the aging of the sisters into the series. Nixon refuses to change subjects over time and regularly shoots the photographs every year. But, in Nixon's series, there is no narrative, no characters, no dialogue. The photographs are mute. The photographs record but they do not let the sisters speak like in the "Before" series where Jesse and Celine in the film reflect on their own aging. As Susan Minot describes Nixon's photographs, they seem to say "Yes, we will give you our image, but nothing else."7 In contrast, in the "Before" series Linklater's narrative reflects

\footnotetext{
${ }^{6}$ B.S. Turner, "Aging and Identity: Some Reflections on the Somatization of the Self," Images of Aging: Cultural Representations of Later Life Ed. Mike Featherstone and Andrew Wernick (New York: Routledge, 1995), 253.

7 Susan Minot, "Forty Portraits in Forty Years," The New York Times Magazine October 3rd, 2014, http://www.nytimes.com/interactive/2014/10/o3/magazine/o1-brown-sisters-fortyyears.html?_r=2.
} 
on its passage of time through interpersonal monitoring, through the recognition of their aging that is itself written into the structure of the series.

In the café sequence, for example, Linklater involves the spectator in this interpersonal monitoring by emphasizing detection and comparison of the couple's bodies that coincides with Jesse and Celine's interpersonal monitoring. His shots linger after Jesse and Celine ask “Do I look any different?” And also lingers on the reverse shot of the person who is expected to answer the question. For Johnson, this scene emphasizes the presence of aging between Before Sunrise and Before Sunset. ${ }^{8}$ Through this lingering, Linklater makes that question between the couple equally between the spectator and the characters. The spectator explores the crooks and crannies of the couple's faces, relating them back to their younger selves in Before Sunrise. Much like recollection in the previous chapter, the detectable bodies become sites where the present visible body is contrasted with a memory of the past film. Indeed, Turner argues, "My body is, so to speak, a walking memory." 9 For Jesse and Celine, their aging bodies are walking memories of their time in Vienna, signs of the passage of time between "then" and "now," for the spectator, their bodies are walking interserial memories of Before Sunrise, signs of the passage of time between films.

But where recollection focused on the act of recollection and memory, the interseriality that emerges from the aging bodies is also firmly rooted in detection, with reading the body as a record. Turner's implication that interpersonal monitoring arises from detection of the body as an "index of

8 Johnson, Richard Linklater, 84.

9 Turner, "Aging and Identity," 250. 
passing time" parallels nicely with the series itself as a record of their aging bodies. The spectator can, beyond their imagination, compare the images of the films in the "Before" series amongst one another to detect the aging, that is itself, a part of the depiction of Jesse and Celine. Replay the series to compare; switch the order of the films if you like. Pause it and stare at the image. Look closely at the lines, spots, marks, shapes, and shades which make up the image and which are on the surface of their bodies. Do they look different? By asking the spectator to compare two images, in effect, to scan the surface of the image for marks and signs of aging, Linklater is making the spectator read themselves as aging against the development of the series, against images of Jesse and Celine aging. The fact this occurs between two films, and not within the film, expresses the passage of nine years, the inability for Jesse and Celine, and for the series, to have been two ages at once, young and old, Before Midnight or Before Sunrise simultaneously. ${ }^{10}$ Underlying the series itself is the order of aging.

Where interseriality in the previous chapter historicized spectatorship, in this chapter by emerging from aging bodies it is also aging spectatorship. Just as interpersonal monitoring between Jesse and Celine, the detection of their aging bodies, allows them to understand themselves as aging, for the spectator, interpersonal monitoring between Jesse and Celine, and the images in the series, detecting the aging bodies that are part of the depictions, allows them to understand themselves as aging as well. Linklater's strategy of duration

\footnotetext{
${ }_{10}$ This is similar to Harrod's emphasis that connecting memory to the body (in this case the body
} as record and the film series as a record of the body) underlies the impossibility of separating present from past. See: Harrod, "The Aesthetic of Pastiche," 26. 
emphasizes that time passes for Jesse and Celine, they age and are aware of that aging. It does the same thing for the spectator.

\section{Dying}

Of course, by writing the detectable bodies of Jesse and Celine, Ethan Hawke and Julie Delpy, into the development of the series itself through his strategy of duration, Linklater also hints at the inevitable absence of these detectable bodies: death. Indeed, photographic images have had an equally strong association for some scholars with death. Susan Sontag argued that "all photographs are memento mori. To take a photograph is to participate in another person's (or thing's) mortality, vulnerability, mutability. Precisely by slicing out this moment and freezing it, all photographs testify to time's relentless melt." 11 This association was picked up in film as well. Andre Bazin described film as, among a host of metaphors, a "death mask."12 Bazin's metaphor and his purportedly indexical view of the photograph, ${ }^{13}$ has continued in the association between film and death in the works by Pier Paolo Pasolini, ${ }^{14}$ Laura Mulvey, ${ }^{15}$ Mary Ann Doane, ${ }^{16}$ Philip Rosen, ${ }^{17}$ and Vivian Sobchack. ${ }^{18}$ Film records, but it

${ }_{11}$ Susan Sontag, On Photography, 11

${ }^{12}$ Andre Bazin "The Ontology of the Photographic Image," Trans. Hugh Gray Film Quarterly Vol. 13 No. 4 (1960): 7

13 Bazin never described nor directly stated the film image was index. Peter Wollen is largely responsible for the longstanding association between Bazin, and an "aesthetic of the index". See: Daniel Morgan, "Rethinking Bazin: Ontology and Realist Aesthetics," Critical Inquiry, Vol. 32, No. 3 (2006): 443-481, for the discussion of Bazin and the index, Peter Wollen, and Morgan's insightful alternative reading of Bazin.

14 Pier Paolo Pasolini, "Observations on the longtake," Trans. Norman MacAfee and Craig Owens October Vol. 13 (1980): 6

15 Laura Mulvey, Death $24 x$ A Second, (London: Reaktion Books 2007), 10, 17, 25, 27, 55-79

${ }^{16}$ Doane, The Emergence of Cinematic Time, 21, 23, 222

17 Rosen, Change Mummified, see Rosen's lengthy reading of Bazin's theories on the ontology of film in the chapter "Subject, Ontology, and Historicity in Bazin," specifically: 21-23, 28, 36, see also, 85, and 232, for further arguments on film's relation to death. 
cannot contain the flux of the subjects aging and so it also suggests their eventual absence, their inability to be in front of the camera. Such an affliction is not limited to the medium of film. For R.G. Collingwood, this primarily afflicts portrait painting, especially those which portend to a "perfect likeness"-we would say "like a photograph"-where with the inevitable passage of time "[t]he sitters are dead and gone, and we cannot check the likeness for ourselves."19 Stanley Cavell's comments encapsulate both the association between film and death and the failings of representation that Collingwood described: "films can only be rerun or remade. You can think of events on a screen equally as permanent and as evanescent...[On film] these moments are no more repeatable than a lifetime is." ${ }^{20}$ Every film made hints at a lifetime lost to the passage of time.

Linklater's strategy of duration and his series is an attempt to restore this lost time. Instead of a single film of "permanence and evanescence," a "snapshot," Linklater's series tracks the aging bodies of its characters and actors across three films and time. It is akin to a family photo album, a record of events and bodies that are "saved" from the passage of time. But, like the family photo album, ${ }^{21}$ the

\footnotetext{
18 Vivian Sobchack, Carnal Thoughts (Berkley and Los Angeles: University of California Press 2004), 269: The death of Renoirs rabbit in La Regle du Jour brings about a "documentary consciousness" for the spectator that charged the fiction "with a sense of the world, existence, bodily mortification and mortality".

19 R.G Collingwood. The Principles of Art (Oxford: Clarendon Press 1945), 44; Andre Bazin discusses a similar phenomenon in regards to Louis XIV's portrait at the beginning of his essay "The Ontology of the Photographic Image," 6: "How vain a thing is painting' if underneath our fond admiration for its works we do not discern man's primitive need to have the last word in the argument with death by means of the form that endures."

20 Cavell, Pursuits of Happiness, 52.

${ }^{21}$ Roland Barthes, Camera Lucida (New York: Hill and Wang, 1981), is a lengthy analysis of the interconnections between the photo albums, post-mortem photography, and photography. In
} 
very strategy of duration that allows Linklater to restore this lost time, also embeds the series in time and makes death possible, the end of the series inevitable. For only in so far as Ethan Hawke and Julie Delpy remain alive is the series able to continue, yet the series, with their aging written into it, is developing towards the eventual moment when that will no longer be possible. ${ }^{22}$ Linklater's attempt to restore lost time also structures the series in a way that foresees its end.

Linklater expresses the inevitability of death and his series by having death occur as the series develops. A key example of this is Celine's grandmother. In Before Sunrise, Celine was on the train where she would meet Jesse and start the series itself because she was visiting her grandmother. Nine years later, in Before Sunset, Celine reveals that the death of her grandmother was the reason she missed their reunion. In Celine's apartment, the spectator is shown a photograph of her grandmother. For Johnson, this photograph, like the photograph for many other theorists previously discussed, "reminds us of the inevitable mortality that she has already met and that Celine and Jesse, if not the audience as well, must one day face." ${ }^{23}$ However, while Johnson links a memento mori experience to the medium of photography, I argue this experience is a part of Linklater's strategy. The grandmother's death is a result of embedding the series in time. Aging occurs across the series and so too, must death. The passage of time that the development of the series expresses makes this death an

particular, see: chapter 28, p. 67-71, for an extended analysis done by Barthes on photos of his dead mother.

22 Turner, "Aging and Identity," 249: "The embodiment of human beings is necessarily of a limited duration because ultimately our bodies are not renewable."

23 Johnson, Richard Linklater, 88. 
eventuality. The relationship between the films is expressed by aging, and by death.

Jesse and Celine cannot escape the inevitability of death either. Across the series, Jesse and Celine ruminate and reflect on their own eventual deaths, most prominently, at this point in the series, in the latest film Before Midnight when they are at their oldest. At one moment during their long walk to the hotel, their conversation concerns Jesse's grandparents. At an earlier moment in the film, Jesse received a message on his cell phone. In their conversation, Jesse reveals to Celine that the message was from his father and it informed him that his grandmother had passed away and finally joined his grandfather. "She'd been just waiting to die," according to Jesse. Amazingly to Celine, they had been together for 74 years. This leads Celine to ask, how old will they be if they stay together for 74 years? They start counting from the first time they had sex: Vienna, Before Sunrise. They will be 98. "Think about how much change they saw," Jesses muses. Celine jokes to Jesse that his father is next, "then you." That joke darkly continues to a discussion about their own future funerals. Neither knows who will outlive the other. Ultimately they agree that, eventually, "one of them will see." Indeed, with their aging written into the series, the "one" to see implied might very well be the spectator.

The presence of death across the series and in Jesse and Celine's discussions can be read as meta-commentary for the spectator on Linklater's strategy of duration. For Christie and Johnson, shifts in the dialogue between Before Sunrise to Before Sunset reflect the passage of time between the two 
films. ${ }^{24}$ With the addition of Before Midnight, however, the discussions reflexively comment on the far longer commitment of time to the series. Jesse's description of his grandmother as "waiting around to die" darkly describes the strategy of the series and its use of their aging itself. "How much change did they see," Jesse mused, about his grandparents, but we can equally ask this question of the "Before" series itself. 25 Their conversation regarding how old will they be if they're together for seventy-four years at once implies Before Sunrise, the leap of nine years to Before Sunset, and a further nine to their present in Before Midnight, and to their continued aging written into the possible future of the series until they are ninety-eight. Their dark humor, then, is a dark joke on the future of the series itself. This meta-commentary emerges again with Celine making reference to Journey to Italy (Roberto Rossellini, 1954) while they walk, a film whose interesting connections between the film medium, performance, and death, have been explored by Laura Mulvey. ${ }^{26}$ These points highlight that at a certain point one of them, Celine/Julie Delpy or Jesse/Ethan Hawke, will die, and only one of them remain until finally, they are both dead, and the series will end.

24 See: Christie, The Cinema of Richard Linklater, 91: "Even the dialogue. . .is subtly different this time around [in Before Sunset]; the dry wit and teasing flirtatiousness are both still there. . .but the interplay demonstrates a general air of wistful melancholy. . At all times we are aware of the fact that these are the same two people with whom we had become so familiarly acquainted in their youth, but now they bear different and equally profound hallmarks of age and experience."; and, Johnson, Richard Linklater, 82: "Before Sunset has a mournful, almost elegiac under current, one that derives in large part from the time that has been lost between its characters, time that cannot be recovered, no matter how hopeful one reads the ending to be." ${ }^{25}$ Stone suggests the passage of time can equally be read in the emergence of social media in the early 2000's and the presence of smart phones in Before Midnight. See: Stone, "About Time: Before Boyhood," 69.

${ }^{26}$ See: Laura Mulvey, "Vesuvian Topographies: The Eruption of the Past in Journey to Italy," Roberto Rossellini: One Hundred Years Ed. G. Nowell Smith and D. Forgacs (London: British Film Institute, 2001). 
Thus, if the interserial use of bodies in the series is aging the spectator, it also reminds them of their eventual death; the "Before" series becomes a memento mori. In Latin memento mori means "remember that you will die," and it commonly appears in art through symbols, such as skulls, and skeletons, that are "a warning or reminder of the inevitability of death." ${ }^{27}$ But whereas Sontag argue "all photographs are memento mori," and Mulvey argued all film narratives yearn to end with a "death drive" towards a repressed stillness, due to their photographic ontology ${ }^{28}$, the "Before" series is more a memento mori by nature of its interseriality, Linklater's strategy of duration and the relationship between the films in the series it creates. By making the aging of the bodies detectable for the spectator, the signs of aging readable, the spectator understands themselves as aging through the relationship between the films. This very structure also makes their death inevitable, and so the spectator, in reading their aging through Jesse and Celine's aging, and their discussion of their own eventual deaths, also reads their eventual death through the eventuality of Jesse and Celine's with the development of the series.

The relationship between the strategy of duration and death suggests there is another aging, though unseen, body tied to series: Linklater. Indeed, just as Jesse and Celine's aging across the series hints at their inevitable death, so to does every film in the series hint at the end of Linklater's ability to continue making the series, his death. A similar feature occurs in On Kawara's Today

\footnotetext{
27 "memento mori, n." OED Online, http://www.oed.com/view/Entry/23396o?redirectedFrom=memento+mori+ ${ }_{28}$ Mulvey, Death 24x A Second, 69-79.
} 
Series of "date paintings." Kawara's destroyed his paintings unless he finished them in a single day. They bear only a graphic date on monochrome canvas ${ }^{29}$. Kawara's strategy of production, like Linklater's series, lead the series to become a memento mori and it took on a threatening effect as Kawara himself described his series as an "everlasting game to enjoy until death." 30 Just as the production of Kawara's series, and his paintings themselves, became a memento mori, so too does the "Before" series and each film becomes a symbol and sign of mortality, a memento mori, for Linklater and the continuation of the series itself.

\section{Living}

But, instead of a memento mori, we can also read the "Before" series as particular kind of record through its regularity: a calendar. Regularity is a fundamental aspect of how we understand our place in time. An event occurring regularly in time allows us to orient our experience of time to it. A classic example is the sun rising and falling. Once we understand this happens regularly, we can call this happening a day and count them. More importantly, we understand they will happen in the days to come; we can plan. This is the basis for a calendar. For Paul Ricoeur, calendars are bridges that connect "lived time" with "universal time," our experience of time with time independent of it. $3^{11}$ Through regularity “it

\footnotetext{
29 Ann Rorimer, “The Date Paintings of On Kawara," Art Institute of Chicago Museum Studies Vol. 17 No. 2 (1991): 121-123.

$3^{\circ}$ Jung-Ah Woo, "On Kawara's 'Date Paintings': Series of Horror and Boredom," Art Journal Vol. 69 No. 3 (2010): 68; it is worthwhile to note that Jung-Ah Woo also cites Mary Ann Doane's The Emergence of Cinematic Time (see citation above) to develop her arguments for Kawara's series, suggesting it is less the medium than the strategy that is important in the reading as memento mori. Similarly, Lurie, in "Digital Déjà Vu: Cinephilia, Loss, and Medial Integrity in Linklater's Before Trilogy," 60-66, argues that Linklater's "deep investment to time" overrides any strict connection to a medium for the "Before" series, be it the use of film or digital cinema technology.

${ }^{31}$ Ricoeur, Time and Narrative Vol. 3, 105.
} 
sets ordinary time and each brief human life within a broader time." 32 This allows the calendar, according to Ricoeur who draws upon the work of Alfred Schultz, to grant a sense of simultaneity, of "growing old together."33

With regularity and the interserial use of aging bodies across the series, the "Before" series becomes a calendar, and allows the spectator to also have a sense of "growing old together." Each successive film ties the lived time of the actors and Linklater into the series at specific moments of their aging, of their lives. Depiction and detection are mutually aligned in the structure of the series. In turn this process of aging visible and emphasized in the series and highlights the spectator's own aging. Viewing the series reveals to the spectator how they are growing old together with those involved in the series. Regularity in the series transforms it into a calendar and bridges its aging with the spectators. The spectator can then read their own aging against the series.

Now, this effect is surely at its zenith of power when one ages in exact simultaneity with the series. By that I mean, the spectator has seen the series in correspondence with Linklater's strategy of duration. The twenty years passed in the "Before" series were also twenty years for this spectator. Indeed, from those I have talked to who have experienced this, the series is profoundly affecting due to the existential chord it plucks.

But, that does not mean that this effect does not persist for those that have watched the series without simultaneity. With regularity, it still functions as a calendar. Regardless of when you watch the series, or in what order, there is still

32 ibid.

33 ibid., 113. 
the aging bodies tied to the development of the series. Indeed, as Ricoeur argues for the calendar, "Simultaneity is not something purely instantaneous. It brings into relationship two enduring individuals." ${ }^{34}$ So long as we understand the regularity of a calendar, we can read our age against it. This happens for the "Before" series as well. In my case, I never saw the "Before" series in exact simultaneity. The only film from it I have seen in simultaneity is Before Midnight. But, insofar as this regularity is written into the development of the series itself through Linklater's strategy of duration, I am able to read my age against it. For instance, I am able to tell that when Jesse and Celine were walking through Vienna in 1995, I was 3, when they reunited in Paris, I was 12, and when they reappeared in Greece, I was 21 while they happened to be 41; should the series continue, I will be older like them. Independent of simultaneity, the strategy and interserial nature of the aging in the series allows the spectator to understand themselves as aging, to know their age against it.

Even for those that are not alive yet, the "Before" series still functions as a calendar because of this regularity. Just as I can understand myself in relation to events that occurred before my life because of their temporal specificity and order, their unique date in the past, the future spectator should be able to read their age and understand themselves as aging against the "Before" series because of its temporal specificity and order, the aging of Jesse and Celine's bodies across the series. Once Ethan Hawke, Julie Delpy, and Linklater are dead, the series can no longer be made and so, like the individual films, the series occupies a 
particular stretch of time associated with the lifespan of certain individuals. While this effect will always be most powerful for those could have direct simultaneity, the effect still emerges for those who can only indirectly, or even not at all, experience it.

The concept of the calendar is also useful for looking at other series that are similar to the "Before" series. Michael Apted's "Up" series displays a variation on the calendar: a national calendar. Apted's series returns to fourteen British children every seven years beginning in 1956, with the latest film released in 2012. Unlike Linklater's series, it is a documentary series. There is no story or characters to keep in correspondence with the passage of time; depiction and detection are collapsed together into a "truth" claim within the documentary mode. Apted uses this to explicitly look at British life, to make a claim about growing up in different classes in British social life, and to explore this claim through the development of the series. As a result, its documentary mode, claims, and development as a series, allow it to tap into a specific context, an "imagined community," 35 the nation of the United Kingdom. The numerous "remakes" of the "Up" series in different nations, from America to South Africa to Japan, reflects the specificity of this national calendar concept. Each one offers a distinct national calendar, a vision of what it means to grow up in a particular nation, for a spectator.

Reading the "Before" series as a calendar also shifts the future of the series from tracking the inevitability of death to an attraction. Read as a memento mori,

\footnotetext{
35 Benedict Anderson, Imagined Communities: Reflections on The Origins and Spread of Nationalism (London: Verso, 1991), 6-7.
} 
each film portended the inevitability of death. But as a calendar, it stands as a record of 20 years spent in the production of this series, much like we may casually read old calendars as records of our lives in the past, of our aging. A future film, nine years from Before Midnight becomes an attraction we look forward to, like a date in the future we mark in a calendar. Like Gunning's "cinema of attractions," where the appeal of earliest films was the functioning of film itself,36 Linklater's series becomes an attraction, something to look forward to, precisely because of the way the technology of photography grants film a status as a record and the way Linklater uses this to write aging into the development and structure of his series. Rather than simply the inevitability of death, each film added to the series is an event and grants the spectator a record of a lifetime invested into the series that enables the spectator to reflect on their own lifetime.

In Before Midnight, Celine tells Jesse a story about her friend George. George was diagnosed with terminal leukemia. He told Celine his first feeling when learning about his diagnoses was a relief. Before he knew he had nine months to live he lived a life of worry. Now, he was finally able to enjoy every moment in his life. "What happened to him? Did he live?" Jesse asks. "No," Celine replies, "he died."

The future inevitably is death for Jesse and Celine, like its was for George, because of Linklater's use of aging in his series. This gives one order to the series:

${ }^{36}$ Annette Kuhn and Guy Westwell, "Cinema of Attractions," A Dictionary of Film Studies (Oxford University Press, 2012). 
aging, and then death. We can read the series as a memento mori. But, the things that make this reading possible, Linklater's interseriality through continuity of casting, his characters' awareness of their aging and eventual deaths, and his strategy of duration, also lends the series to be read as a calendar and an attraction of invested time. The depiction and detection of aging bodies is woven into the series such that it becomes a calendar. This has the effect of aging the spectator. They can read their own aging against the series, and reflect on their own lifetime through the investment of time that is the "Before" series. How long will the series continue? As long as they are alive it is possible to continue. This fact makes us look forward to it continuing, to it recording their living. 


\section{Conclusion:}

This thesis has argued that Linklater uses his strategy of duration to explore what it means to be in time. In turn, this creates a temporal experience for the spectator that highlights being in time and their own temporality. Linklater does this by embedding the films in time through his strategy, leading the relationship between the films to become an expression of being in time, and creating an experience for the spectator that highlights change and consequences, memory and our understanding of the past, and aging and the inevitability of death, features of being in time.

The simple story of the "Before" series belies a complex and multifaceted expression of being in time that emerges between the films and with the spectator. With his strategy of duration Linklater grants his series a past and a future, a feature of being in time shared by the spectator of the series. This allows him to highlight consequences and change, to emphasize how the past, present, and future, are interconnected in an experience similar to durée rather than starkly separated. This is made possible by making his series reflect on a specific past interserialy, and, in turn, highlighting the process by which we try to understand the past and ourselves as historical through recollection and historical narrative. That there is one order to the series, and to this recollection, is brought about by Linklater weaving the aging body of his characters, and himself, into the development of the series. As a result, the series highlights the process of aging for the spectator, as well as the inevitability of aging and death that will come with the future. 
This thesis suggests that by looking at the relationship between the films in a series there are novel ways to approach film temporality. Many recent works on film temporality have prioritized the index. They have sought film time in the photographic base of the film medium. This thesis does not dismiss the work of these scholars. However, this thesis suggests that film time is a complex and multifaceted interaction between the temporality of the spectator, the temporality of the film, and that film's temporal relationship to other films. The "Before" series highlights this in its interaction with the spectator and also with its own past as a series.

This also suggests that close analysis of the relationship between the films in a series taken as an interconnected whole, such as what is presented in this thesis, can reveal how filmmakers articulate and create certain culturally unique expressions of being in time for the spectator. Historiography and anthropology have identified a number of cultures where temporality and history are expressed in novel and unique ways, sometimes in clear opposition to a hegemonic power. ${ }^{1}$ For instance, a number of languages have grammatical tenses that differ from English. Certain languages, like Chinese, are tenseless, while others feature far more tenses than those occurring in English. How might these cultural articulations of time reflect on a film series from within the same context, and in turn what might these series reveal about the particular experience of time from within this culture? How might these series speak different experiences of time? Are certain features universal? More broadly, a large international survey of

\footnotetext{
${ }^{1}$ Rosen, Change Mummified, 265.
} 
various series could attempt to show how we come to understand ourselves within a nation in time.

This thesis has not sought to answer once and for all what the "essence" of film time is. Instead, this thesis has approached the "Before" series, and the relationship between the films brought about by Linklater's strategy of duration, as interacting and in dialogue with the spectator's experience of time. The results point to a need to approach film time as an experiential and dynamic temporal relationship between the screen and the spectator. 


\section{Figures:}

Figure 1

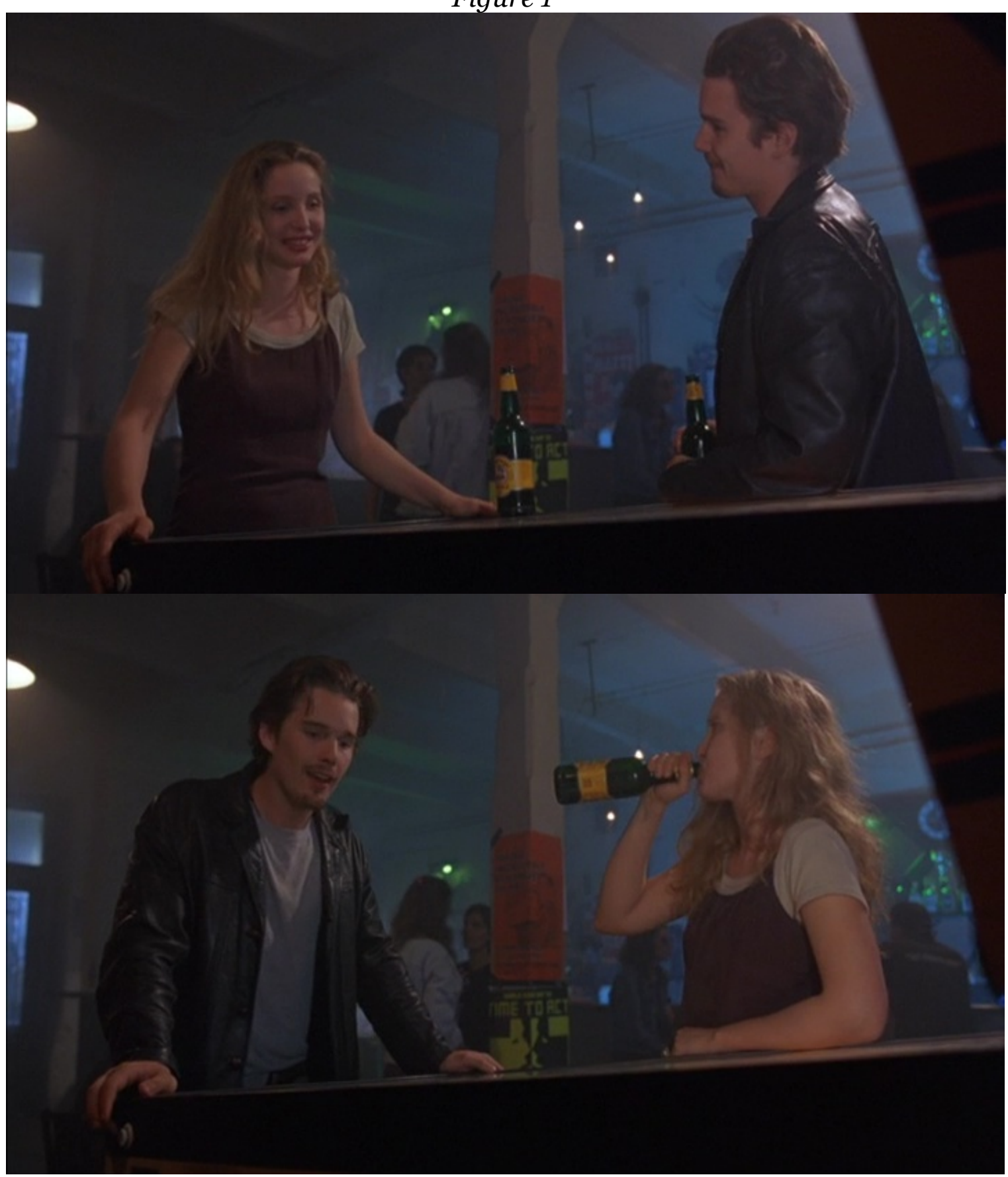


Figure 2

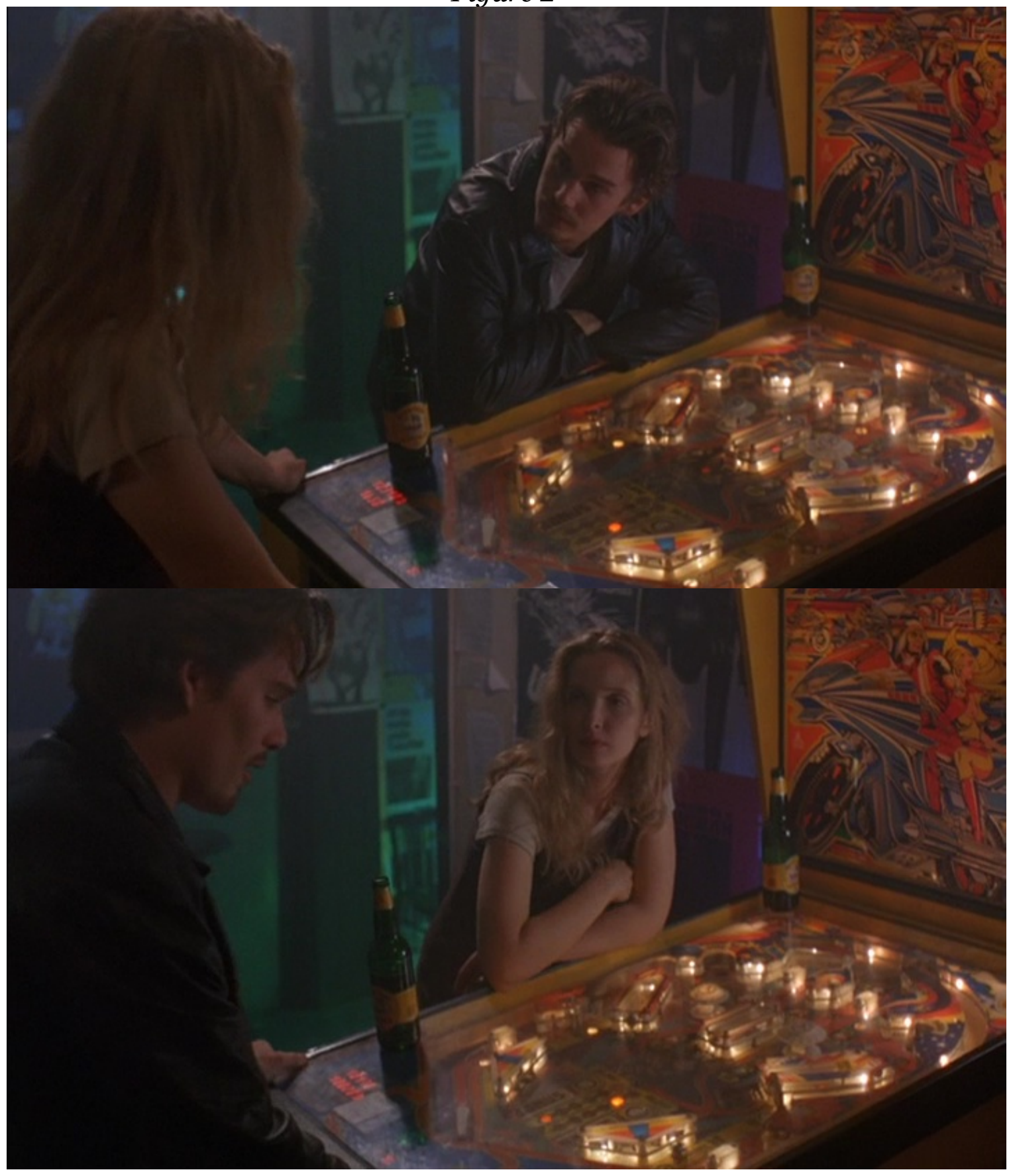


Figure 3

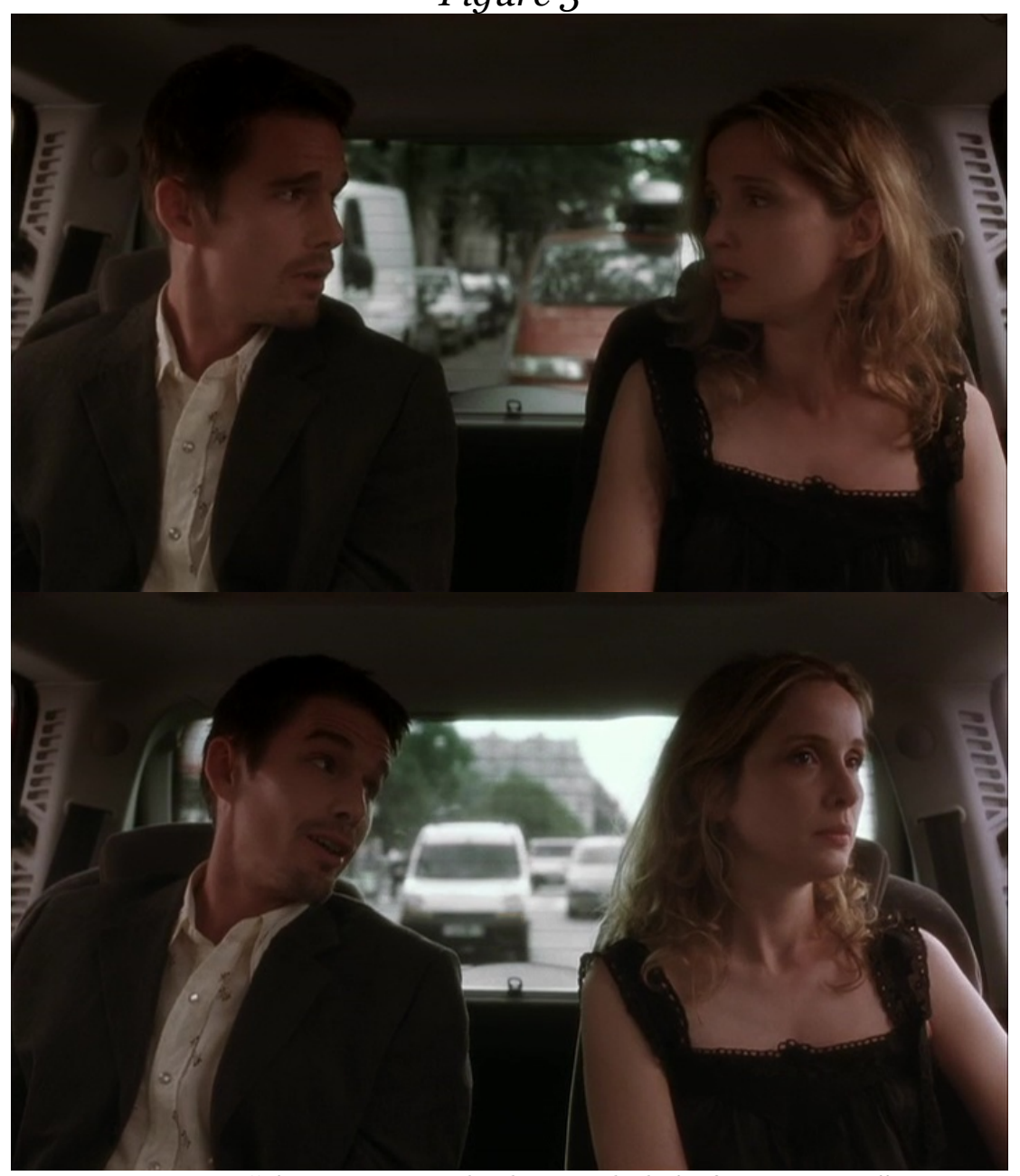

Jesse: "I'm just so glad you didn't forget me."

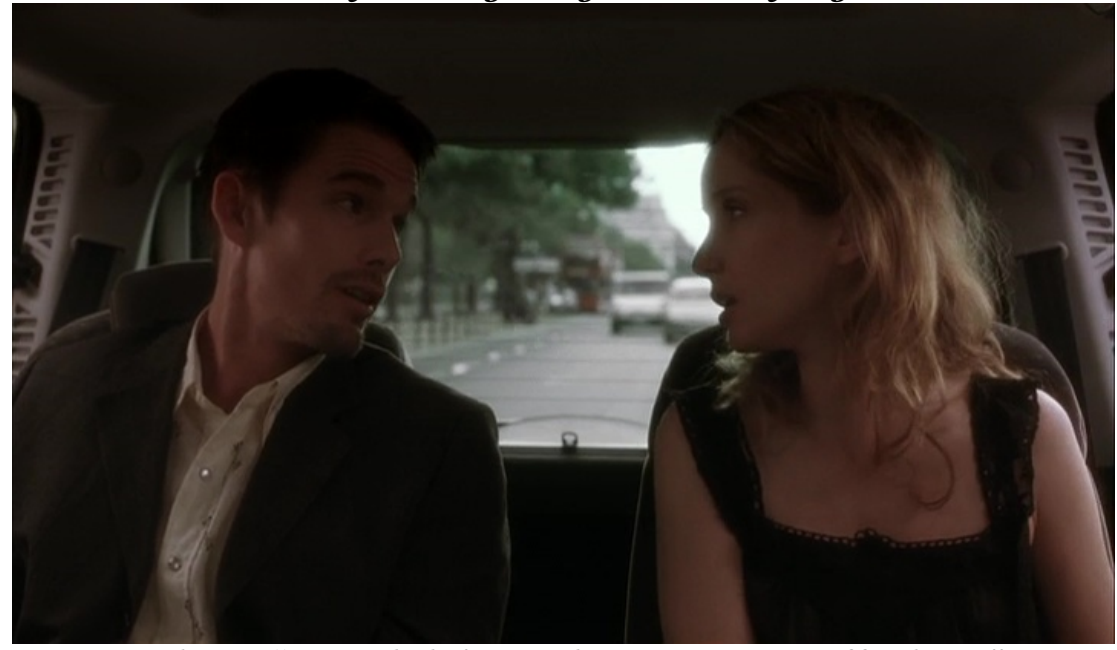

Celine: "No I didn't. And it pisses me off, okay." 
Figure 4

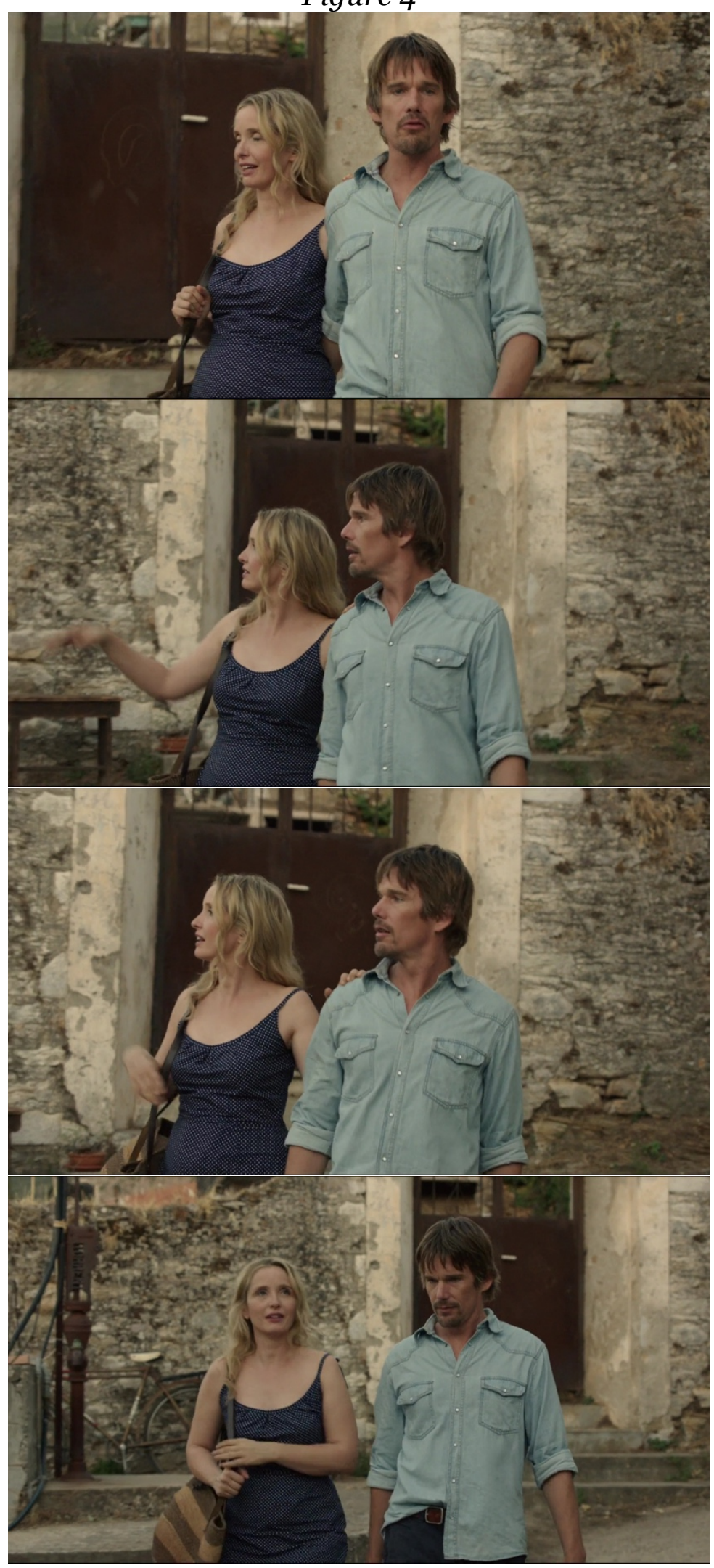


Figure 5 (continues to next page)

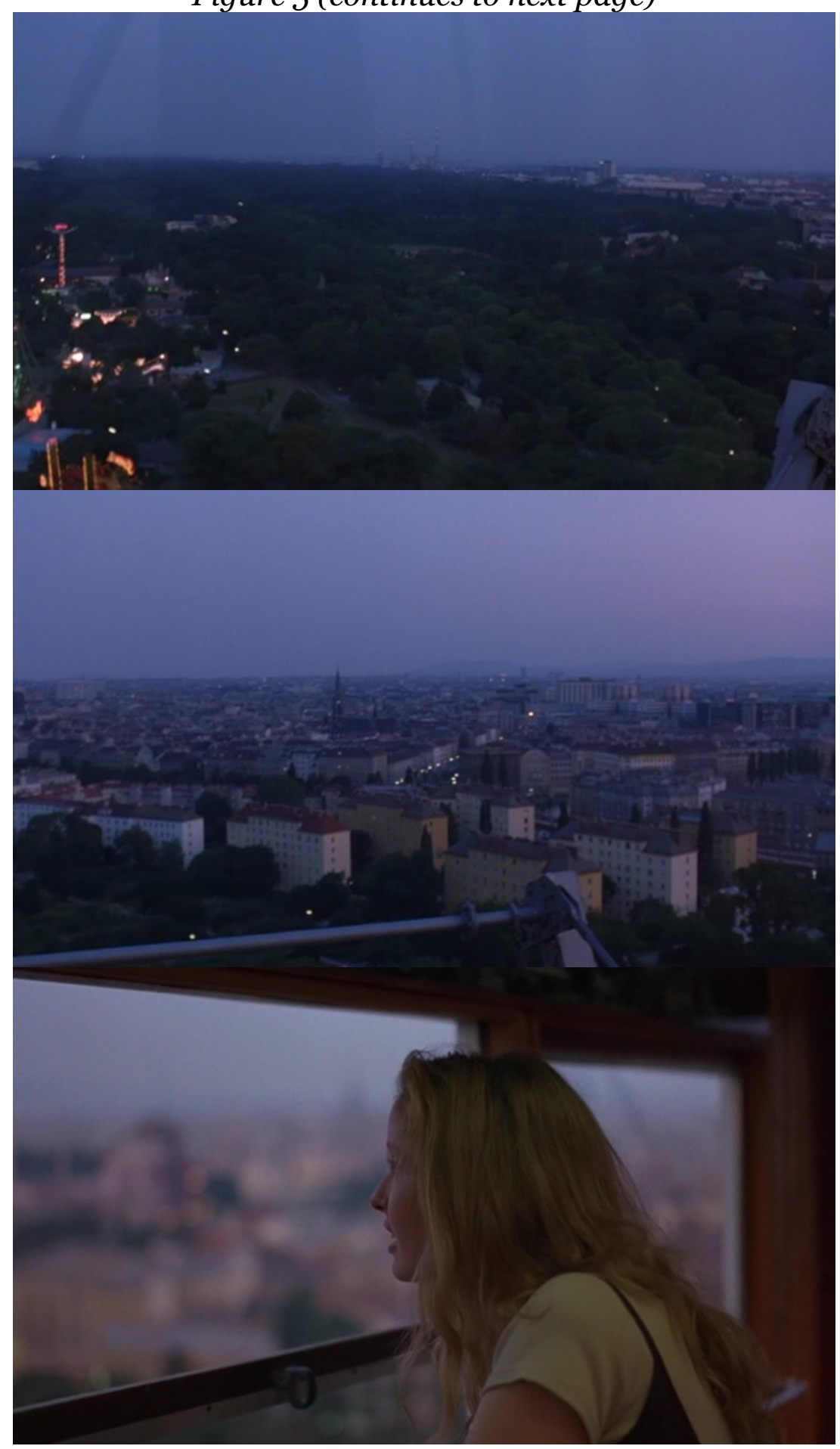


Figure 5 (Continued from previous page)

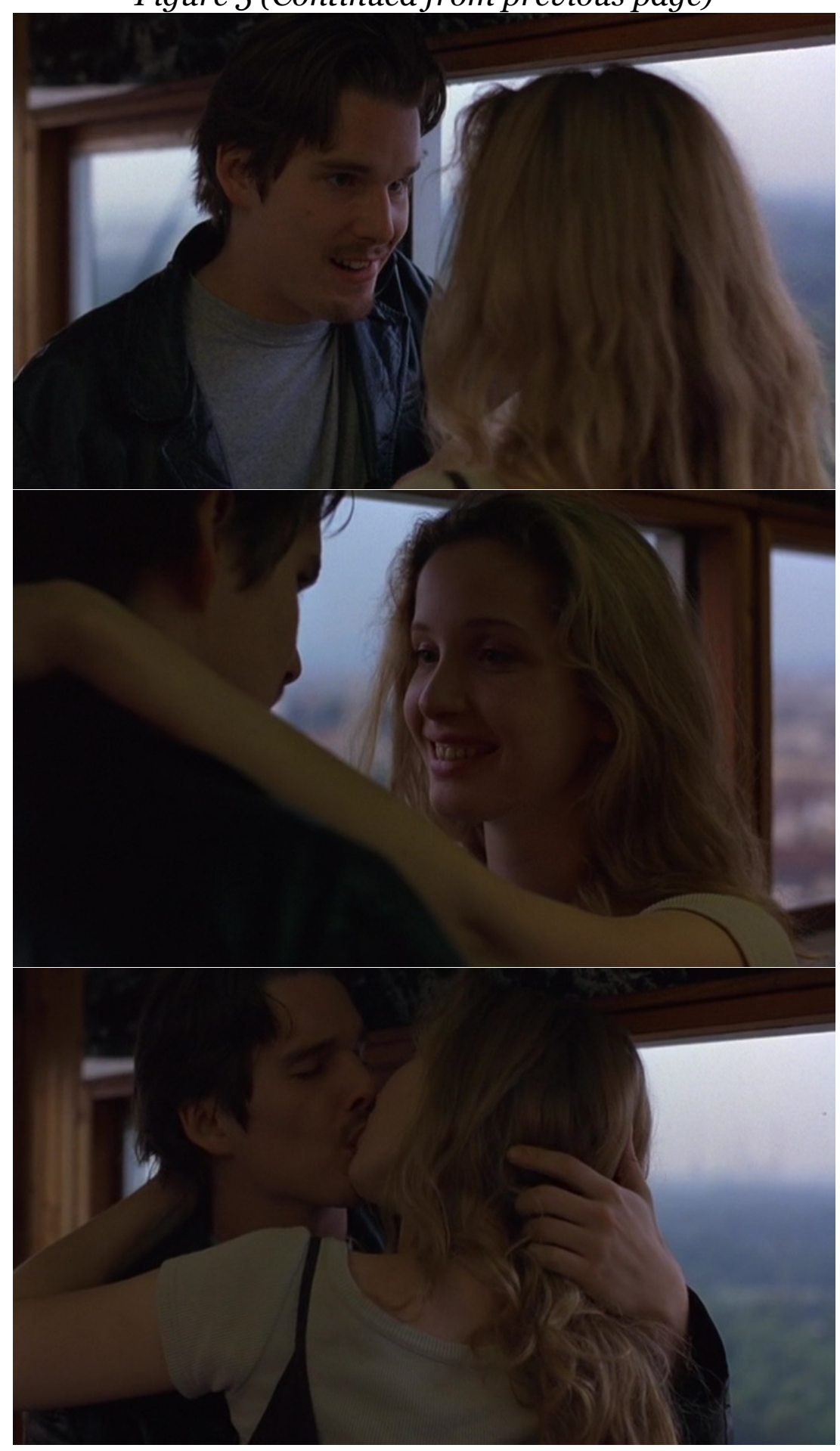


Figure 6 (Continues to next two pages)

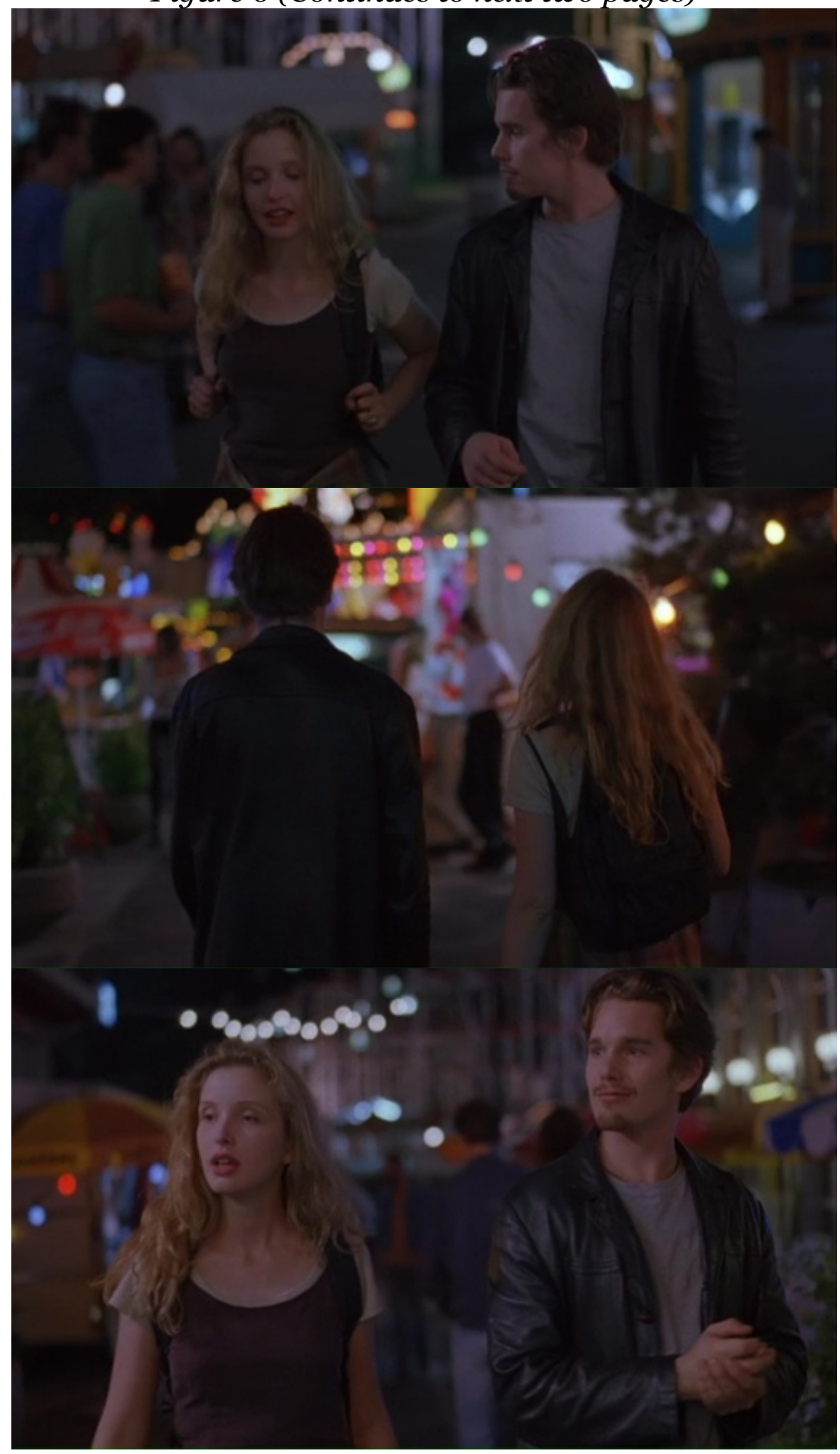


Figure 6 (Continued from previous page)

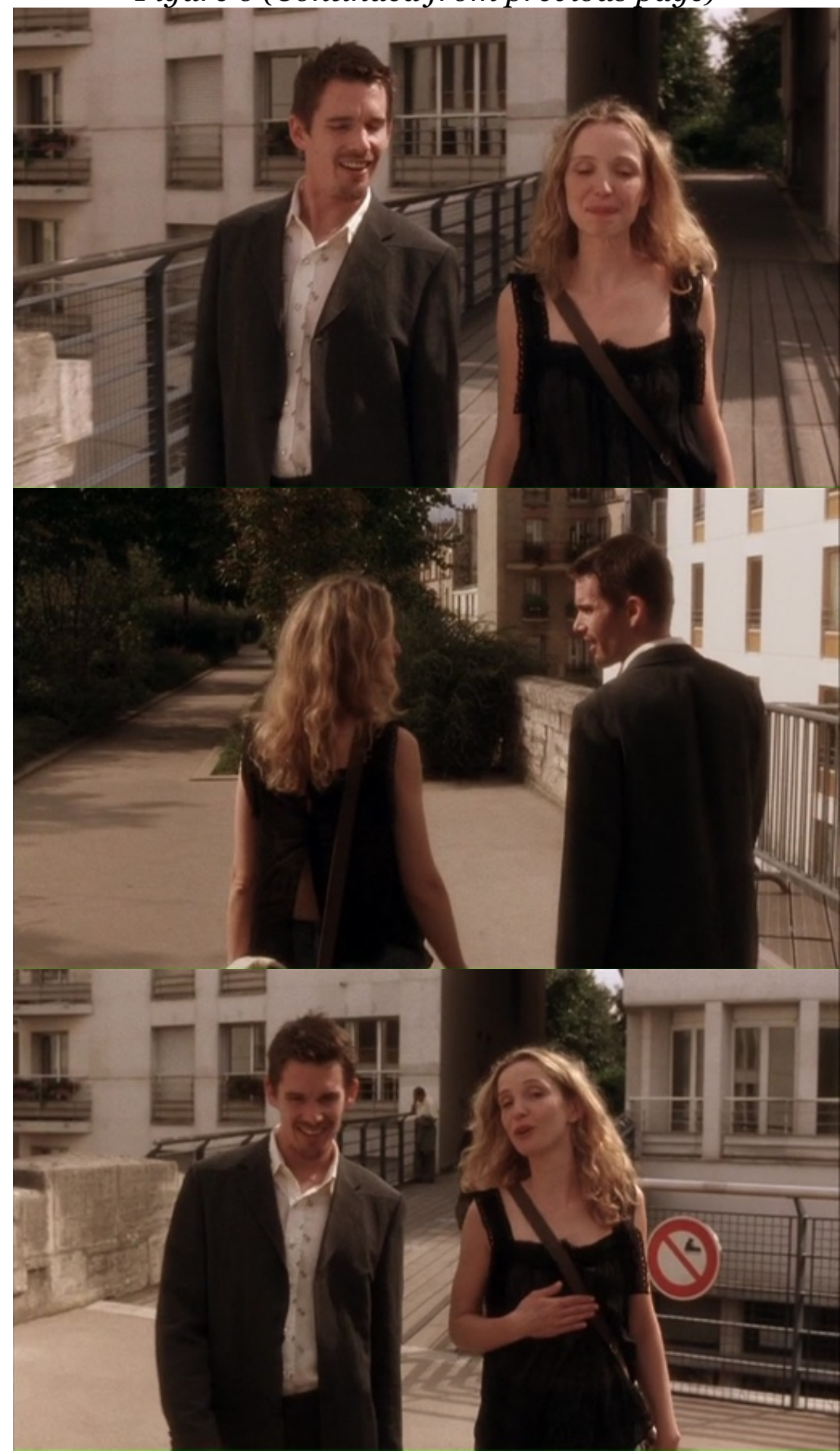


Figure 6 (Continued from previous page)
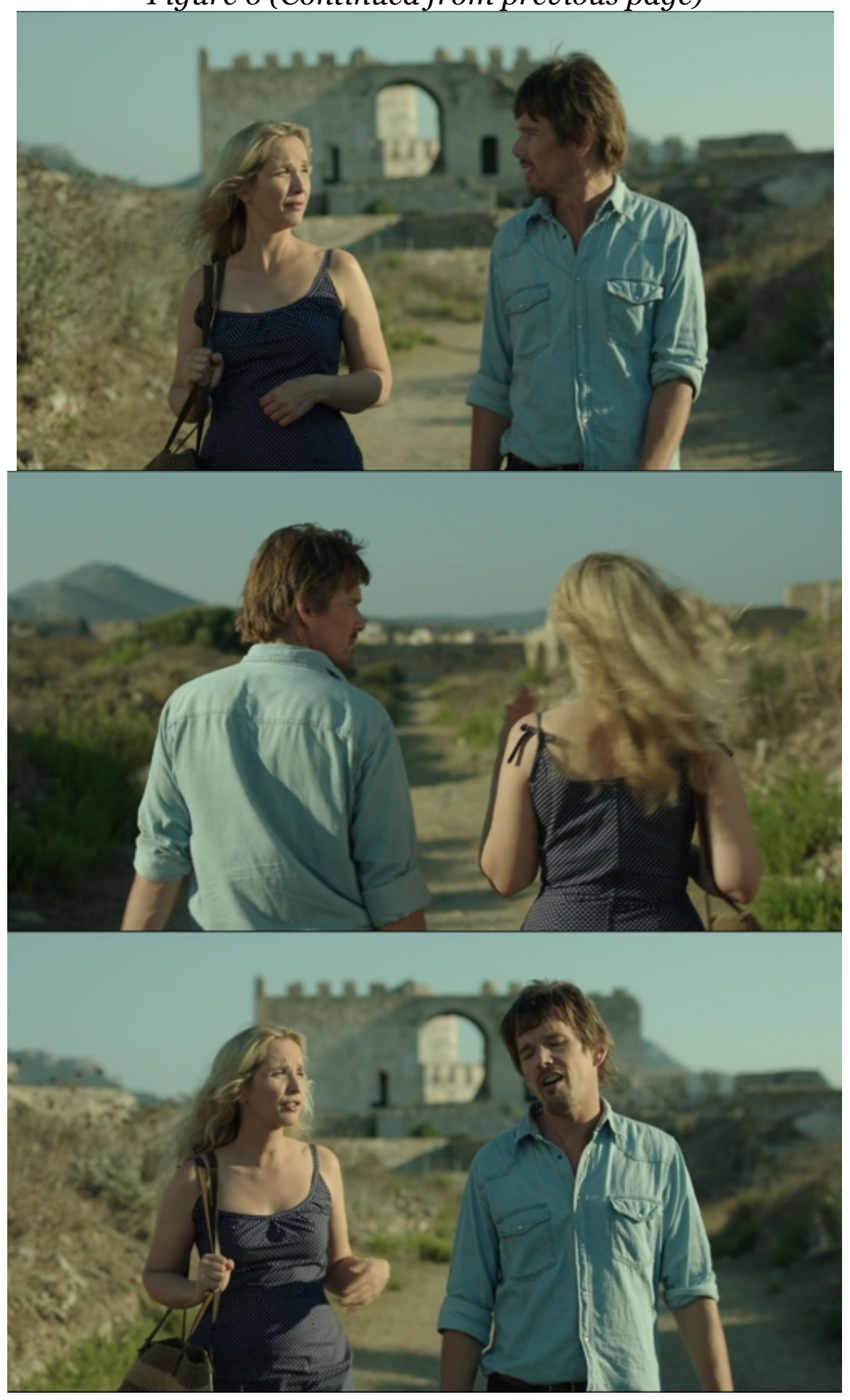
Figure 7 (Continues to next page)

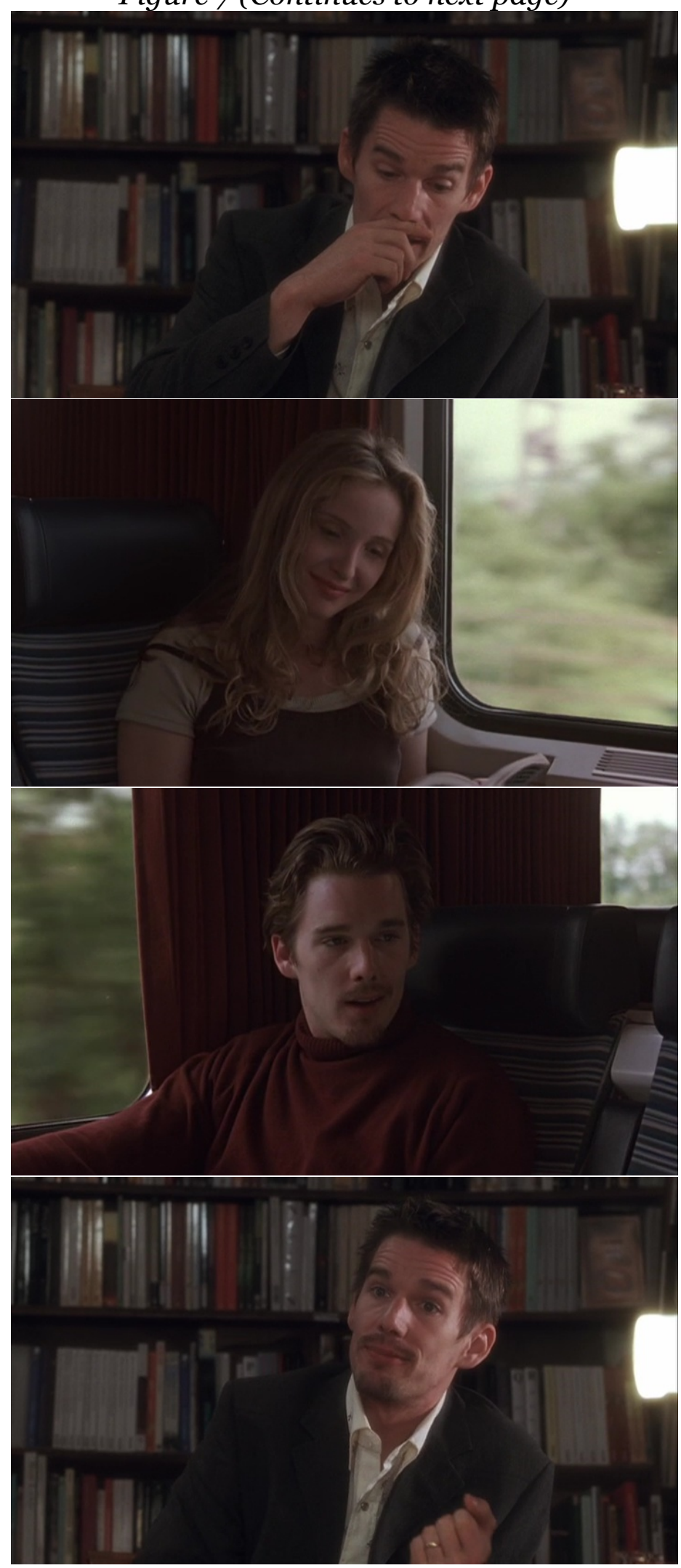


Figure 7 (Continued from previous page)

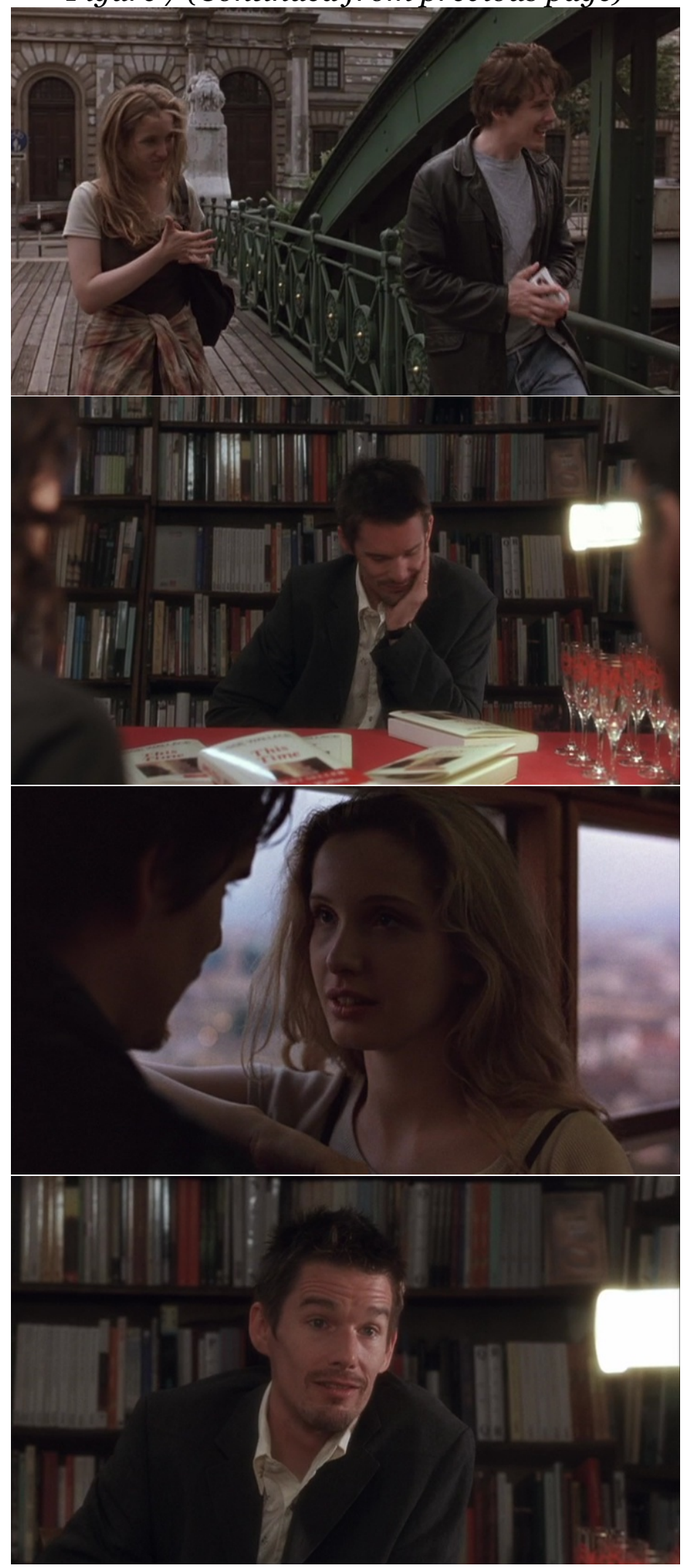


Figure 7 (Continued from previous page)

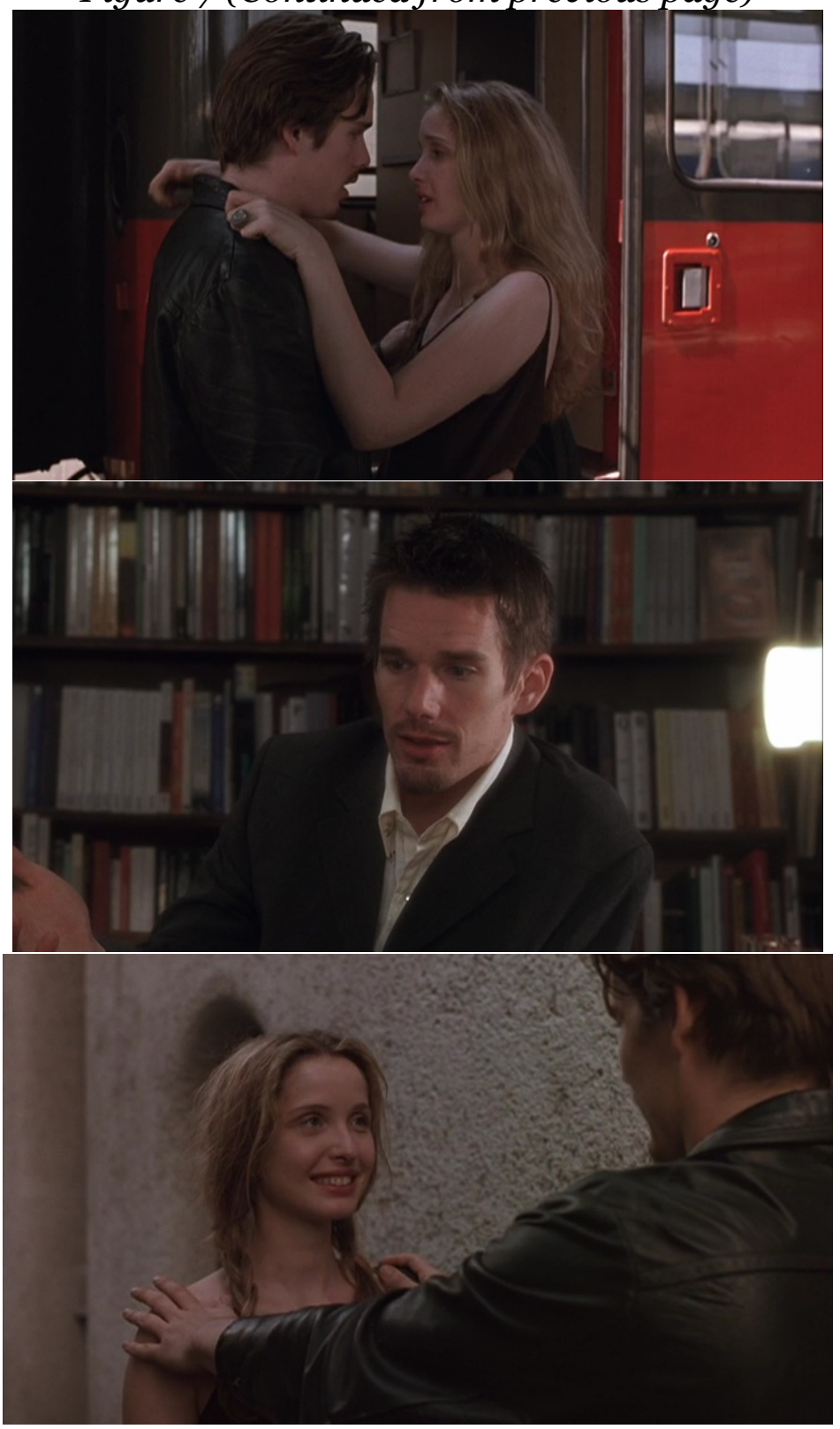


Figure 8

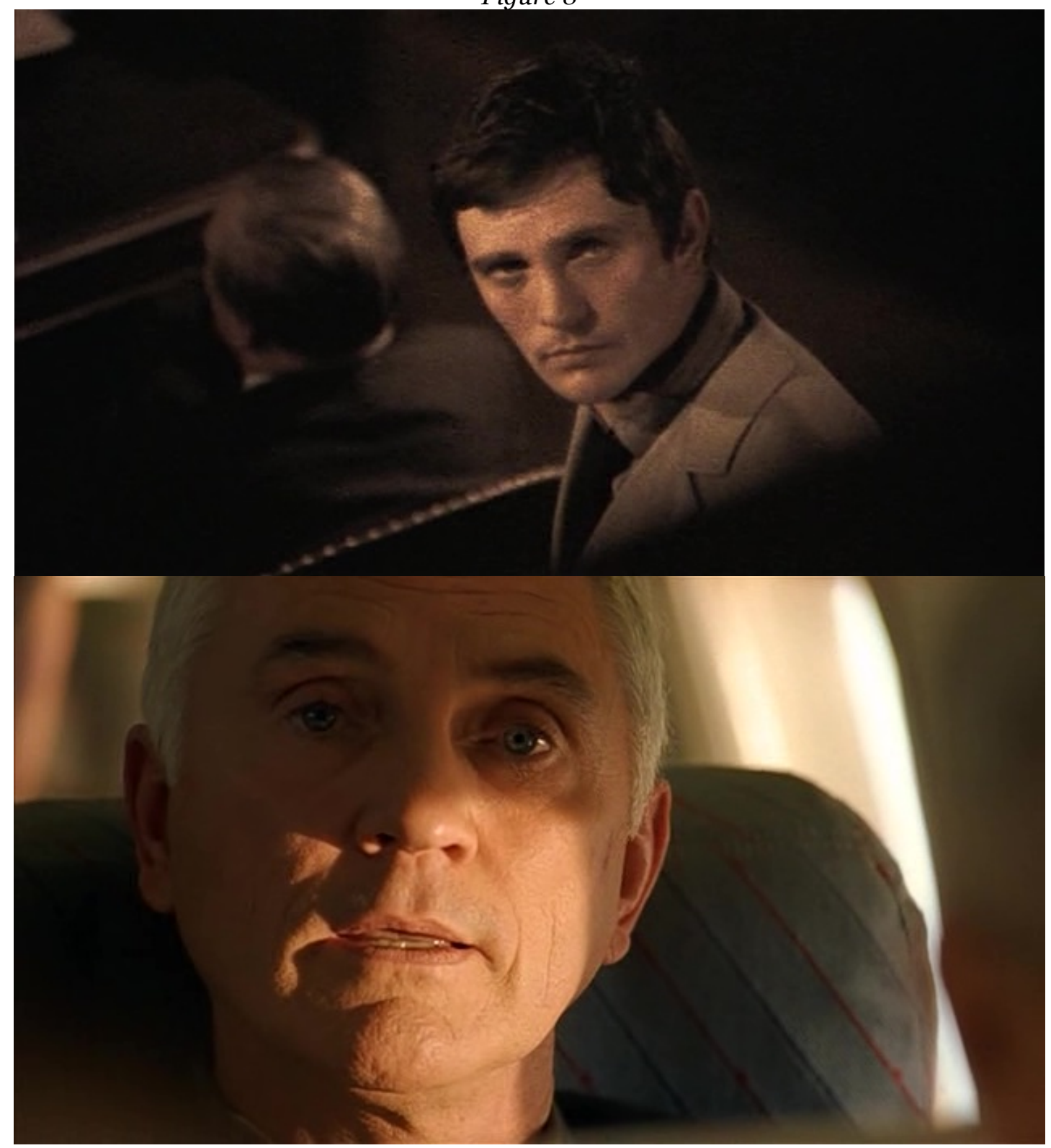


Figure 9

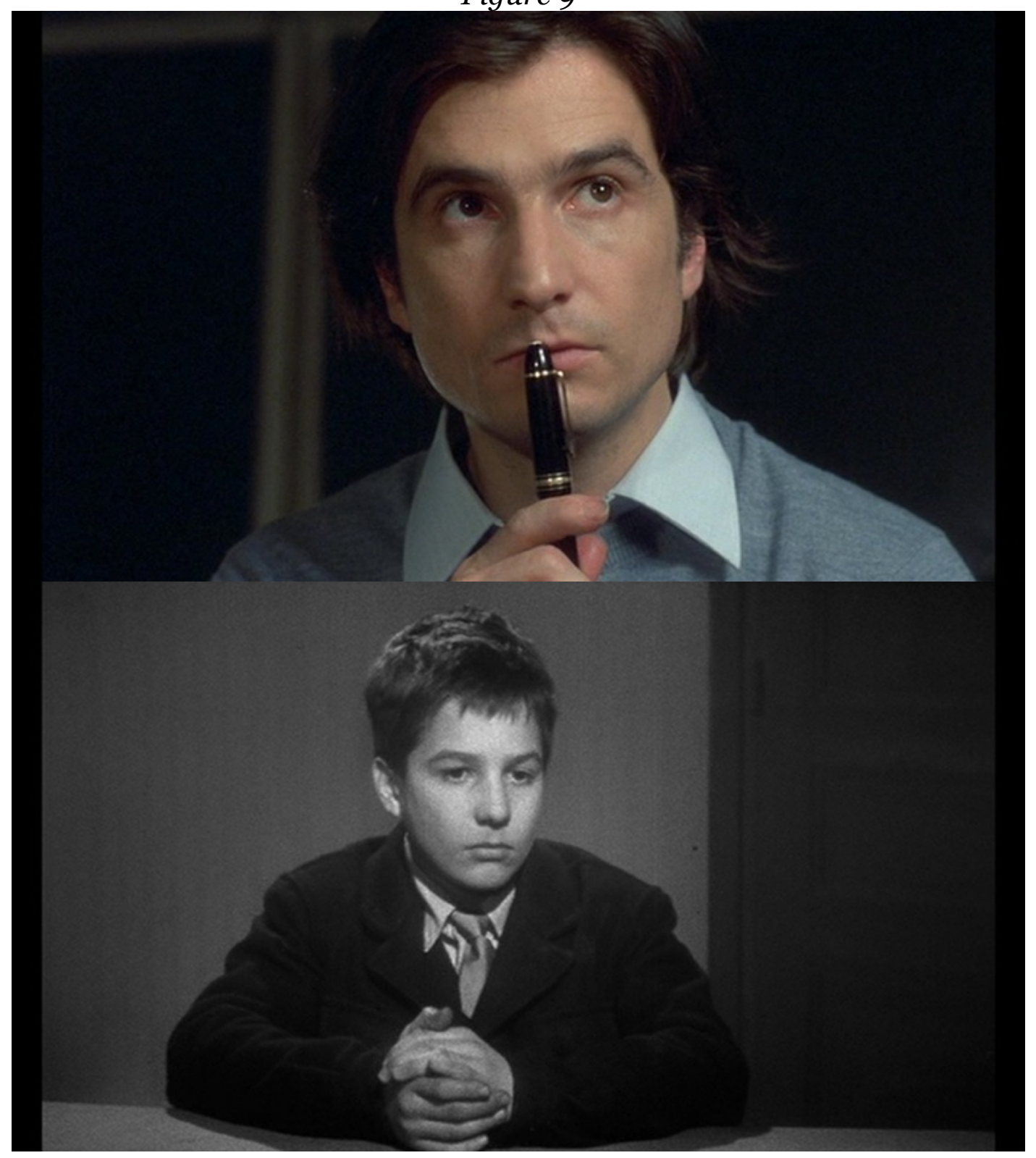


Figure 10

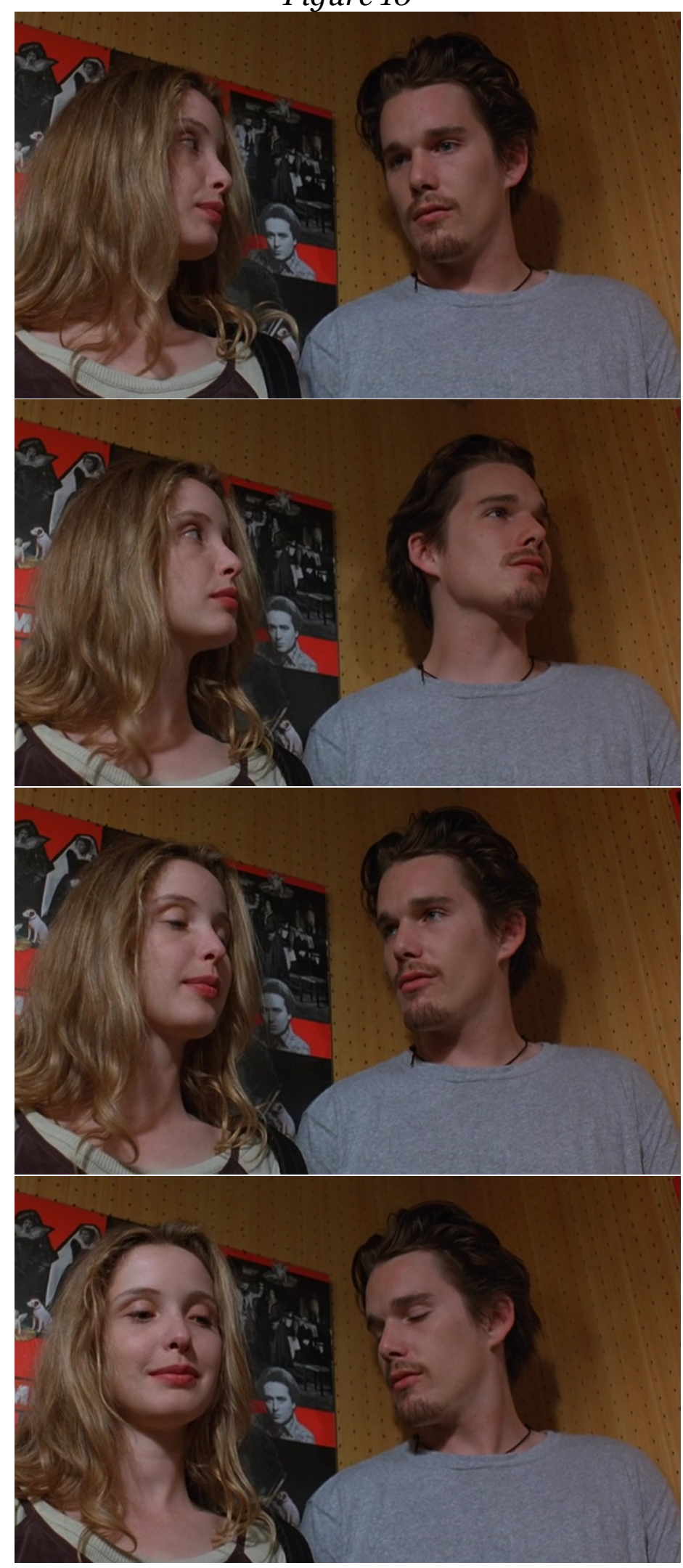


Figure 11 (Continues to next page)
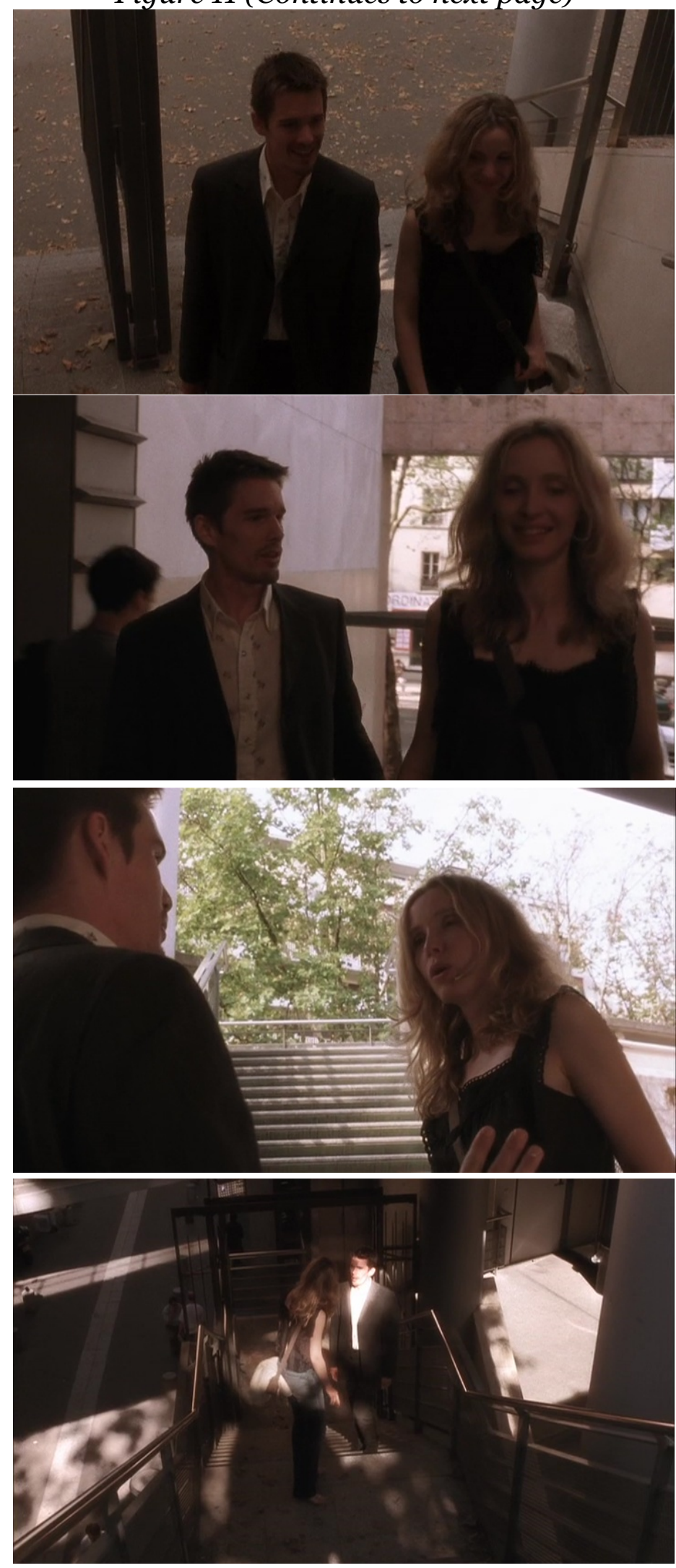
Figure 11 (Continued from previous page)
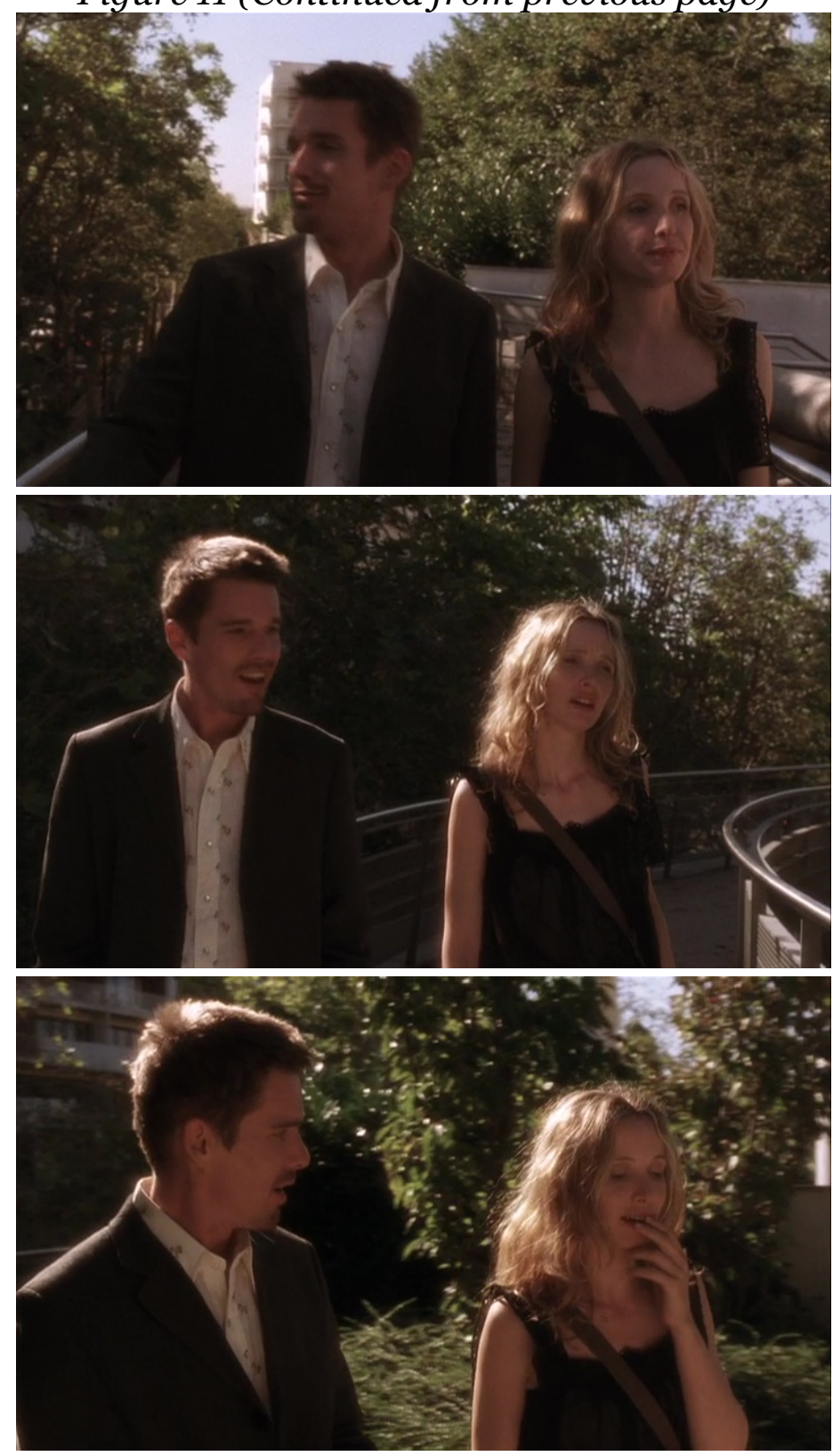
Figure 12
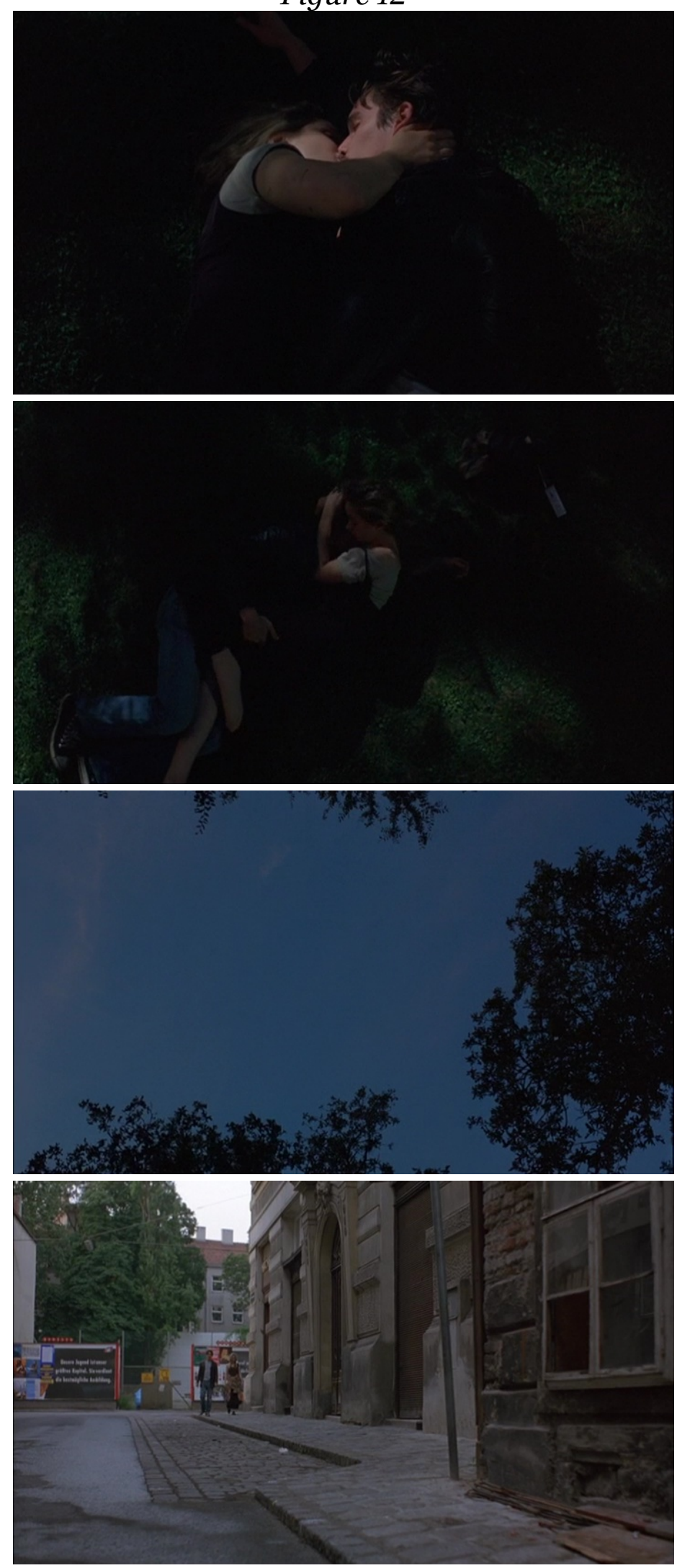

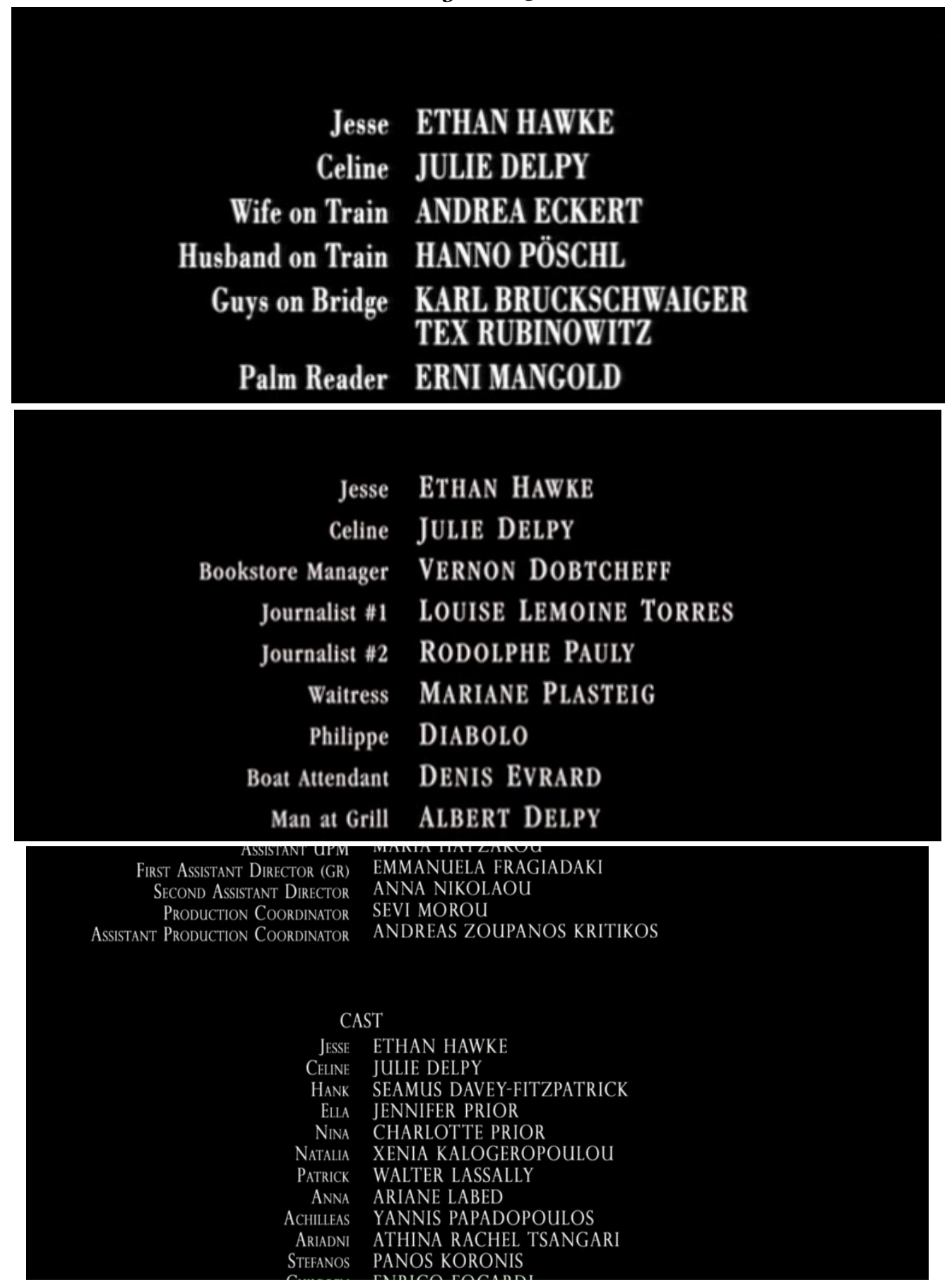


\section{Bibliography:}

Adler, Judith. "Origins of Sightseeing." Annals of Tourism Research Vol. 16 No. 1 (1989): 7-29.

Anderson, Benedict. Imagined Communities: Reflections on The Origins and Spread of Nationalism London: Verso, 1991.

Baron, Jamie. The Archive Effect: Found Footage and the Audiovisual Experience of History. New York: Routledge, 2014.

Barthes, Roland. Camera Lucida. New York: Hill and Wang, 1981.

Bazin, Andre. "The Ontology of the Photographic Image.” Trans. Hugh Gray. Film Quarterly Vol. 13 No. 4 (1960): 4-9.

Bergson, Henri. Creative Evolution, Trans. Arthur Mitchell. New York: Henry and Holt Company, 1913.

---. "Matter and Memory." Henri Bergson: Key Writings. ed. Keith Ansell Pearson and John Mullarkey. New York: Continuum, 2002.

Blassnigg, Martha. Time, Memory, and Consciousness and the Cinema of Experience: Revisiting Ideas on Matter and Spirit. Amsterdam: Rodopi, 2009.

Bordwell, David. Narration in the Fiction Film. Madison: University of Wisconsin Press, 1985.

---. The Way Hollywood Tells It: Story and Style in Modern Movies. Berkeley: University of California Press, 2006.

Bordwell, David, Kristin Thompson, and Janet Staiger. The Classical Hollywood Cinema: Film Style and Mode of Production. New York: Columbia University Press, 1988.

Brégent-Heald, Dominique. "Vacationland: Film, Tourism and selling Canada 1934-1948." Canadian Journal of Film Studies Vol. 21 No. 2 (2012): 27 -48 .

Canjels, Rudmer. Distributing Silent Film Serials: Local Practices, Changing Forms, Cultural Transformation. New York: Routledge, 2011.

Carroll, Noël. "Narrative Closure.” Philosophical Studies Vol. 135 No. 1 (2007): 1 -15 . 
Carruthers, Lee. "Bazin et le prens-temps: The Timeliness of Cinema." Screen Vol. 52 No.1 (2011): 13-29.

Cavell, Stanley. Pursuits of Happiness: Hollywood Comedy of Remarriage. Cambridge: Harvard University Press, 1981.

Christie, Thomas A. The Cinema of Richard Linklater. Kent: Crescent Moon Publishing, 2008.

Coleman, Regina A. "Why Seeing Isn't Always Believing: A Look at Videotape Evidence and Change of Venue in the Wake of Rodney King." Western State University Law Review Vol. 21 No. 1 (1993-1994): 321-340.

Collingwood, R.G. The Idea of History. Oxford: Clarendon Press, 1946.

---. The Principles of Art. Oxford: Clarendon Press, 1945.

Csönge, Tamás. "Moving Picture, Lying Image: Unreliable Cinematic Narratives." Acta Universitatis Sapientiae Vol. 10 No. 1 (2016): 89-104.

Deleuze, Gilles. Quoted in Russel J. Kilbourn, Cinema, Memory, Modernity: The Representation of Memory from the Art Film to Transnational Cinema. New York: Routledge. 2010.

Doane, Mary Ann. The Emergence of Cinematic Time: Modernity, Contingency, the Archive. Cambridge: Harvard University Press, 2002.

Durham, Carolyn A. "Sighting/Siting/Citing The City: The Construction Of Paris In Twenty-First Century Cinema.” Post Script Vol.27 No.1 (2007): 72-89.

Ebert, Roger. “Slacker.” RogerEbert.com. August $3^{\text {rd }}, 1991$.

Eco, Umberto and Natalie Chilton. "Review: The Myth of Superman." Diacritics vol. 2 No. 1 (1972): 14-22.

Evans, Nicola. "No Genre for Old Men? The Politics of Aging and the Male Action Hero." Canadian Journal of Film Studies Vol. 24 No 1 (2015): 25-44.

Filippo, Mary San. “Growing Old Together: Linklater's Before Trilogy in the Twilight Years of Arthouse Distribution.” Film Quarterly Vol. 68 No. 3 (2015): 53-59.

Galican, Mary-Lou. Quoted in Kevin A. Johnson, "Unrealistic Portrayals of Sex, Love, and Romance in Popular Wedding Films." Critical Thinking About Sex, Love, and Romance in the Mass Media. Ed by. Mary-Lou Galican and Debra L. Merskin. Mahwah: Lawrence Elbraum Associates, 2007. 
---. Sex, Love, \& Romance in the Mass Media: Analysis and Criticism of Unrealistic Portrayals \& Their Influence. Mahwah: Lawrence Elbraum Associates, 2004.

Grabiner, Ellen. "The Holy Moment: Waking Life and Linklater's Sublime Dream Time," Film Quarterly Vol. 68 No. 3, (2015): 41-47.

Grindon, Leger. “Annie Hall (1977) The Trials of Partnership.” The Hollywood Romantic Comedy: Conventions, History, Controversies. Malden: Wiley Blackwell, 2011.

Gullette, Margaret Morganroth. Aged by Culture. Chicago: University of Chicago Press, 2004.

Harrod, Mary. "The Aesthetics of Pastiche in the works of Richard Linklater." Screen Vol. 51 No. 1 (2010): 21-37.

Johnson, David T. "Not in One Dream, But in Many: Discipline, Dialogue, and the Cinema of Richard Linklater." Film Quarterly Vol. 68 No. 3 (2015): $37-40$.

---. Richard Linklater. Urbana: University of Illinois Press, 2012.

Kuhn, Annette and Guy Westwell. "Cinema of Attractions." A Dictionary of Film Studies. :Oxford University Press, 2012.

Linklater, Richard. Quoted in "Richard Linklater on his accidental movie franchise, the Before' trilogy.” Peter Howell, The Toronto Star. June o6 2013.

Lefebvre, Martin. "On Memory and Imagination in the Cinema." New Literary History Vol. 30 No. 2 (1999): 479-98.

Lurie, Peter. "Digital Déjà Vu: Cinephilia, Loss, and Medial Integrity in Linklater's Before Trilogy.” Film Quarterly. Vol. 68 No. 3 (2015): 60-66.

Maynard, Patrick. Quoted in Lauren Perini, "Depiction, Detection, and the Epistemic Value of Photography." Journal of Aesthetics and Art Criticism Vol.70 No.1(2012): 151-160.

Minot, Susan. "Forty Portraits in Forty Years." The New York Times Magazine. October 3rd, 2014.

Morgan, Daniel. "Max Ophuls and the Limits of Virtuosity." Critical Inquiry Vol. 38 No.1 (2011): 127-163. 
---. "Rethinking Bazin: Ontology and Realist Aesthetics." Critical Inquiry Vol. 32 No. 3 (2006): 443-481.

Mulvey, Laura. Death 24x A Second. London: Reaktion Books, 2007.

Nichols, Jeff. Quoted in Robert Abele. "Year of Fade to What?” Variety January $9^{\text {th }}, 2012$.

Norton, Glen. "Seductive Slack of Before Sunrise." Post Scipt Vol. 19 No. 2 (1999): 62-72.

Orr, Stanley. "Postmodernism, Noir, and The Usual Suspects." Literature Film Quarterly Vol.27, No. 1 (1999): 65-74.

Pasolini, Pier Paolo. "Observations on the longtake." Trans. Norman MacAfee and Craig Owens, October Vol. 13 (1980): 3-6.

Powell, Helen. Stop the Clocks!. London: I.B. Taurus, 2012

Radwan, Jon. "Generation X and Postmodern Cinema: Slacker." Post Script Vol. 19 No. 2 (1999): 34-48.

Reader, Keath A. "Literature/cinema/television: intertextuality in Jean Renoir's Le Testament du docteur Cordelier." Intertextuality, ed. Judith Still and Michael Worton, New York: St. Martins Press, 1990.

Ricoeur, Paul. "Narrative Time." Critical Inquiry Vol. 7, No. 1 (1980): 161-190.

---. Time and Narrative Vol. 3. Trans. Kathleen Blamey and David Pellauer. Chicago: University of Chicago Press, 1990.

Rorimer, Ann. "The Date Paintings of On Kawara." Art Institute of Chicago Museum Studies Vol. 17 No. 2 (1991): 120-137, 179, 180.

Rosen, Phillip. Change Mummified: Cinema, Historicity, Theory. Chicago: Minnesota University Press, 2011.

Russell, Bertrand. "The Philosophy of Bergson." The Monist Vol. 22, No. 3 (1912): 321-347.

Sims, David. "The Frozen in Time Optimism of Before Sunrise." The Atlantic. January $27^{\text {th }} 2015$.

Smith, Stacy L., Marc Choueti, and Katherine Pieper. Inclusion or Invisibility? Comprehensive Annenberg Report on Diversity in Entertainment. Los Angeles: Institute for Diversity and Empowerment at Annenberg, 2016. 
Sobchack, Vivian. Carnal Thoughts. Berkley and Los Angeles: University of California Press, 2004.

---. "What is Film History? Or the Riddle of the Sphinxes." Spectator Vol. 20 No.1 (1999/2000): 8-22.

Sontag, Susan. On Photography. New York: Picador, 2001.

Speed, Lesley. "The Possibilities of Roads Not Taken: Intellect and Utopia in the Films of Richard Linklater." Journal of Popular Film and Television Vol. 35 No. 3 (2007): 98-106.

Still, Judith and Michael Worton, "Introduction." Intertextuality: Theories and Practices, ed. Judith Still and Michael Worton. New York: St. Martins Press, 1990.

Stone, Rob. "About Time: Before Boyhood." Film Quarterly Vol. 68 No. 3 (2015): 67-72.

Tobias, Scott. "The New Cult Canon- Slacker." AVClub. September. $3^{\text {rd }} 2009$.

Thomas, D.J. "Framing the 'Melancomic' Character, Aesthetics, and Affect in Wes Anderson's Rushmore." New Review of Film and Television Studies Vol. 10 No. 1 (2011): 1-21.

Thompson, Kristin. Storytelling In the New Hollywood: Understanding Classical Narrative Technique. Cambridge: Harvard University Press, 1999.

---. “The Duplicitous Text: An Analysis of Stage Fright.” Film Reader Vol. 2 (1977): 52-64.

Totaro, Donato. "Muriel: Thinking With Cinema About Cinema." Offscreen Vol. 6 No. 7 (2002).

Truffaut, Francois. In interview from Love on the Run (1979) DVD special features from The Adventures of Antoine Doinel DVD Collector's Set (The Criterion Collection).

Turim, Maureen. Flashbacks in Film: Memory and History. New York: Routledge, 1989. 
Turner, B.S. "Aging and Identity: Some Reflections on the Somatization of the Self." Images of Aging: Cultural Representations of Later Life. Ed. Mike Featherstone and Andrew Wernick, New York: Routledge, 1995.

Wahlberg, Malin. Documentary Time: Film and Phenomenology. Minneapolis: University of Minnesota Press, 2008.

White, Hayden. The Content of the Form: Narrative Discourse and Historical Representation. Baltimore: John Hopkins University Press, 1987.

---. "The Value of Narrativity in Representations of Reality." Critical Inquiry Vol. 7, No. 1 (1980): 5-27.

Woo, Jung-Ah. "On Kawara's 'Date Paintings': Series of Horror and Boredom.” Art Journal Vol. 69 No. 3 (2010): 62-72. 